\title{
Comics and Literature: A Love Story
}

\author{
by
}

\section{Robert Hutton}

A thesis submitted to the Faculty of Graduate and Postdoctoral Affairs in partial fulfillment of the requirements for the degree of

Doctor of Philosophy

in

English

Carleton University

Ottawa, Ontario

(C) 2017

Robert Hutton 


\begin{abstract}
This dissertation investigates the conjunction of comics, literature, prestige, and narratives of development and deviance. Drawing on case studies from the forty-year history of alternative comics, I argue that comics creators and publishers referenced literary figures and characters as a means of developing their ideas of artistic autonomy and development. This tangle of ideas stems from the suspicion and censorship of comics in the 1950s, when the young medium was accused of promoting deviance and maladjustment. Early figures in alternative comics such as Harvey Pekar, Dave Sim, and the critics of The Comics Journal fought this idea by drawing on the prestige of literature to present a vision of comics that adhered to conventional ideas of autonomous elite culture. In doing so, these writers sought to create a new form of comic that could help the medium and its readers out of the maladjustment it found itself in. Later, the writers of "groundlevel" comics referenced canonical literary authors in ways that both reaffirmed and, in the case of Alan Moore, questioned their canonical light. It is here that we begin to see total rejection of the developmental narrative, and a celebration of comics' low cultural status. Finally, I argue that the work of Ariel Schrag and Alison Bechdel takes a step forward in developing a queer idea of reading and writing that disrupt the narrative upheld by earlier authors. By shifting the focus of the developmental narrative to their personal queer journeys, Schrag and Bechdel call into question the heteronormative premises of the discourse around the status of comics. By focusing on how these comics present the literary, this dissertation aims to demonstrate how such representations are always entangled in questions of status and normativity, and how the world of alternative comics' attitude towards these questions changed during their period of cultural ascendance.
\end{abstract}




\section{Acknowledgements}

I started reading comics regularly in high school, specifically in the form of manga. My parents deserve credit (or blame) for perenially renewing my subscription to the Englishlanguage Shounen Jump and never complaining about the unwieldy boxes of paperback volumes that began to pile up. On a more serious note, I'd like to thank my parents for continually supporting my education over the last two decades and change in both financial and spiritual ways, and for never asking me what a degree in English was good for.

My supervisors Franny Nudelman and Brian Johnson have provided invaluable guidance throughout this process, always offering both support and a daunting amount of suggestions, most of which have hopefully been incorporated in this final draft. I would also like to thank all the members of my committee for their time and consideration, and for their feedback which will doubtlessly result in a better version of this work in the future.

Many more people in the Carleton English department and the broader academic sphere have their fingerprints on this project. Rob Holton helped to shepherd me through comps and refine my ideas about theory as well as always provide a calming presence. Sarah Brouillette both graded the assignment that started this whole mess and has influenced my thought throughout my time at Carleton. Jodie Medd provided crucial expertise on some of the literary history which I was unfamiliar with. The anonymous reviewers at Contemporary and Image$\mathrm{TeXt}$ helped to refine the section on Fun Home throughout its frustrating but ultimately edifying publication process. The various attendees of the Canadian Society for the Study of Comics have provided great feedback for most of the dissertation as well as general inspiration over the past three years. And of course, none of this would be possible without the administrative work of Lana Keon and the other department administrators who have helped me in so many different ways over the past five years.

I was also forunate to be part of a vibrant and friendly group of students here in the English department. My cohort-mates Kim Sigouin and Chris Kerr have been my most constant ears to unburden myself to over the years. My Americanist predecessors Andrew Connoly, Chris VanDerWees and Rob Mousseau blazed the trail before me and provided both inspiration and bitter realism in equal measure. A special shout-out goes to my comics kouhai Ryan Prittie and Jonathan Chau, who I expect to write much better dissertations than mine in the coming years, as well as everyone who came out to trivia, softball, and the many other ways I distracted myself. Despite the weather and the elevators and everything else, I never felt quite so much at home at a school. 


\section{Table of Contents}

Abstract $\quad$ ii

Acknowledgements

Introduction $\quad \mathbf{1}$

A Brief History of Comics, Sex and Prestige $\quad 6$

$\begin{array}{ll}\text { Literature and Degeneracy } & 13\end{array}$

An Alternative by Any Other Name 19

Prestige and the Literary in Comics Scholarship $\quad 22$

$\begin{array}{ll}\text { Literary Tactics and Strategies } & 26\end{array}$

Comics Versus Art Versus Literature $\quad 30$

Chapter 1: Prestige and Ideology at the Dawn of Alternative Comics 36

The Crusade of The Comics Journal

Graphic Novels and the Comics Canon $\quad 53$

"Erotica for the Juvenile Mind!” 58

Grub Street, USA: Prestige and Literary Realism in American Splendor and Beyond 66

Modernism, Misogyny and Self-Publishing in Sim's Cerebus 80

Comics and Literary Machismo 95

Chapter 2: The Groundlevel and Canonical Remixes $\quad 100$

Canonical Genius in The Sandman 103

Romantic Rebellion in The Invisibles 108

Metafictional Magic in Promethea 114

Perverse Victoriana in The League of Extraordinary Gentlemen 119

A Literary Pornography: Moore and Gebbie's Lost Girls 132

$\begin{array}{ll}\text { Iconic Resonance } & 142\end{array}$

Chapter 3: Queer Reading Strategies in Schrag and Bechdel 145

Likewise and the Crises of Identity and Authorship 147

Queer Reading Strategies and Identification in Fun Home 156

Bruce Bechdel and Identificatory Reading 159

Alison's Rebuke: The Queer Erotics of Reading 173

The Graphic Memoir as Queer Literary Education 192

$\begin{array}{ll}\text { Conclusion } & 195\end{array}$

$\begin{array}{ll}\text { Works Cited } & 204\end{array}$ 


\section{Introduction}

Chris Ware dramatizes the hopes and anxieties of the alternative comics creator in the mainstream book market on the back cover of the paperback edition of his graphic novel Jimmy Corrigan, the Smartest Boy on Earth. This miniature comic narrative situates the graphic novel in a very specific commercial and cultural context. An anthropomorphized version of the book is about to be shelved in the literature section of a book superstore, cementing its place in the literary canon :“Tolstoy... Updike... Vonnegut... Ware!” (Ware bc). An ignorant sales manager intervenes, and insists that it should be shelved in the graphic novel section ("somewhere near science fiction and role-playing games, I think") because it is "kid's lit... you now... superhero stuff... for retards!" (Ware bc). Separated from its true literary audience, the graphic novel is neglected and thrown out, only to be rescued by Ware himself. Questions of shipping, distribution, and marketing, the mundane business transactions that the autonomous author is supposed to be disdainful of, are here positioned as vital to the work's identity. This comic is obviously tongue-in-cheek and could be dismissed as a throw-away gag, but in the process of being flippant Ware hits on the hopes and anxieties that drive much of alternative comics. The ambition of Ware's graphic novel, as expressed by the back cover, is not to be acclaimed within its own subculture but within the cultural economy of literary fiction, with Tolstoy and Vonnegut forming more logical antecedents then Lee and Kirby. The back-cover narrative is also noteworthy because the specialized comic book store, where Ware's book would presumably face unimaginable indignities, is never mentioned. Indeed, from its bookstore-ready size to its baroque instructions on how to read a comic, the collected Jimmy Corrigan is a comic that obviously aspires to an audience that does not normally read comics.

How did such a paradoxical bit of marketing come about? It is not that Ware is a 
snobbish outlier among alternative comics artists. If anything, he is among the least obviously "literary" of the major figures in contemporary comics, being more obviously influenced by graphic design and the eccentricities of turn-of-the-century print culture than literary fiction (Bredehoft, "Comics Architecture" 884-885). But he nevertheless promotes a discourse that positions acceptance by the literary sphere as the natural aspiration for comics creators who have ambitions beyond the commercial. Graphic novels are now sold in the same stores as literary novels and reviewed in the same publications. Those within both the comics sphere and mass media present this as the maturation of the medium (Pizzino 1). Comics, having passed through decades of juvenile adventure narratives, have finally reached their full potential of being heavily-illustrated novels. This assumption is embodied in the very phrase "graphic novel," with the novel as the central noun being modified. This is a term that has been used by alternative comics artists since the 1970s and popularized by Will Eisner as an expression of literary ambition as much as format, and been criticized by some scholars as an appeal to the authority of another medium (Weiner 6). By comparison, Scott McCloud's preferred term of "sequential art" (5) is almost never used by publishers.

I do not believe this paradigm to be a betrayal of comics, nor do I wish to denounce those who created and advocated for it. The emergence of comics-as-literature has brought a broader array of readers and writers into the medium, and produced more diverse and frankly more interesting work than the continually-shrinking cloister of the direct market. But it is not a natural endpoint for the comics medium, nor is it an entirely organic outgrowth of the autonomous desire of creators. The comics-as-literature paradigm was produced by a variety of actors, including authors but also critics, editors and booksellers. These actors saw the advancement of the medium as synonymous with entry into the mainstream literary field, a belief 
that certainly had its pragmatic justifications but also reflected a credulous faith in that field as a guarantor of respect and artistic autonomy. Entering the world of the book - from stores to libraries to reviewers - was a way for comics to become a true art form instead of low-cultural detritus. This assumption has been reproduced in many histories of comics, from the simplified “comics aren't for kids" narrative in the mainstream press to academic works such as Paul Lopes' Demanding Respect which describe the dawn of alternative comics as part of a "Heroic Age" in which creators asserted their rights (121). It is undeniable that alternative and literary publishers have offered writers and artists more liberty in terms of subject matter and style than Marvel and DC did. But the association of the literary with artistic merit occurs in comics discourse from at latest the mid-1970s, a full decade before said literary world would give comics the time of day, and anxieties around the literary continue to proliferate in contemporary comics texts and para-texts. Even when such a project appeared idle fantasy, it still had a grip on the imaginations of comics creators and fans. It is the purpose of this work to examine the way in which the comics-as-literature project was created and argued for by writers and critics, and to highlight the ideological underpinnings of this project.

Those arguing for comics-as-literature were influenced by a variety of literary works and artistic and political belifs, but there are surprising commonalities between their arguments. One trope that continually reoccurs is the discussion of the comics medium's literary development in a psycho-sexual register. Comics achieving literary maturity is repeatedly portrayed as akin to the individual achieving healthy sexual maturity. What constitutes sexual maturity varies widely in this discourse, from Dave Sim's misogynist vision to the anarchist sexual politics of Alan Moore to the queer exploration of Alison Bechdel, but the implied parallel between sexual maturation and literary development remains a constant. In turn, the prolonged immaturity of 
comics seen in its investment in repetitive and corporate superhero fantasies is depicted as a form of sexual deviance and maladjustment.

The investment in metaphors and narratives of maturity and growth is an example of what Barbara Hernstein Smith describes as the "developmental fallacy," the concept of a life's progression from undeveloped and childish tastes towards mature appreciation of greatness (79). If comics were only for children, this view would suggest that they were less developed than adult-oriented literature, and hence adult-oriented comics were necessary to advance the medium. These "adult comics," to use Roger Sabin's term, suggested the attainment of maturity on the part of not just the reader but also the artist, as suggested in graphic kunstlerromans like Fun Home, and the medium itself (Sabin 3.) The fixation on literary "adulthood" has lead to an ongoing marginalization of children's and young adult comics within comics criticism, even when these comics share many of the aesthetic and narrative techniques of adult-oriented alternative comics (Beaty and Woo 103). The developmental narrative has, as Christopher Pizzino has argued, remained one that marginalizes comics, with many educational institutions still viewing them as part of a developmental arc that will lead eventually to a mature appreciation of prose literature. Nevertheless, this developmental narrative is one told over and over again by creators and critics within alternative comics.

If the maturity of "adult comics" is the mark of a successful developmental one, the mark of a failed one is not just immaturity but perversion. The prolonged juvenility of the comics medium is frequently and rather alarmingly associated with rhetoric of sexual deviance or predation. The root of this anxious intersection can be traced back to the public outcry against indecent crime and horror comics, and the subsequent Comics Code which censored any trace of sexual or deviant imagery from comic books. As Joe Sutcliffe Sanders has argued, any analysis 
of sexuality in comics has to be informed by this history of suspicion and censorship (161). Bart Beaty has productively placed the 1950 s comics scare into the intellectual context of the midcentury critique of mass culture, a critique that described comics, along with other mass media like television, as brainless and harmful to American culture. Beaty's reading of Fredric Wertham's accusations against comics reminds us that comics lost their chances at sexual expression and artistic legitimacy at the same time, and that attempts at artistic comics would have to grapple with both halves of this legacy. This is not to say that all reproduced the homophobic aspects of Wertham's arguments. Authors such as Alan Moore and Alison Bechdel have done their best to reclaim this image of the deviant, comics-addled youth - but even so, the image persists. Intersecting narratives of sexual and literary development became a way for alternative comics creators to figure out their own place in an increasingly muddled cultural hierarchy. For this reason, examining how alternative comics treat literature and sex, and especially how they treat the two in conjunction, provides a glimpse at the changing aesthetics and ideology of alternative comics.

What I will suggest, then, is that the discourse around artistic development within alternative comics is constantly and hopelessly intertwined with a more metaphorical narrative about psycho-sexual development. The putative goal of the former is to dispel the latter, to assert that Wertham's historic claims about the perversity of comics were unfounded. But the maladjusted and deviant comics reader, to say nothing of the cynical smut-peddling comics creator, constantly returns to haunt alternative comics, often making its way into the very arguments of those seeking to legitimate the medium. These contradictions become most apparent when literary texts and figures, or just an abstract idea of the literary, are invoked. Literature, in the most polemical versions of the developmental narrative, is the horizon of 
maturity towards which comics must travel. However, which literary texts should be emulated, what that maturity will look like, how comics should approach this pole, and whether such a voyage is even possible are subjects of dispute between authors of alternative comics. The figure of the literary is one that is constantly contested, and used to make competing ideological and aesthetic claims. Even later alternative comics which call into question the developmental narrative, such as Alan Moore's late work, still make claims about literature. So, rather than suggesting one monolithic developmental arc to which all creators adhere, I suggest that there are many competing and contradictory versions of this basic narrative, all of which are a means of contesting value within the sphere of alternative comics. The arc of literary development, then, becomes a way of uncovering aesthetic pressures and ideological fissures within comics history.

\section{A Brief History of Comics, Sex and Prestige}

The association between comics and sexual deviance began in the 1920 s with the advent of "Tijuana bibles," amateur pornographic work that often featured celebrities or mainstream comics characters such as Popeye and Blondie. These comics were produced in a clandestine manner and often subject to seizures by police and customs officers, but were printed in large numbers (Adelman). The Tijuana bibles would more or less die out after the conclusion of World War II, but the state's concern with the potential obscenity of comics would not.

The post-war period saw a boom in the popularity of comics, especially among children. Comics of every genre from funny animal stories to romance flooded drug store shelves (Hadju 6). Amongst these were crime and horror comics, which often featured graphic violence and sexually suggestive imagery. The most famous of these were put out by EC Comics, whose 
comics like Tales from the Crypt and Shock SuspenseStories attracted a cult audience (Hadju 175-192). Crime and horror comics became the subject of a public uproar, blamed for juvenile delinquency and perversion. Fredric Wertham, a psychiatrist, became one of the leaders and the intellectual authority of the anti-comics campaign. In his bestselling book The Seduction of the Innocent, Wertham drew on his work with juvenile delinquents to argue that comics' use of violent imagery contributed to both violent behaviour and warped sexual development (15). In addition to the lurid imagery of crime and horror comics, Wertham argued that superhero comics such as Batman and Wonder Woman subliminally promoted homosexuality, pedophilia and sadomasochism $(34,189)$. More recent scholarship, most notably by Bart Beaty, has argued against the common fan image of Wertham as a censorious villain, highlighting his interest in social justice, but it is clear that the popularity of Wertham's argument raised fears of censorship, as well as a loss of distributors due to controversy, among comics publishers.

As a response to this fear, the major comics publishers established a set of self-imposed restrictions designed to quell public fear (Lopes 54). These regulations, called the Comics Code, would be rigidly followed by comics publishers for decades and formally continued until 2011. The Comics Code effectively banned the horror and crime genres, and placed severe restrictions on other types of comics. These restrictions dealt with not just violent and sexual material but the plot and themes of comics stories. Under the Code, "in every instance good shall triumph over evil" and comics were forbidden from displaying "policemen, judges, government officials, and respected institutions $[\ldots]$ in such a way as to create disrespect for established authority" (Nyberg 165). Stories were to emphasize "the sanctity" of marriage, and any portrayal of "sex perversions" was banned (Nyberg 168). In short, the Code demanded that comics abide by conservative morals and offer didactic moral lessons, with the result being the return of 
superhero comics to their spot as paradigm genre (Lopes 56).

Whatever youthful deviance had been suppressed by the comics code would re-surface in the late 1960s in the form of underground comics (or "comix" as they were often called). A group of artists involved in or inspired by the counterculture movement such as R. Crumb and S. Clay Wilson began creating anthologies of short amateur comics that usually involved graphic sex and violence or political radicalism (Lopes 75). Distributed via mail order and countercultural institutions such as head shops, the undergrounds took glee in displaying just about everything the Comics Code was meant to prevent. The underground scene was not, however, welcoming to all. Underground comics frequently included blatantly misogynist and racist imagery, including the work of R. Crumb, the most popular and celebrated of the underground artists (Lopes 82). If underground comix were a celebration of sexuality, that sexuality was entirely heterosexual and male. Artists such as Trina Robbins and Howard Cruse challenged this, creating anthologies for publishing female and gay voices respectively, while underground artists with greater artistic ambitions such as Spiegelman and Justin Green ended up drifting out of the underground movement (Lopes 83). The market for underground comix collapsed in the early 1970s due to fears of obscenity prosecutions and the waning influence of the counterculture, and for a moment it seemed as if the squeaky-clean monoculture of Codeapproved comics had won (Lopes 86).

However, there were other economic forces that would create a space for comics that existed outside of the Marvel/DC mainstream. Due to declining newsstand sales and the growth of organized fandom, the 1970s saw the location of comics sales shifting to dedicated speciality shops (Lopes 100). These new stores, which would become known as the direct market to comics publishers, created a space for both adult fans and comics which might appeal to them 
(Lopes 103). Speciality shops could accommodate comics with much smaller print runs and without Comics Code approval (Hatfield Ch. 1). Most of the comics aimed at the direct market were stories in popular fan genres such as science fiction and fantasy, but unlike their mainstream counterparts they frequently contained explicit sex and violence. These comics were labelled "groundlevel," a term which suggested a place halfway between the underground and the high-flying adventures of superheroes (Beaty and Woo 56). Perhaps the most notable of the early groundlevel titles were Howard Chaykin's American Flagg, an ultraviolent action series, and Elfquest by Wendy and Richard Pini, a self-published fantasy series whose intentional sex appeal included an infamous orgy scene (Decker, "Poughkeepsie to Elfland," The Comics Journal No. 63 p. 127). Other artists used this opportunity to produce more purely aestheticallymotivated work and a group of artists that aimed at artistic genius within the comics medium emerged. This new genre went by many names - alternative comics and art comics were among the most prevalent - and made up a kind of movement, albeit one much less aesthetically and ideologically unified than underground comics. Gary Groth and Kim Thompson laid out the most extreme version of the philosophy behind alternative comics in their periodical The Comics Journal, denouncing the mainstream and demanding artistic autonomy and work which could be discussed alongside art and literature (Lopes 127). They would go on to publish the work of many prominent alternative cartoonists such as Los Bros. Hernandez, Daniel Clowes and Peter Bagge.

Alternative comics took a more measured approach to explicit sex and violence, and many of the most celebrated alternatives (such as Maus and most issues of Harvey Pekar's American Splendor) were virtually sexless. This did not mean that alternative comics did not traffic in erotic imagery, but that it had to be justified through artistic ambition. Groth argued 
that comic stores had an obligation to sell works of literary merit even if they contained explicit material (e. g. The Comics Journal No. 116 pp. 21-22). The Hernandez Brothers' Love and Rockets was a font of what was known in comics as "good girl art": attractive female characters with flattering proportions and tight (or no) clothes (Royal 10). Some of the material praised and circulated by alternative comics fans was openly pornographic, such as the funny-animal soap opera Omaha the Cat Dancer. These perceptions of salaciousness may have been a selling point, but also resulted in brushes with censorship by both state and market actors. Bud Plant, a prominent distributor of comics in the South, refused to carry certain alternative books that offended his Evangelical morals, and a Milwaukee comic shop was prosecuted for obscenity after selling issues of Love and Rockets and Omaha to a child (The Comics Journal No. 116 pp. 21-22). Despite their greater artistic ambitions, alternative comics still faced the stigma and danger of pornography.

In 1987, the American mainstream discovered the possibility of comics aimed at adults. That year saw the release of the first collected volume of Maus by a mainstream publishing house as well as the collected versions of Watchmen and The Dark Knight Returns, two DC Comics miniseries that offered a dark take on superheroes filled with graphic violence and sexuality. All three books became bestsellers, and helped to create the bookstore-ready "graphic novel" as a comics format (Lopes 132). This term, which validated comics explicitly through comparison to the literary, proved controversial but was ultimately adopted by both authors and fans of alternative comics (di Liddo 15-21). At last, the avenue to mainstream literary acceptance and respectability dreamed of in alternative-comics discourse appeared to have opened (Lopes 133). But while the trinity of breakthrough works quickly became canonized and earned a permanent spot on the shelves of both bookstores and speciality shops, other alternative 
artists had a hard time finding a way in (Lopes 135). Spiegelman personally campaigned for the Book Industry Study Group to recognize "graphic novels" as a category for booksellers to use, but few had interest in stocking an entire shelf of comics (McGrath). Mainstream comics also attempted to recapture the buzz that the "class of " 87 " had generated. Superhero comics were increasingly pitched at an adolescent and older male audience, and overflowed with sex, violence, and angst (Lopes 113). None of these imitators were able to capture the mainstream success and critical appreciation of Watchmen or The Dark Knight, but they created a brief market boom based largely on collector-driven speculation (Lopes 116). DC Comics had more critical success with its Vertigo brand of adult-oriented comics. They also traded heavily on the reputation of their writers, most notably "British invasion" authors like Grant Morrison, Neil Gaiman and Warren Ellis following in the footsteps of Moore (Beaty and Woo 60). While these authors typically had no more legal ownership of their characters and plots than those working on DC's superhero comics, almost all of the Vertigo titles had a single writer with relative creative autonomy for the entirety of the series. This marked a shift towards an understanding of writers (and notably not artists) as autonomous creators (Beaty and Woo 57).

We can see similar dynamics at work in the foundation of Image Comics by popular artists who had left Marvel. Artists such as Rob Liefield and Todd McFarlane, as critically derided as they were commercially successful, gave up mainstream security to write and publish their own superhero series, seeking both creative control and the full financial rewards of their successes (Beaty and Woo 76). While Image had much less highbrow ambitions than Vertigo, and focused on the artist and not the writer as the central creator of comics, it signified both a financial and cultural shift towards the idea of autonomous authorship (Gabilliet). It was only when Image authors wrote their books as well as drew them, no matter how poorly reviewed the 
books were, that they could conceive of themselves as autonomous creators.

While the comics of the 1990s did not shy away from depicting explicit sexuality, the comics industry remained a difficult place for queer creators. From confessional independent comics like Joe Matt's Peep Show to the exaggerated bodies of Rob Liefield, heterosexual male desire seemed to be the default perspective of the new "adult" comics. Vertigo provided somewhat more diversity than other publishers, featuring numerous sympathetic gay characters and publishing graphic novels by Howard Cruse and David Wojnarowicz. Female creators and those of colour were ignored by both the alternative press and mainstream publishers alike. All of the much-advertised auteurs of Image, Vertigo and Fantagraphics in the 1990s were white and male. On the fringes of the comics world, however, artists such as Alison Bechdel, Phoebe Gloeckner, Julie Doucet and Lynda Barry created their work that dealt frankly with topics such as sexual abuse and misogyny within the comics world (Chute 61).

The twenty-first century brought with it new changes in the comics industry. Major media conglomerates now owned both Marvel and DC and used their recognizable intellectual property for numerous hit films and television series, all without substantially increasing comics sales. Alternative comics finally made a permanent breakthrough into mainstream bookstores. This was due in part to the advocacy of creators like Art Spiegelman to create an institutional space for alternative comics and the creation bookstore-ready graphic novels that appealed to highbrow aesthetics like Chris Ware's Jimmy Corrigan or Alison Bechdel's Fun Home. Just as important was the explosive popularity of Japanese comics sold through bookstores, suggesting that comics could be profitable in a way that a technologically threatened bookstore industry could not deny. Mainstream publishers had never truly given up on the graphic novel, and now had a window to make both the commercial and critical wings of literary publishing amenable to 
comics.

This leads us to the present state of the North American comics industry, which seems to have been consumed by two larger cultural institutions - multimedia giants for the mainstream, and traditional publishing houses and stores for what was once called alternative comics. A form that was once marginal and stigmatized is seen by some as the best hope for literacy. However, as I will argue in my dissertation, the tensions between literary ambition and the medium's obscene past have remained a motivating force for comics authors. My dissertation will examine how prominent authors such as Alan Moore and Alison Bechdel mediate between the historic associations of comics with deviancy and the new push for historical respectability in complex and productive ways.

\section{Literature and Degeneracy}

For the purposes of this dissertation, we can define "the literary" as the cultural-economic field associated most closely with prose fiction and poetry, constituted of prose texts and the institutions which circulate them and place them in a critical context including publishers, reviewers, bookstores and universities - a set of institutions I will refer to as the "literary sphere." While genre narratives certainly exist on the borders of the literary, and are important to numerous comics creators I study, this is a field that gives pride of place to texts that reject the form and/or the content of popular genres such as crime, romance and science fiction. The literary emphasizes, but consists of more than, the set of texts codified by academia as the canon. As Barbara Hernstein Smith has suggested, the literary sphere suggests not just canonical works but canonical audiences observing under canonical conditions, and excludes noncanonical 
audiences such as children and noncanonical conditions of production such as mass-mediated (35-36). These other audiences and conditions are defined as "defective, deficient, or deprived" (Smith 41). Following Smith, I will be using a definition of the literary which treats literary value as always contingent on numerous factors both social and personal.

Many of the creators I study understood this latter element of the literary at least implicitly, and longed for the audience and conditions of canonical literature at least as much as its content. Groth, Pekar, Sim, and to a lesser extent Gaiman and Morrison all view literary production as being free of editorial constraint and motivated by inner emotional desires instead of material need. In contrast to comics, literature is seen as a mature art form that is both financially and spiritually rewarding. However, all of these definitions cast the literary in terms that are altogether too stable. Literary history is a never-ending struggle over boundaries and prestige, and the definition of the literary is never entirely certain. These struggles within literature are productive and intriguing when read alongside the history of comics, but infrequently recognized.

In particular, most of the comics creators I study focus on a rather narrow band of literary history: the forty years between Oscar Wilde and F. Scott Fitzgerald, a period that marks the rise of literary modernism. Modernist literature is taken by many of these creators to represent a kind of literary maturity marked by a disinterest towards both material and didactic goals as much as a willingness to experiment with form and content. This conception is somewhat supported by modernist manifestos and braggadocio. T. S. Eliot's "Tradition and the Individual Talent" imagines literary history as a set of great works divorced from both setting and authors. These great works cannot occur without the poet "surrendering himself wholly to the work to be done." This idea of the disinterested and ultimately obscured artist can be traced back to the decadence 
of Oscar Wilde, who in his preface to The Portrait of Dorian Gray writes that "To reveal art and conceal the artist is art's aim" (1). Wilde explicitly argues that this goal requires a renunciation of morality: "There is no such thing as a moral or an immoral book. Books are well written, or badly written. That is all" (1). While Wilde and Eliot both suggest the artist as fundamentally subordinate to his work, they also suggest that the sphere of art requires a kind of necessary autonomy from both economic and political concerns. Literature was to be an end in itself.

However, Wilde would soon discover how fragile his literary autonomy was. The modernist movement was often surrounded by the same language of maturity and perversion as comics. Max Nordau's Degeneration, popular in both Germany and England, attributed all aspects of turn-of-the-century European fiction to criminal and degenerate minds. Drawing on Cesare Lombroso's phrenological pseudoscience, Nordau diagnosed both decadence and realism as signs of "the impotent despair of a sick man, who feels himself dying by inches in the midst of an eternally living nature" (3). Wilde's proto-modernist texts were cited in his trial for sodomy as an example of his perverted mind (Parkes). The works of D. H. Lawrence, James Joyce, and Radclyffe Hall were all tried for obscenity and ultimately censored. Associations with homosexuality and other forms of sexual deviance were ever-present: at the Ulysses trial, Joyce's lesbian publishers were a particular object of press and judicial scorn (Parkes 73). The concept that modernism represented a lack of proper development was suggested even by its supporters. Virginia Woolf, in justifying the experiments of "Georgian" authors, compared Joyce to "a boy staying with an aunt for the week-end [who] rolls in the geranium bed out of sheer desperation as the solemnities of the sabbath wear on" (Woolf, "Mr. Bennet and Mrs. Brown," 18). This youthful, sometimes filthy play is necessary because "where so much strength is spent on finding a way of telling the truth, the truth itself is bound to reach us in a rather exhausted and chaotic 
condition” (Woolf, "Mr. Bennet and Mrs. Brown,” 19). Even in Woolf's polemical praise of modernism, then, modernists are depicted as unruly juveniles in a state of misbehaviour precisely the image that has chased comic books throughout their history.

These texts were only rehabilitated and exalted after World War II, their original associations with degeneracy discarded in order to use them as symbols of Western high culture against the spectres of both communism and mass culture. The CIA funded literary magazines such as The Paris Review and Encounter to promote American modernism as a paradigm literary genre to the world. The New York Intellectuals cast the great works of modernism in opposition to the emerging mass culture, which they described using Nordau-esque pathology (Beaty, Fredric Wertham 48). They were mirrored in academia by the New Critics, who focused on formalist approaches towards canonical works. I. A. Richards, a progenitor of the New Critics, perhaps stated the consequences of this choice most baldly by writing that "bad literature, bad art, the cinema, etc. are an influence of the first importance in fixing immature and actually inexplicable attitudes towards most things" (202-205). The modernist impulses towards autonomous innovations became a tool to be used in solving the juvenility and dysfunction of mass culture. The conservative refrains of the New York Intellectuals and the New Critic were paralleled on the left by the Frankfurt School and their followers, who saw mass culture as a horrific magnification of capitalist ideology. To them mass culture, and later postmodernism, marked the apocalyptic destruction of human values by capitalism (Smith 75). Modernist art appears in some of these critiques as a vanishing alternative to the culture industry. As Andreas Huyssen has argued, critics often been described mass culture as effeminate and implicitly contrasted it with the virile masculinity of artistic creation (45). Comics were a part of this mass culture threatening artistic individualism, and Beaty argues that Wertham, the most famous 
condemner of comics, drew on the broader critique of mass culture in his work (Fredric Wertham 49).

Postmodern art and literature emerged in opposition to this cultural hierarchy. While postmodernism retained modernism's stress on autonomy, it mixed high and low referents and showed the work of art to be constructed. Rather than Wilde and Eliot's idea of the artist being subordinate to their work, postmodern writers such as Thomas Pynchon and Paul Auster proudly displayed the marks of their own creation and the limitations of fiction. Poststructuralist theory challenged the underpinnings of literary modernism by calling attention to the ways in which the material world shaped language itself. Barthes' famous "Death of the Author" actually subverts Eliot and Wilde's idea of the humble author who is less important than his work by highlighting the role authorial identity plays in reception. Mass culture, associated in the writings of conservative figures with television and film, would come to consume the literary realm as well. The centralization of both publishers and bookstores that occurred in the 1980s created much less room for discretion and value judgements in the trade, and an emphasis on profit and mass appeal. Even academia began to transform into something more profit-oriented. Both the literary avant-garde and institutional forces in the last third of the twentieth century pushed against the strict hierarchy of genres and the moral aesthetics which undergirded it.

Despite being on the wrong side of the division between mass and high culture, many early figures in alternative comics, most notably Gary Groth and Kim Thompson, embraced this line and cast alternative comics as the healthy high culture to Marvel and DC's degenerate mass culture. By the time the alternative comics movement was in full swing, postmodern and poststructuralist ideas were firmly established in the literary world and the academy. However, the leading figures in alternative comics largely ignored these ideas, instead fixating on the now 
old-fashioned modernist hierarchies that had dismissed them decades ago. Perhaps this was a result of the trauma of self-censorship the comics industry suffered in the 1950s, or perhaps it is simply, as Huyssen says, that "mass culture, saddled as it is with pangs of guilt, yearns for the dignity of serious culture which forever eludes it" (17). Whatever the cause, debates over autonomy and the role of the artist in comics would often come to resemble re-enactments of debates that had happened decades ago in the literary sphere. Creators such as Alan Moore, however, specifically paid attention to the overlap between mass and popular culture, and aimed to subvert if not outright demolish cultural hierarchies. In both cases, it is clear that the writers were maneuvering in a cultural milieu in which modernism was no longer deviant and suspect, but rather a canonized form of genius that needed to be protected from deviant and suspect forms such as comics.

These historical similarities between the emergence of modernism and the emergence of comics have been treated in different ways by various comics writers. The early proponents of alternative comics, who relied on an exalted conception of literature for the comics medium to aspire to, either did not mention the ways in which high-modernist texts had been considered degenerate or treated these past incidents as narratives of brilliant work being censored by smallminded authorities in a way that resonated with comics history. Thus, when Dave Sim re-stages the drama of Oscar Wilde's death in "Melmoth," Wilde is a genius persecuted by society. The accusations of degeneracy were, it is suggested, entirely inaccurate judgements of autonomous and brilliant literary work. Later creators, however, began to use the history of literature as obscenity in ways that partially embrace the idea of degeneracy. In his literary remixes, Alan Moore brings the ways in which literature has been degenerate, immature and commercial to the surface and celebrates these traits, placing them in continuity with the most low-cultural 
traditions of comics. Alison Bechdel uses the ways in which literary modernism, particularly Joyce, was treated as a symptom of degeneracy to twine together her own literary education and her emerging queerness. Rather than presenting a problem for the comics-as-literature paradigm, the history of literary censorship and obscenity becomes a productive resource for comics to move past a narrow concept of literary respectability.

\section{An Alternative by Any Other Name}

As this history shows, the relationship between alternative comics and the mainstream is often contradictory, and often there are multiple mainstreams and multiple alternatives. To begin with, "alternative comics" is a necessarily vague term that, while still broadly meaningful, does not have the descriptive or categorical precision of periodizing phrases such as underground comix or the Golden and Silver Ages of superhero comics. These periods were marked by similarities in art and storytelling that aren't found in the diverse group of titles which fall under the phrase "alternative comics." Rather, alternative comics was a movement defined negatively, encompassing everything that fell outside the narrow strictures of the superhero comics published by Marvel, DC and their imitators. Thus, alternative comics could encompass everything from the epic fantasy of Cerebus and Elfquest to the bitter realist stories of Eightball and Optic Nerve. What these comics did have in common was an economic and social milieu that consisted of a network of fanzines, small publishers and direct market stores that enabled them to establish relationships with each other and readers. Despite their aesthetic and sometimes political differences, this was a group of artists that largely were aware of each other and influenced by each other. As I will argue, alternative comics also participated in a larger project to create an autonomous form of comics art inspired by what they saw as the core values 
of literature. This project is what Bart Beaty and Benjamin Woo refer to as "comics as literature" discourse, and argue has been the dominant means of interpreting comics within both literary and academic spheres.

Of course, the word "autonomous" also conjures up a jumble of positive but not easily definable associations. For participants in the discourse of comics as literature, autonomy meant chiefly artists having creative control over their own work. This demand stood in contrast to the reality of Marvel and DC, where editors dictated plots and policy from on high based on commercial concerns. A secondary issue was the right for artists and writers to receive appropriate economic rewards from their comics, including royalties and original art which could be saved or sold to collectors. The Creators' Bill of Rights, enumerating these grievances and others, was an attempt to codify autonomy as it relates to the comics market. However, this declaration had little effect, and while mainstream comics publishers did make concessions they were never likely to provide the type of creative freedom demanded by alternative artists. Alternative comics turned for this sense of autonomy to another market. Literary publishers promised possible financial reward along with the creative freedom required by these creators' ideas of autonomy. Thus, rather than autonomy meaning complete separation from and disinterest in the market (as in Bourdieu), autonomy in alternative comics came to mean insertion into the mainstream literary marketplace. As John Guillory argues, autonomy does not "transcend" social institutions, but rather exists "in complex relations to the motors of social change," and as such leads comics in a different direction than it had literature (496).

Mainstream literature or literariness is in itself difficult to define. When alternative comics creators aspired to enter the bookstore, they did not aim to achieve the status of the science-fiction or romance novels within. Rather, they aimed to be considered by the same 
institutions that considered the elusive subgroup of adult fiction known as "literature." These institutions include literary awards, academia and prestigious book reviewers. The literary small press would have been at best a lateral move for alternative comics: instead, they wanted the consecration and the platform that came from the major New York publishing houses and large bookstore chains. This contradictory motion can lead to a bit of terminological confusion, as alternative comics rejected one "mainstream" (that of Marvel and DC Comics) that was in fact a rather niche cultural element in favour of another "mainstream" (that of the major publishing houses). Of course, proponents of comics-as-literature such as Groth or Pekar were not likely to speak in quite so mercenary terms, instead associating the literary with acceptance, creative freedom and trans-historical genius. Later writers such as Moore and Bechdel would treat the literary in more complicated way, but nevertheless use the platforms and figures of a fairly conventional Western canon.

This eventually successful courtship of the literary mainstream makes the term "alternative comics" questionable and contradictory. It seems strange to label the bestselling Fun Home "alternative" and a superhero comic with circulation in the low five figures "mainstream," especially when both are published by major conglomerates. At the same time, Fun Home is a clear descendent of Bechdel's Dykes to Watch Out For, serialized in gay weeklies, and distinctly un-commercial comics such as Justin Green's "Binky Brown and the Holy Virgin Mary" (Gardner, "Autography's Biography" 7), making it difficult to argue that Fun Home should be placed in a different category than its less-illustrious forbearers. It is for this latter reason, as well as familiarity, that I will use the term "alternative comics" throughout this work to describe comics of a certain temperament, even if those comics were mass-market successes. 


\section{Prestige and the Literary in Comics Scholarship}

We can see a similar developmental narrative in early comics scholarship. Roger Sabin's pioneering book Adult Comics presents underground comics and their successors as the final realization of a latent potential that existed but was frequently suppresse throughout comics' history (171). Paul Lopes' later history of comics entitled Demanding Respect offered a narrative where the history of comics was just that: a process of gaining respect and external consecration through great work. Lopes separates the brief history of American comics into two epochs: the "Industrial Age," defined by art being made-to-order according to corporate logic, and the "Heroic Age," defined by art that is an expression of individual creativity (xiii). In his introduction, Lopes uses developmental language, suggesting that his reader should "pick up a graphic novel or comic book and discover how comic books have really grown up" (xxv.) Lopes' narrative is not inaccurate, especially when it comes to the economic bargaining power of the American comics creator, but it does fall into the sincere autonomy/bankrupt heteronomy dyad that Bourdieu critiques and complicates. This narrative was strategically important in making space for comics as a valid object of academic study, but resulted in a simplified and moralistic view of comics history.

Building on the work of Sabin, later scholars began to sketch out the generic characteristics of alternative comics. Charles Hatfield's Alternative Comics shows a great respect for alternative comics but also treats them as material objects. Hatfield argues that it was an economic shift in the rise of the direct market that provided alternative comics with a means of survival and allowed for creative experimentation (Ch. 1). He goes on to examine the various publication strategies and modes of serialization that alternative cartoonists pursued, and comments on how these choices affected the overall work (Hatfield Ch. 2-3). In Hatfield, the 
process of alternative comics publication appears in its entirety, including not just creation but also distribution and reception. The subgenre of autobiographical comics also became a favourite of scholarship, and this too was subjected to genre-based analysis by the likes of Jared Gardner and Hillary Chute. Gardner termed these texts "autography," highlighting the ways in which autobiographical comics often (and perhaps necessarily) occupied a space between fiction and nonfiction, while Chute described the significance of female-authored comics autobiography in general. The interest in "autography" drew on the contemporary surge of scholarship on life writing, with the result that most of the most-studied comics (Maus, Fun Home, Persepolis) were autobiographical ones. While Hatfield, Gardner and Chute did not idealize the genres they studied, they may have contributed to the rather narrow conception of a "plausible text" for comics scholarship.

Another branch of scholarship took an even more doggedly materialist approach to comics. Jean-Paul Gabilliet's Of Comics and Men relates a history of comics in which changes in the medium occur not through the efforts of heroic individuals but through market forces and institutional pressure. Gabilliet provides an useful breakdown of the various ways in which comics obtained prestige through internal and external consecration. This suggests that the comics-as-literature frame is an artificial one, and the narrow range of comics it elevates are not the only ones worthy of reading and scholarship. Bart Beaty, who co-translated Gabilliet's book into English, has expanded on this suggestion. In his work on Fredric Wertham, Archie comics, and the interaction between comics and the art world, Beaty challenges the narrative of comics as evolving from some primeval state into maturity. His book with Benjamin Woo, The Greatest Comic Book of All Time, argues that the comics canon reflects just one of many sets of possible aesthetic values. Beaty and Woo argue that "Despite the form's dubious and marginal origins, 
notions of quality, greatness, and exemplarity have become so entrenched in the standard operating procedure of comic scholarship that they - and the biases they introduce - disappear into the background" (15-16). Beaty and Woo explore other possible aesthetic criteria which would create alternate canons. My readings of authorial paratexts in my first chapter can also serve this purpose - if one wishes to imagine an aesthetic rubric under which Dave Sim or Harvey Pekar would be central masterpieces, the rubrics which they themselves developed and argued for are a good place to start. Beaty and Woo's description of "plausible texts" provides a useful reference for the works that comics-as-literature discourse privileges and the ones it neglects.

Gabilliet, Beaty and Woo's work marks a shift from narratives of artistic creation to narratives of reader reception - either by academics and other cultural authorities and the publics at large. Beaty criticizes the dominance of approaches based on English literary scholarship in comics studies, arguing that this has contributed to the narrowly-defined comics canon. The Greatest Comic Book deals little with authors except as signifiers, instead treating comics as ready-made objects whose meaning and value are determined by the reaction of readers and the judgement of cultural elites. Jared Gardner's work Projections goes even farther in defining the audience of the serial comic book as the central subject in the creation of meaning and social significance. In my dissertation, I would like to re-focus attention on the author - not the romantic author of pure creativity, but the canny author of Bourdieu who uses strategies and tactics to manoeuvre through the cultural field. As I will show, many alternative comics creators and publishers were actively invested in the reception of their work and the establishment of the aesthetic categories which Beaty and Woo attribute to critics and literary authorities.

Christopher Pizzino’s book Arresting Development represents perhaps the most extensive 
treatment of the developmental narrative of comics history so far. Beginning with the seemingly unceasing deluge of "comics aren't for kids anymore" news articles, Pizzino critiques both the underlying assumptions of this narrative and its veracity, arguing that "while comics are less reviled now than they were in the worst years of censorship, the medium is still designated illegitimate by default" (3). Pizzino focuses on the ways in which cultural hierarchies and regulation are promoted by education, mainstream journalism and academia (22). In this argument, the developmental narrative which privileges a few comics at the expense of the many is enforced by outside institutions and responded to by creators. While Pizzino accurately identifies the role of outside forces, my study will focus on the way in which authors and editors within the sphere of alternative comics propagated what he describes as the "coming of age" narrative and the questionable ideas of normalcy and development it relied upon. Rather than creators simply reacting to an outside narrative, I suggest that there was an essential give and take between internal and external pressures towards a narrow definition of comics as literature.

It is also important not to homogenize alternative comics creators and their claims. There was no one vision of alternative comics, or of comics-as-literature. Rather, alternative comics are in a continual process of revising and reconsidering their relationship with literature. Individual creators and publishers offer different and competing models of the literary comic. The turn in comics studies towards complicating the assumptions of comics-as-literature is one that was presaged alternative comics through the self-reflexive narratives of authors such as Alan Moore and Alison Bechdel. By taking a less broad perspective than Lopes and Gabilliet, I hope to examine the aesthetics and philosophies of key figures in alternative comics in more detail, demonstrating the complexity of their visions and the ways they expressed it as well as the sometimes contradictory quality of their work. 
My project could certainly be accused of continuing the dominance of literature-driven approaches in the study of comics that Beaty and Woo identify: it is, after all, a project born within an English department that seeks to describe the relationship between comics and literature largely through close reading of several highly verbose comics texts. However, I would argue that the predominance of the comics-as-literature paradigm is not primarily the result of narrow academic biases but rather a result of the strategies of consecration pursued by those within the comics sphere. While, as Bart Beaty has ably demonstrated in his book Comics Versus Art, the art world remains an important point of reference for comic creators, the literary sphere remains a privileged proving-grounds for comics in both economic and cultural terms. In part, this difference in focus may simply be a choice of artists studied - a telling of comics history that focuses on R. Crumb, Art Spiegelman and Chris Ware, as Comics Versus Art does, will naturally find the fine art world more relevant than a history that focuses on Harvey Pekar, Alan Moore and Alison Bechdel, as this work does. But, with the possible exception of Crumb, even art-focused creators must reckon with the literary realm, as Spiegelman has done with his advocacy for the graphic novel as a bookstore category and Ware does with the satiric back cover to his bookstore-available masterwork. ${ }^{1}$ Conversely, literary-focused creators have no need to reckon with the art world. While the close reading techniques of literary studies may have become hegemonic, I believe that they can still shed light on the ways in which alternative comics work to suggest their place in a literary world within the text itself

\section{Literary Tactics and Strategies}

If literature was to be the ideal to which comics aspired, then the question of what literature was

\footnotetext{
${ }^{1}$ For more on Spiegelman's interaction with the materiality of publication and the literary sphere, see my previously published work "A Mouse in the Bookstore" (South Central Review).
} 
became a way of arguing what comics should be. If literature was autonomous and mature, as Groth, argued, then it followed that comics should pursue both aesthetic and economic models that guaranteed this autonomy and maturity. If it was essentially realist, as Pekar suggested, then comics should adapt a mimetic approach. But if literature was commercial and perverse, as Moore presents it, then the project of comics-as-literature became a matter of stressing the similarities between the two mediums rather than the differences. In the body of this dissertation I present three different moments within the history of alternative comics, and use this connection to present both the way in which literature and literary development appear in key texts and the implications this had for the creators' aesthetics and politics.

My first chapter examines the work of three equally vituperative but ideologically and aesthetically diverse figures: critic and publisher Gary Groth, writer Harvey Pekar, and writer, artist and self-publisher Dave Sim. These three men all began their long-running works - The Comics Journal, American Splendor, and Cerebus respectively -- in 1976, which serves as an origin point for my narrative of the ascent of comics-as-literature. Without the benefit of hindsight, the landmark periodicals mentioned above are mostly unremarkable - another fanzine, another self-published underground unlikely to see a second issue, maybe better than the rest but certainly not historic. But they would each prove to be important in the rise of alternative comics. These three publications straddle the history of alternative comics, from their beginnings in the mid-1970s to their incorporation into mainstream publishing in the mid-2000s, and all three can be seen as part of an ongoing attempt to create a body of comics that adhered to values associated with more prestigious art forms, most notably literature. The literary appears here as a somewhat nebulous constellation of print literature, serious, and artistic autonomy which comics could gain respect by emulating. This incarnation of the literary also has an 
implied link to masculine sexual maturity, with sub-literary work described as effeminate, juvenile or perverse - an association which was taken to an extreme by Sim's open and hateful belief in female inferiority. However, all three texts had different understandings of these terms and different ideas of which literature was worth emulating. For these reasons I will be analyzing these three publications in order to discern a general orientation of early alternative comics towards the culturally-defined field of "the literary."

My second chapter moves to the 1990s and the parallel quest for prestige within groundlevel comics, works which existed within the genre-driven mainstream while embracing the values of alternative comics. There is a shift in focus here from an author's individual selfexpression to the resonance their literature has with a wider society. I argue that writers such as Neil Gaiman and Grant Morrison used literary figures as characters in a fairly straightforward, reverential way that both reaffirmed the status of the canonical author as a transcendent genius. Gaiman and Morrison both use the tropes of their genres to literalize the figurative praise which is bestowed upon the canon, and in doing so suggest their own work as a continuation of not just the low-cultural tradition of comics but the high-cultural tradition of literature. However, the work of their contemporary Alan Moore shows a more complex relationship with the figure of the literary. In his period writing under the America's Best Comics imprint and immediately after, Moore created heavily and noisily intertextual works such as Promethea, The League of Extraordinary Gentlemen, and Lost Girls. However, these works do not seek to use literary intertexts to elevate the comics medium, but rather to highlight the ways in which the literary is already sensationalist and degraded, levelling the hierarchies of genre which comics-as-literature discourse adheres to. Moore highlights the ways in which literature has been obscene, deviant and commercial in its own right, painting a rather different literary history than the magical 
canon of Gaiman and Morrison. Rather than aiming for respectability, Moore uses his intertexts to imagine an utopian anarchist mode of authorship. In Moore, then, we can begin to see the transition between an unidirectional, reverential approach to the literary and a more complex use of literary referents to develop aesthetic and political arguments.

Of course, the association of comics with sexual deviance - and literature, by extension, with normality - has different connotations for the actual deviants. In my third chapter, I examine Alison Bechdel's Fun Home, the most notable use of the literary by a queer comics artist. Bechdel's dextrous use of literary intertexts certainly serves the purpose of appealing to a bookstore audience, but I argue that Fun Home ultimately develops a queer strategy of reading that challenges both canonical reverence and academic close reading in favour of personal and bodily engagement with the text. I also examine Ariel Schrag's graphic memoir Likewise, a lessstudied predecessor which contains a nascent form of Bechdel's approach to the question of the literary comic. Like Moore, Bechdel and Schrag use literature not simply as a cultural marker but to develop their own creative ethos - a shift that marks not only the development of the comics form in light of its acceptance into the literary sphere, but also the different pressures and circumstances shaping queer and female artists. The strange connection between literature and sexual maturity remains, but it shifts into different shapes when "sexual maturity" becomes queer coming-out.

I am wary of creating too neat a historical arc, with the transition from reverence to utilitarian borrowing simply retelling the story of comics' maturation. It is worth noting that the reverential strategies of early artists required its own complex tactics and literary knowledge. We can also see elements of each approach within the other - Fun Home and League of Extraordinary Gentlemen are, if not reverential towards the literary, certainly not hostile to it, 
and owe much of their prestige to their literary associations. Nevertheless, there is a distinct shift towards an incorporation of literature in altered and irreverent forms that occurs once the graphic novel is safely ensconced within its corner of the literary world. My choice of texts is also intended to represent different corners of the alternative comics world and their perspectives. Comics and literature both signify different things to the pioneers of alternative comics than they did to the more commercial work of the groundlevel or the contemporary lesbian-feminist perspective of Schrag and Bechdel. However, that this relationship between comics and literature is significant to all three suggests that it is something that alternative comics artists are continually having to reckon and negotiate with.

\section{Comics Versus Art Versus Literature}

The bulk of my analysis will focus on the methods which creators and critics used to advocate for literature becoming the primary intermediary of alternative comics, and not the reasons for this choice. The justification for comics-as-literature in these arguments, when the arguments are made explicitly, is that the literary world is synonymous with the artistic autonomy that comics lack - a claim that would surprise many literary scholars. But the question remains as to why the bookstore is the only source of this autonomy, as opposed to the art gallery or the record store or the newsstand. One aspect is a crudely material one: that, unlike the art world, the bookstore promised a continual stream of revenue and exposure to an audience that was substantially wider than that of the comics speciality store. The art gallery and other "highbrow" cultural spaces could not offer this. Conversely, explicitly commercial spaces such as variety stores, where comics had reigned in the postwar era, or other sites of visual culture such as video stores did not offer the image of prestige and learnedness that even the 
commercialized bookstore did. Art Spiegelman perhaps expressed this most openly in saying that comics' survival depended on embracing "a system that includes university studies, museum shows, the literary 'respectability that allows them to exist in bookstores $[\ldots][$ S]ome kind of pact with the Devil has got to be made for comics to survive" (Groth interview 62). This pact with the devil was a modest and unreliable one -- few alternative comics artists made more money, or became more famous, than they would have if they had drawn superhero work for the Big Two. But the bookstore at least opened the possibility for both these things. And the ideological work of Groth and his allies was to make this transaction seem less like a deal with the devil and more like ascension.

The mainstream book industry was also in a state of flux that allowed for comics to enter it. The rise of the graphic novel as a bookstore product coincided with the rise of big-box bookstore chains such as Borders or Barnes \& Noble as well as the consolidation of major book publishers under a small number of large corporations (Squires). The result was a literary market less interested in conventional notions of prestige and more invested in economic profit. The "class of ' 87 " texts which established a beachhead for graphic novels in bookstores (Maus, Watchmen and The Dark Knight Rises) all became perennial sellers, although many of the subsequent alternative comics published by mainstream houses would not. For an industry that was increasingly dependent (and increasingly comfortable with its dependency) on formulaic bestsellers, celebrity autobiographies, magazines and lifestyle goods, a shelf of comics was not out of the question. At the same time as comics were seeking the literary world for its cultural capital, the book industry sought comics for their economic capital.

Pierre Bourdieu famously illustrated the cultural field as a graph with two axes, prestige and autonomy (Fig. 2). Rather than autonomous artists being disinterested in this literary field, 
Bourdieu instead argued that they were actually canny and intentional actors within it, seeking to place their work in a particular area. Comics creators can be discussed the same way - as the body of my work (especially the first chapter) will show, alternative comics creators were often deeply invested in the reception and distribution of their work. Comics was, in the postunderground era, a medium firmly positioned in the bottom left of Bourdieu's graph: it was both poorly regarded by cultural arbiters and offered its artists little freedom or independence. The goal of publishers such as Fantagraphics and Drawn \& Quarterly, or independent comic creators such as Harvey Pekar and Dave Sim, was to progress diagonally upwards and to the right, obtaining both more freedom and more respect. In the critical belief system most commonly associated with alternative comics, forcefully embodied in The Comics Journal, these two axes are collapsed into one: to work independently is often assumed to result in work automatically demanding respect, while producing more "literary" and prestigious work is treated as a benefit for all creators. This is, of course, when things are done "properly": Gary Groth frequently denounced independent work that was not sufficiently alternative, while Sim mocked alternative artists who laboured under the yoke of a publisher. Autonomy and quality had to be achieved together, or not at all. The literary world seemed to offer both.

This dual belief in independence and artistic greatness was the source of much activism by comic fans and professionals in the 1980s and 90s. The drawn-out legal battles through which artists such as Kirby, Siegel and Schuster attempted to obtain everything from original art to back royalties from publishers who had accorded them very little rights were a flashpoint attracting interest and indignation from all types of comic readers. The Comics Journal broke with its general disinterest in the superhero world to dedicate an entire issue to Jack Kirby's lawsuit against Marvel over original art (The Comics Journal No. 105). Current artists, 
unsatisfied with Marvel and DC's slow rollout of royalty payments, also advocated for greater remuneration and freedom to work for multiple companies. Alterative artists Dave Sim, Scott McCloud and others advocated for a “Creators' Bill of Rights” that would give creators full control over their work and the products thereof. These economic struggles were generally seen as part-and-parcel of the struggle for independent-minded and artistic comics.

However, separating autonomy and consecration as Bourdieu does provides a more complex image of the move towards autonomous comics. We could describe the "comics-asliterature" movement as a diagonal transition that attempted to obtain both prestige and freedom by gesturing towards literature, the most economically successful and robust art that had both. By contrast, many segments of the movement towards creators' rights, such as the activity of Frank Miller and the founders of Image Comics, envisioned a vertical movement that would secure autonomy without fundamentally changing the material of comics book or requiring consecration from external authorities ${ }^{2}$. Autonomous comics content in their obscurity, such as the undergrounds or minicomics, are also part of the latter movement - making strange bedfellows with the likes of Rob Liefield (Fig. 3). Both of these strategies were ultimately successful, albeit with many peaks and valleys, but neither transported the entirety of the comics field along with it. Rather, as a result of this efforts the comics field expanded to cover a broader range of the larger cultural sphere, meaning that individual artists can occupy very different positions on Bourdieu's axes (as in fiction, film, music, etc).. While there is still a ceiling for consecration set lower than that of more established art forms, that ceiling has risen.

For this project I have selected the major figures in alternative comics who most vociferously argued for comics-as-literature within and without the pages of their work. This

\footnotetext{
${ }^{2}$ See Woo and Beaty's discussion of Liefield in The Greatest Comic Book of All Time.
} 
selection bias means that some caution must be used when drawing conclusions about all alternative comics. Most artists did not use these arguments and tactics as frequently and prominently as the creators I analyze. However, these tropes did occur even in texts that were not particularly vociferous in their support for the comics-as-literature position used these tactics occasionally. Los Bros Hernandez's Love and Rockets, for example, was more obviously indebted to California punk culture and B-movies than literary fiction, but Gilbert Hernandez's "Love Bites" begins with a three page sequence of Heraclio (Gilbert's most sympathetic male character) raving about Gabriel Garcia Marquez's One Hundred Years of Solitude. This sequence goes so far as to include a two-paragraph excerpt from Marquez's novel, with Heraclio proclaiming "it's about our lives" (Hernandez 213-215). The next page features Heraclio discussing literature with a fellow teacher, including references to Tolstoy, Dostoevsky and Nabokov. This is a clear statement of Gilbert's influences, which positions his Palomar comics in a lineage of magic realist Latin American literature alongside Marquez. While the influence of various films and other pop-culture texts is not hidden in Gilbert's oeuvre, no other work in any medium receives as thorough an exegesis. Taken together with the above examples from Ware and Tomine, it becomes clear that even artists whose work had heavy non-literary influences turned to the discourse of comics-as-literature on occasion. This suggests that the trend towards alternative comics defining themselves as literature was, if not an universal one, at least broad. Studying the most extreme and prominent examples of this trend provides insight into the tactics that the comics-as-literature genre used as well as the variety of ideological and aesthetic ends which it could be used for.

By focusing on a group of creators who achieved varying levels of prominence in alternative comics, my study necessarily suffers from the same absences as the putative comics 
canon. The image of the serious and independent artist exalted in the early days of the alternatives was largely white, male and heterosexual, and six of the eight figures I treat in depth fit this description. In my third chapter, I examine the ways in which a female and queer perspective shifts the terms of comics-as-literature. However, the central figures of this story are entirely white. There are certainly people of colour within alternative comics, the most notable perhaps being Los Bros. Hernandez and Adrian Tomine, but the figure of the author within alternative comics has remained a decidedly white one. While I will not be addressing the issue of race in-depth in my dissertation, past postcolonial critiques of the literary could certainly be applied to the operation of the literary within alternative comics.

I have given this project the title of "Comics and Literature: A Love Story." This subtitle is not meant to suggest a straightforward adoration of literature by less prestigious comic authors. Rather, it is to suggest that alternative comics authors' relationship to literature has been every bit as torrid and mercurial as any love affair, full of misrecognition, infatuation, anger, longing, experimentation, and eventually a tentative co-existence. It has also involved, of course, its share of sexual anxiety that seems foolish in retrospect. The works belonging to the nascent comics canon (Fun Home, The Sandman) which I discuss were major players in this story, but just as important were the works and thoughts of numerous less-heralded artists, critics, and publishers. By incorporating major works, minor works and paratexts and using both close textual approaches and materialist historiography I hope to capture as full as possible a picture of comics' complicated relationship with the literary. This is a crucial chapter in not just the story of comics but also the story of contemporary literature. As comics take an increasingly prominent place in the literary field and in academia, I hope to shed light on the material conditions and authorial manoeuvres that made the "literary comic" possible. 


\section{Chapter 1: Prestige and Ideology at the Dawn of Alternative Comics}

In 1976, Gary Groth took over the editorship of the Nostalgia Journal, soon to be retitled The Comics Journal. At the time, the Journal was a cheaply-printed tabloid that consisted mostly of advertisements for mail-order comics vendors, barely distinguishable from the legion of other comics fanzines. In the same year, Harvey Pekar self-published the first issue of American Splendor, featuring stories from Pekar's life illustrated by prominent underground cartoonists. Pekar's signature brand of working-class realism is certainly evident in this issue, but it seems tempered with a desire to appeal to underground readers - drugs and sex play a much more prominent role than in later Pekar stories, and the cover prominently advertises that the lead story is illustrated by underground icon R. Crumb. Dave Sim's Cerebus would begin its 300-issue run the next year with an unassuming Conan the Barbarian parody that would eventually turn into one of the most ambitious narratives attempted in North American comics. All three publications would become long-running fixtures of the alternative comics movement, each lasting until roughly the mid-2000s.

These periodicals operated in very different genres and registers - allegedly dispassionate criticism, high fantasy, and autobiographical realism. However, they bear more than chronological similarities. Groth, Sim and Pekar were all vociferous advocates of comics as literature, a cause which involved not just a cultivation of autonomous comic art but the denunciation of derivative and commercial work. Their advocacy of artistic freedom was chiefly an advocacy for the freedom to produce particular types of comics. They promoted the most orthodox version of the developmental narrative in which literature acted as an exemplar of artistic maturity to which comics should aspire and take example. These authors thus marshalled literary referents as well as accusations of maladjustment and immorality against those they 
perceived to be their enemies.

The ways in which they used these figures, however, reveals some crucial ideological differences as well as broad similarities. A critical reading of these three periodicals will thus reveal both how figures within alternative comics promoted a narrow comics-as-literature discourse as well as how the meanings of both "comics" and "literature" were contested within this discourse. This reading will involve paying attention to both the explicit cultural positioning of the authors in question as well as the way in which they deploy literary referents and tropes in their work. I will also be looking at both the comics texts with which Pekar and Sim obtained their platform and the paratexts that they used, including writing in the Journal. Both comics art and prose nonfiction were a part of these firebrands' arsenal, and thus any examination of their aesthetic must pay attention to paratext as well as text. It is by considering Groth, Sim, and Pekar as both authors and actors within the field of alternative comics that we can bring into focus the complexity of what would become "comics as literature."

\section{The Crusade of The Comics Journal}

The Comics Journal was the periodical that most explicitly attempted to shape the discourse around alternative comics and indeed played a large part in establishing the alternatives as a body of work and constructing a public of intellectual comic readers. Groth and prominent Journal writers like reviewer R. Fiore and co-editor Kim Thompson saw themselves as part of an artistic and moral mission to advance the comics art form and make it into an art form that adhered to the same values as literature and fine art. The Journal was one of the most popular and prominent fanzines of its time, alongside the more fandom-oriented Comics Buyers Guide, but has received little attention from comics scholars and historians. Jean-Paul Gabilliet briefly 
mentions the Journal as a mechanism of "internal consecration" but goes into little detail (274276). Paul Lopes cites some important Journal articles but mostly dismisses the writing within it as "for the small minority of the already converted connoisseurs" (132). This point may be true, but most preaching is done to the already-faithful, designed less to convert them to a broad idea (in this case alternative comics) than to channel their commitment into a specific narrative and encourage them to take specific actions. Previous scholars may have understandably seen The Comics Journal as a secondary text with a limited audience and as such relatively unimportant in comparison to primary texts such as Maus, but this ignores the historically important work the Journal did in developing a narrative arc connecting comics and the literary. It is this narrative, its tropes and biases, and the actions it encouraged that are my subject here. It is not just the fact that the Journal advocated for artistic and independent comics which is important, but the ways in which it did so which are important for understanding the history of comics. This advocacy was accompanied by an idealized image of autonomous literature drawn from conventional literary theories. This image lead in turn to three narratives which are central not just to the Journal but also to early comics scholarship: alternative comics as a moral correction to the cynicism of the mainstream, the clash between autonomous "literature" and corporate mass culture, and a kind of artistic comic-of-age that would lead comics out of a state of prolonged and deviant adolescence. These stances were often implicitly or explicitly tied to the values of literary modernism and the 1950s critique of mass culture. In their advocacy for alternative comics, the Journal drew on existing and conventional cultural ideas about literature and sexual development, and in some ways did not so much challenge the reigning logic of mainstream culture as reinforce it.

It is important not to overstate the impact or influence of The Comics Journal. By no 
means did its articles represent the opinions of a majority of comics readers or even a majority of independent artists. They may not even have represented the opinions of most Journal readers: many letter columns include criticisms from readers who saw the Journal's articles and reviews as too elitist or pretentious, but read the magazine for the neutral-toned "Newswatch" column and the extensive interviews. It is also worth noting that the various writers who contributed to the Journal were not unanimous in their opinions, although there was a strong editorial line that was best reflected in Groth and Thompson's writing and which remained consistent for at least the first 25 years of the Journal's run. Nevertheless, the Journal's editorial mission was something that influential writers, artists, and publishers felt a need to respond to even if they did not agree with it. Almost every prominent artist, writer or publisher of the period sat for one of the Journal's lengthy and sometimes combative interviews, and several contributed columns or letters to the editors. ${ }^{3}$ The Journal became a public forum for creators and fans to comment on and argue about the state of the industry. And the kind of comics that the Journal championed, those which privileged authorial vision and literary qualities, have grown from a niche of a niche to a substantial segment of the mainstream publishing industry, exemplified by best-selling graphic novels such as Maus and Fun Home and the rise of creator-owned serialized comics. The comics world that exists today is largely the one that Groth and Thompson dreamed of, to the point that a recent oral history of their publishing house Fantagraphics was titled We Told You So. Because of this importance, any study of how and why comics aspired to become art has to consider the discursive role of The Comics Journal.

Issue No. 55 of The Comics Journal opens with a one-page editorial by Kim Thompson,

\footnotetext{
${ }^{3}$ For instance, Jim Shooter, the long-serving Marvel editor who the Journal frequently villified, sat for two interviews and contributed to five articles in the Journal between 1978 and 1981 (tcj.com). His DC counterpart in this period, Jenette Kahn, was interviewed in issue 37.
} 
ironically titled "Another Relentlessly Elitist Editorial." At this early point in its run, Groth and Thompson's Journal had already received extensive criticism for their negative attitude towards mainstream comics, and was beginning to transform from a more general-interest fanzine that also covered film and science-fiction into one that aimed to be both the paper of record for comics and the home of a critical vanguard pushing comics towards a nebulous literary. Thompson was specifically stepping in to defend Groth's belief that mainstream comics were "bland, useless garbage" (7). Thompson argues that the harshness of Journal's reviews stems from not hatred for the medium but love: "If someone sets particularly high standards for a medium, it is a token not of contempt, but of deep and abiding respect for its potential" (7). Thompson thus justifies harsh reviews and abrasive tone of the Journal as part of a constructive project. This editorial is also significant for the way in which it assumes an universal and objective metric of artistic quality. Thompson uses the analogy of food, describing the typical comics fan as a gourmand who will eat anything and himself and Groth as gourmets with discerning taste (7). This imagery of slobbish and sinful excess will recur. The editorial portrays taste as not simply a subjective opinion but as an objective, almost physical quality. The quest to elevate that quality is then not simply an attempt to bend the medium to one's own subjective preferences but an exercise of moral judgement in order to elevate an art form.

Thompson's editorial, twenty-odd issues into The Comics Journal proper, was not an official mission statement but offers a window into the Journal's mission as its editors and writers conceived it. The writers conceived of themselves as gourmets, possessed of a taste that was uncommon but not subjective. In an early issue, Groth argues that criticism which does not distinguish good from bad is only a useless process of "accumulating an encyclopedic knowledge of ephemera" ("Criticism vs. Analysis" 33) He argues that the kind of "high 
criticism" that the Journal aspires to can only have "High Art" as its subject, and as such it is only fair to pillory or dismiss cheap superhero comics instead of considering the context and tradition in which they were produced. Groth's comments suggest that part of $T C J$ s purpose was not just to evaluate the comics industry as it existed but to encourage the creation of comics which could be considered "High Art" and hence elevate the Journal itself to the status of high criticisms. This would be done through an attempt to praise and nurture certain artists within the Journal and, later on, more directly through Groth's publishing company Fantagraphics.

The TCJ editors' ideas of the literary were largely shaped by modernist aesthetic philosophy and the mid-century critique of mass culture. ${ }^{4}$ Dwight MacDonald, a leftist who ferociously condemned mass culture, was an inspiration for Groth, who described him glowingly as a "perennial outsider and chronic agitator" ("Kenneth Smith interview" 130), and many of Groth's editorials might as well be culled from MacDonald's famous essay "Masscult and Midcult." In this essay, MacDonald argues that cultural standards have been degraded by the rise of a mass audience 5 ."Masscult," the Orwellian abbreviation that MacDonald uses, "destroys all values, since value-judgements require discrimination, an ugly word in liberal-democratic America" (11). The traditional class divide between folk art and high art had been replaced with the vulgarized forms of Masscult and Midcult, the latter a kitschy middlebrow substitute for genuine literature (MacDonald 32). MacDonald contrasted these forms with the authentic genius of avant-garde modernism, an "elite community" that nevertheless "anyone could join" (MacDonald 53). The origin of MacDonald's critique was the leftist aesthetic philosophy of Adorno, whose ideas he brought to the American middlebrow, but as Beaty has argued, both

\footnotetext{
${ }^{4}$ See the more extensive description of this influence in the introduction.

${ }^{5}$ MacDonald tracks this back as far as the rise of Grub Street in the late eighteenth century (17), but suggests that it has been aggravated by the massive entertainment apparatus of post-war America (21).
} 
right and left critiques of mass culture shared several implicit premises (Beaty 48). The ideological differences between MacDonald and the likes of conservative New Critic Lionel Trilling, to say nothing of the frequently anarchic modernist work that both held up as the apex of literary maturity, are unimportant to Groth - rather, he presents these thinkers as a heritage of what Thompson jokingly admits to as "elitism" and which The Comics Journal aims to continue. It is intriguing, however, that he formulates this elitism as rebellion, and the cultural authority as an iconoclastic outsider - another contradiction unresolved in the Journal's critical project.

In the opening editorial to the Journal's $100^{\text {th }}$ issue, Groth strikes a similar tone by lamenting what he describes as the demise of High Culture and its universally accepted artistic standards: "Chaotic standards is [sic] part of the modern condition, the result of High Culture and its unified system of values being diluted and denatured by Mass Culture, effectively erasing the shared understanding of the cultural community, and turning art and culture into a single, homogenized glop" ("Another Call to Arms" 12). To support his argument, he cites no less a canonical authority than Ezra Pound, extensively quoting a passage where Pound compares mediocre art to a cultural disease. Kenneth Smith, whose columns were a regular feature in the Journal despite rarely directly discussing comics, struck a similarly apocalyptic note in describing the declining intellectual and artistic standards of consumer society. Groth and Smith both argued that capitalism corrupted art, resulting in the abomination that was mass culture ("Howard Chaykin" 77, "The Inferno of Flame" 62). Fantagraphics, by contrast, was meant to be a publisher motivated by artistic concerns instead of financial ones: a 1987 advertisement proclaims that "At Fantagraphics Books, Comics Isn’t a Commodity. It's An Art" (Fantagraphics 2). The values of "high art" were thus presented as a way to escape the commodifying influences of capitalism - although the fact that this statement was part of an 
advertisement suggests that Fantagraphics was ironically commodifying these ideals in the process of championing them. For Groth, The Comics Journal was not just a way to improve the comics medium but a way to rescue autonomous art from the claws of commercialism, a mission clearly influenced by mid-century critics and their elitist cultural values.

As with MacDonald, the guiding aesthetic values of The Comics Journal were shaped by modernist ideas of artistic autonomy and individual talent. High modernists such as Eliot advocated for artists to be freed from the demands of commerce, politics, and realist descriptions. Politically, this advocacy for autonomy was often anti-capitalist, although it seemed to lead just as often to fascism (as in the cases of Pound and Eliot) than socialism. Modernist scholar Andrew Goldstone has argued that modernist ideas of autonomy are more complex and variable than often realized, but nevertheless argues that "modernism represents autonomy as a distinctive, relatively independent mode of relation with the very domains that seek to contain it" (13). Groth and Thompson embraced an extreme version of this pursuit, arguing that great art had to be driven by the desire for personal expression and not commercial interest, a position that was anathema to the work-for-hire comics industry. In the introduction to an interview with Steve Gerber, writer and creator of Howard the Duck, Groth advocates for this dichotomy:

Broadly speaking, there are two kinds of writers: the commercial writer and the artist. The commercial writer caters to public taste. [...] The commercial writer may be a meticulous craftsman, a creator of fine, energetic entertainments; or he may simply be a tawdry and talentless merchant, a peddler of popular bombast. The artist, on the other hand, writes out of an inexplicable need borne out of a creative temperament, a need to realize himself through his imagination. (28)

This neat separation between the autonomous, internally-motivated artist and the dependent, externally-motivated artist is perhaps a more extreme one than even most critics of mass culture 
would draw. The division between autonomous and commercial art separated works as well as creators, as The Comics Journals retraced the distinction between genre fiction and literature present in high-cultural taste and argued for it to be applied to comics. This is predictable if we look at the well of literary ideas from which the Journal writers drew, but perhaps less so if we consider the context of the comics medium at the time the Journal begun. Comics had almost exclusively featured stories which hewed to popular and culturally-stigmatized genres such as science-fiction, horror, humour and romance. The Comics Journal emerged from a fanzine scene that was rooted in science-fiction fandom, a group that frequently bemoaned the prejudice against genre literature, which makes it even more surprising that Groth and company were so eager to replicate such a bias in the world of comics. Upholding the literature/genre dichotomy required arguing that the comics medium was great, but that the material of almost all existing comics was trash. The fact that The Comics Journal nevertheless used this dyad to judge comics, and the ways in which it justified this division, shows just how important conventional ideas of the literary were to the Journal's critical project.

For the most part, this bias took the form of contempt towards superhero comics. Writers frequently lamented the dominance of the superhero as the subject of comic books, and lampooned the formulaic plots of mainstream 1970s comics. In their editorial on "Formula and the Superhero," Hal Blythe and Charlie Sweet draw on Dean Koontz (of all people) to divide literature into two types: "Mainstream and Category Fiction" (83). Blythe and Sweet initially state that this is not a judgement of quality, but attribute to "mainstream fiction" -- by which they appear to mean realist literature -- greater depth, significance and understanding of the human condition. By contrast, the superhero story is shallow and formulaic, which Blythe and Sweet prove by listing the formula in detail. Ultimately, Blythe and Sweet aim to introduce the 
literature/genre divide in order to more easily understand and dismiss superhero comics and create a category for more literary and alternative works. Groth and Thompson were much more brusquely dismissive of superheroes, with Thompson at one point stating that superhero comics were "by nature, inferior" to other genres ("Waiting for the Fruit Salad" 39). When writers or artists of superhero comics were praised, they were always portrayed as struggling against or subverting the genre - even a dedicated genre writer like Doug Moench had to be praised as "transcending" the industry in which he worked (Harvey, "DC Tries Again" 112). And if a superhero comic received too much praise, it could always be brought back in line, as when Groth responded to his own writers' praise for Frank Miller's run on Daredevil by arguing that it could never reach the originality of an alternative comic ("Recycling the Old" 40). At times, comics would be praised by simply suggesting that they were reminiscent of prose literature Maus was a "significant attempt [...] at a genuine literary comics event" (Groth, "Recycling the Old" 43), while Love \& Rockets had "a lot of the virtues that make novels a treat for our intelligence and wits, where comics, as a rule, do not" (Smith, "Shaggy Shapes" 43). Whether comics were good or bad, for The Comics Journal the metric by which they would be measured was a conventional literary one.

However, it is important to remember that mainstream comics in the 1970 s were not quite as monolithic as they are sometimes remembered. Superhero comics dominated, but the major comics companies published numerous science-fiction, horror, fantasy and war comics, with some of these, such as Conan the Barbarian, Star Wars and Heavy Metal, being among comics' best-sellers. ${ }^{6}$ These other genres received no more favourable treatment from The Comics

\footnotetext{
${ }^{6}$ Precise sales data was not made public during the 1970s, but John Jackson Miller writes that Star Wars was "certainly the No. 1 title in the industry in 1977 and 1978"

(http://www.comichron.com/titlespotlights/starwars.html), while Heavy Metal's sales peaked at over 200, 000 during this period (http://www.heavymetalmagazinefanpage.com/sales.html) and Comic Book Resources describes
} 
Journal. The three comics mentioned above were all regarded with skepticism if not disdain from the Journal. When independently-published fantasy comic Elfquest became popular, Groth published a lengthy article by John Clifton attacking the excesses and flaws of "elf comics" ("De-Elfing Comics" 64). The magazine's attitude towards the idea of replicating other genres of fiction in comic can be summed up in its attitude towards Eclipse Comics, another alternative publisher that focused on science-fiction, fantasy and mystery comics, often from established writers and artists of superhero comics. In a scathing review of the first issue of its magazine, Groth notes that Eclipse is "nothing more than a disguised reflection of [the] status quo" and concludes that the magazine is "a culmination of corrupt aesthetics and impoverished minds" ("Eclectic Banality" 68, 71). Groth goes on to contrast Eclipse unfavourably to RAW, Art Spiegelman's magazine which had no interest in conventional genres or forms. Eclipse, its publications, and sometimes its staff would go on to be punching bags for Journal writers for the next decade, a feud aggravated by Eclipse publisher Dean Mullany's libel suit against the magazine (covered in detail in The Comics Journal No. 115). This is not to suggest that $T C J$ demanded realism - among its most-praised comics were genre fusions Love \& Rockets and Cerebus - but rather that it saw comics that fit neatly within popular genres as inherently of a lower order than comics which did not. John Guillory has argued that the elevation of certain work to consecrated or canonical status is essentially relational, and thus requires the identification of works which fail to meet the standards of the canon (494). The Journal's acerbic reviews of genre comics by both major and minor publishers served this purpose.

Because they saw the poor state of comics as indicative of a disintegration of literary

Conan as "one of Marvel's biggest hits of the 70s"( https://web.archive.org/web/20140821115810/http://goodcomics.comicbookresources.com/2013/06/07/comicbook-legends-revealed-422/2/) 
values, the writers of The Comics Journal described this attempt to foster great comics art as not just an aesthetic mission but a moral one. Those that promote mainstream comics and inhibit the growth of alternatives are described as irresponsible or flat-out evil, as when Groth describes Marvel's promotional faux-fanzine Marvel Age as a "moral abomination" ("A Paltry Matter of Principle" 5) or when R. Fiore compares DC Comics' publishing strategy to the bombing of Cambodia ("Funnybook Roulette" 46). The Journal suggested that all actors in the comics field - artists, critics, publishers and retailers - had a moral responsibility towards the elevation of the medium. This philosophy is perhaps most apparent in Groth's reaction to the bursting of the black and white comics bubble in the mid-1980s. In a lengthy and vehement editorial, Groth condemns all parties as moral grotesques: the retailers are "positively delighted at their ability to shovel so much crud across their counters," independent publishers "schlepped into the directsales market with all the enthusiasm and integrity of purpose as a brothel greeting the debarkation of the $5^{\text {th }}$ street," consumers are easily dismissed as "ignoramuses" and the artists and writers involved are simply "schlockmongers" ("Black and White" 9-10). The words "Sodom and Gomorrah" are not used, but the narrative of a sinful industry being struck down by righteous devastation is certainly narrated by Groth in near-Biblical terms. The idea that the value of a particular comic is subjective is here presented as simply a flimsy excuse for retailers and publishers to knowingly shovel out garbage. Groth argues that retailers in particular have a moral obligation to sell comics they believe in: "You are a thinking human being with the capacity to tell good from bad, right from wrong, and it's about time you started doing so. If you admit to a complete inability to do so, you should probably be locked up as a moral incompetent and a social menace" ("Black and White" 10). The striking rhetoric here underlines the belief inherent in $T C J$ s editorial line that publishing, promoting and supporting quality works was not 
just an aesthetic good but a moral obligation, and that any attempt to shirk that obligation in the name of being a profitable business was somewhere between childishness and sociopathy. The terms of the Journal's arguments slide between the language of aesthetics and that of morality without any apparent differentiation. This slippage again suggests an adherence to the critics of mass culture, who argued that the deadening effect of mass media would lead to a loss of the nation's moral character and, in the Adornoian critique, a return to fascism. Groth and Thompson rarely explicated this argument, but treated what Guillory describes as "the moralist reduction $[\ldots]$ determined by the equation of text-selection with value-selection" (490) almost as a given. By extension, it is clear that Groth viewed his own work with the Journal and Fantagraphics as a moral project, promoting good work regardless of commercial concerns.

However much they used moral language, Groth and Thompson also attempted to separate their work from political concerns. Early issues included regular columns by both Bill Mantlo, an avowed Marxist, and Rick Marshall, an open conservative, both of whose political opinions appeared frequently in their columns. While Groth frequently opined on the negative influence of the profit motive, $T C J$ 's writers were on the whole as likely to quote Ayn $\operatorname{Rand}^{7}$ as Karl Marx, and Groth criticized what he saw as the excesses of the feminist movement ("Blood and Thunder" (1989) 36). By attempting to represent all political perspectives, TCJ aimed to separate its mission from any particular political valence. Its criticisms of capitalism did not result in support for collective political action. One clear instance of a conflict between Groth's nominal anticapitalism and his belief in artistic disinterestedness arose during attempts to organize comics creators. Any idea of solidarity with other creators regardless of quality - in other words, any attempt to conceive of artists as a class-- violated the individualized notion of

\footnotetext{
${ }^{7}$ As Thompson does in "Another Relentlessly Elitist Editorial"
} 
artistic rebellion. Gary Groth was openly critical of WAP!, a newsletter founded by Frank Miller and others to advocate for better rights and working conditions for freelancers. In the Journal, Groth and Fiore criticized this mission for violating the principles of artistic autonomy and not fundamentally challenging the nature of mainstream comics. Groth described the freelancer as described by WAP! as "a demoralized lackey constantly jockeying for position and scavenging for a buck" and the autonomous artist "whose professional stature rests on his imminent value as an autonomous creative intellect and not on his ability to, say, sell a bunch of Batman comics," the latter a clear jab at WAP! co-founder Frank Miller ("Blood and Thunder" (1988) 30-31). R. Fiore follows on by arguing that "one can have nothing but respect for the artist who is true to himself regardless of financial pressures; a qualified appreciation of the artist who manages to put something of himself and his belief in his work despite the compromises he must make to please his bosses, and nothing but contempt for the hack who justifies himself by claiming he is just a whore who got lucky" ("Blood and Thunder" 1988 30-31). Solidarity with other artists, or conceiving of artists as a class which can be organized, is presented here as an obfuscation of inherent differences of talent and morality among creators. In an interview with Dave Sim, Groth opines that WAP! is "just fighting for better conditions in the coal mines, which I don't think is going to lead to us doing more mature work" and even suggests that "as long as they think about themselves as labor, though, they can't possibly think about themselves as autonomous creators." (The Comics Journal No. 130, pp. 109, 98). Like publishers and retailers, artists were expected to forgo self-interest in pursuit of a better medium.

Of course, for all their disavowals TCJ's stance on WAP and other publishing issues were profoundly political, advancing an individualistic and libertarian concept of creative labour. There is a certain amount of Fantagraphics' own self-interest here, as Groth was a publisher and 
thus a figurative coal mine owner himself. Any kind of organized campaign for increased wages would have compromised the already tenuous economics of Fantagraphics, and hence Groth's evangelical mission. However, in $T C J$ 's ideology, any admission of economic interest was a betrayal of the medium's advancement. A disavowal of explicit political positions was central to its idea of great art. Overtly political comic artists like Sue Coe and Spain Rodriguez were rarely featured in the Journal. Letter writers criticized columnists like Mantlo and Marshall for political biases, with one writer pointedly stating that "It is hard to seriously consider myself a part of the proletariat as I fork over $\$ 1.95$ or $\$ 3.50$ for a magazine devoted to the art of the comic strip" ("Blood and Thunder" (1980), 72). The overall editorial line of The Comics Journal presented the pursuit of true art as autonomous of and incompatible with political concerns, particularly class struggle. Battling mass culture through autonomous art was the sole mission, and nothing could be allowed to supersede it. As per Raymond Williams, TCJ used the ideology of autonomous art to make its own political priorities appear apolitical and natural.

The struggle for literary comics was frequently depicted in masculine terms of battle or war. A 1988 column by R. Fiore bemusedly describes "attacks" from the Journal's "enemies" as "like strategic bombing: It disrupts routine but it doesn't seriously hamper your ability to wage war" ("Funnybook Roulette" (1988) 36). Elsewhere, this militaristic language escalates to the point of violent fantasy. In an early issue, a panel discussion between mainstream comics writers is illustrated with a cartoon of the four writers being fitted for the noose (Potts 54). This cartoon situates the art gallery as not simply a place of consecration, but also a place of retribution. Cartoonist Stu Potts indulges in a fantasy where the judgements of the art world become an avenue for future revolutionary violence against the cavalier pushers of trashy comics. If the ultimate goal of comics is to "hang in galleries," as $T C J$ suggests, then the only way in which mainstream comics 
can do so is through condemnation. The small figure responsible for this resolution, resembling the marginal figures from MAD Magazine, is told "no more ECs for you," suggesting again the lost age of EC horror comics as the source for both the cartoonist's violent fantasies and his high aesthetic standards that leads to such desire for violence. Potts' fantasy of violent judgement was not unique. After an article denouncing the hypocrisy of WAP! for censoring an editorial cartoon, Groth idly fantasizes about how in a just world a mob would tear the WAP! editors limb-from-limb ("Gutlessness and Greed" 5.). The purpose of this violent, war-like rhetoric is to establish comics criticism as not a product of childlike or possibly sexual deviant fans, but as an adult and masculine pursuit. It is worth noting that the writers and editorial staff of the Journal were predominantly male, as were the creators it praised. The two female columnists in the early period of $T C J$ were the most frequently attacked - Marilyn Bethke by numerous letter-writers, and Cat Yronwode by Groth himself after she left to write for the Comic Buyer's Guide. ${ }^{8}$ TCJ would have few if any female contributors over the next decade, for which Greg Basden apologized at one point ("Blood and Thunder" (1989) 36). Comics industry and fandom as a whole had a distinct gender bias at the time (one that continues to this day), ${ }^{9}$ so $T C J$ is not exceptional in this regard, but it notably did not struggle against this bias in the same way it struggled against many other aspects of comics fandom.

The violent metaphors mentioned above were not, however, purely macho posturing. As editors, Groth and Thompson sought to encourage the progression of the comics field not through co-operation but through conflict. The Journal became infamous for the extended

\footnotetext{
$835 \%$ of Journal readers voted Bethke as the magazine's worst writer in 1978 , although $21 \%$ voted for her as the best (Groth Et. Al, "Best and Worst of the Comics Journal" 8).

${ }^{9}$ See Chute, Graphic Women and Lopes, Demanding Respect 82-83
} 
vitriolic arguments that raged throughout columns, letters, and in some instances court cases. ${ }^{10}$ Groth and Thompson encouraged disagreement not just through their inflammatory writing but through editorial decisions. When letter writers would object to a particular column or review, the Journal would frequently print a response from the writer criticized directly after the letter, formally presenting the two writers as being in direct conflict even if they actually agreed on some points. The very title of the letters section, "Blood and Thunder," suggests an aspiration to virulent arguments. The editors of The Comics Journal consistently encouraged and glorified heated argument within its pages.

Groth laid out his reasons for encouraging such furious debate in an early edition of "Blood \& Thunder." He suggests that the arguments that raged in TCJ required a lengthy series of replies and counterarguments in order to fully explore the intellectual implications of the argument: "In any debate beyond the most foolishly superficial, there must be an additional give and take, as the opponents are confronted with and react to each other's viewpoints. I would respectfully suggest that anyone who finds boring or futile a discussion drawn out beyond the thesis/antithesis has a somewhat shallow view of the world and the problems the human mind can confront" ("Blood and Thunder" (1981) 77). The gladiatorial language of "opponents" and the not-so-subtle insult towards the letter writer Groth was responding to suggests that these debates were not always as intellectually removed as Groth makes out. This response argues that the cantankerous nature of $T C J$ was deliberate, not simply to court attention and controversy but rather because its editors believed that the struggle of literary ideas was essentially agonistic. Only by direct confrontation could authors fully develop their ideas and in the process advance the state of the art. In an almost dialectical progression, the conflict between critics allows more

\footnotetext{
${ }^{10}$ For instance, the Journal was sued by Rich Buckler after accusing him of plagiarism and by Michael Fleischer after a negative description of his personality.
} 
developed ideas to emerge and enrich the genre. The Comics Journal adapted conventional ideas of literary progression for a comics world in which they could, as critics, also be essential actors. These actors would be literary warriors, fighting the good fight against sinful commercial work.

\section{Graphic Novels and the Comics Canon}

Extending the dichotomy between the generic and the literary, $T C J$ frequently suggested that comics should strive towards prose literature not just in style or content but also in means of distribution. The merging of the comics sphere with that of prose literature had long been a kind of dream amongst part of the comics fandom, and the Journal certainly did not create this desire whole cloth. Works in the late 1970s such as The Last Kingdom and A Contract with God were advertised as "graphic novels," a term which here suggested not so much format (The Last Kingdom was a serialized fantasy story and A Contract with God a collection of short stories) as aspiration. ${ }^{11}$ In this period Byron Preiss also attempted to break into bookstores with graphic albums that illustrated the works of popular science-fiction authors. Even before Groth began attempting to introduce literary values through The Comics Journal, comics artists and publishers hungered for the prestige offered by the literary sphere.

The Comics Journal provided a welcome forum for these artists to campaign for entry into the literary world. In a 1985 interview with the Journal, Alex Toth mused that the bookstore would ultimately be the best place for a sophisticated comics publication (Davis Et. Al, "Still the Artist's Artist" 73). Steve Gerber suggested in an earlier interview that standalone paperback books would be a better form for comics and allow artists greater editorial freedom (Groth, "Steve Gerber" 43). In 1987, despondent at the low cultural ambitions of comic book store

\footnotetext{
${ }^{11}$ The Last Kingdom was advertised as a "graphic novel" in The Comics Journal No.37, while Will Eisner discussed his use of the term in issue No. 100.
} 
owners, columnist Dale Luciano wrote that the bookstore and the mainstream publishing industry were the best chance for comic books to develop fully into a respectable artform. For Luciano, this was only confirmed by the release of Maus by a mainstream publisher into mainstream bookstores (45). As Charles Hatfield argues in his book Alternative Comics, the speciality comic book store made alternative comics more available to consumers and allowed some to be financially viable (Ch. 1). However, those who created and advocated for such comics felt constrained by this environment, and $T C J$ both allowed them to express this frustration and echo it with columns like Luciano's.

As a part of this aspiration, Groth, Thompson and their associates encouraged comics publications that could be sold in bookstores, and were similar products to "real" books. In issue No. 73 of The Comics Journal, Kim Thompson bluntly stated that "American comics needs the graphic album," drawing inspiration from the format of French comics ("Death Warmed Over" 50). In the next issue, Dwight Decker would call for systematic re-printing of older comics in book-length form ("Editorial the First" 9). As publisher of Fantagraphics, Gary Groth would fulfill this wish with an extensive and still-ongoing line of comics reprints. These reprints attempt to create a comics canon that is akin to the literary canon, with all works readily available and able to be positioned next to each other. The numerous retrospective articles published in the Journal arguing for the virtues of various older artists are at least in part arguments over which comics would belong in this then-nonexistent canon. In collecting these largely serialized works, however, Fantagraphics transformed them from the ephemeral, lowculture objects they once were into permanent artistic objects, effectively creating the bookstoreready comic that they themselves desired.

This desire for a canon which was essentially comparable to the literary one can best be 
seen in TCJ's 1999 issue that listed the top 100 comics of the twentieth century. The list was a project comparable to the end-of-century rankings of novels and nonfiction works compiled by TIME and The Modern Library to great publicity. TCJ's list, coming relatively late in the lifespan of a periodical not especially given to numerical ratings or rankings, is perhaps the definitive statement of Groth's critical project. By this time Groth had been editing the Journal for over 20 years and the publication had gone through a series of writers, formats and even locations, but Groth's strong editorial voice was still largely similar, as can be seen in the choices for the top 100 list. The introduction, written by Tom Spurgeon, argues that comics needs a clearly-defined canon in order to provide it with a sense of history that the ephemeral and corporate nature of the medium has denied. Expressing the Journal's characteristic disdain for commercial publishing, Spurgeon writes that “The story of this medium's struggle against commercial restraints and the blandness of its generally-held mass audience values is so deeply ingrained within the views of many knowledgeable comics readers that it has changed the way the medium is viewed" (34). Spurgeon here expresses canonization not as a conservative force but as a radical one which pre-empts the perpetual novelty of the culture industry. However, the project cannot help relying on conservative ideas of tradition and objective literary greatness. As Spurgeon describes it, in order to become a better art form comics must be more backwardslooking. He calls for "a uncompromising re-examination of the comics medium in terms of its best works" (34). What qualifies a work to be among the "best" is not stated in the introduction, but the brief descriptions of individual works on the list suggest that it is both individual expression and a revelation of an universal inner truth. In the entry for Dick Tracy, Robert Edison Sandiford writes that "What makes good art is truth," suggesting that even a pulpy adventure comic can only be praised by appealing to an inner truth (71). Thompson applies 
similar praise to the list's No. 2 comic, Peanuts, beginning his two-page write-up with a paragraph of abstract statements about how artists interpret "reorganize, clarify, highlight, explain" the universe (106). And the No. 1 entry, Krazy Kat, is credited with setting the path for all artists who used the comics medium for "personal expression" (34). In short, the list rests on the same modernist aesthetic valuation that Groth and Thompson developed in the early days of the Journal, valuing individual expression and universal truth. Krazy Kat was even a personal favourite of several modernist authors, including T. S. Eliot.

However, the categorical messiness of the list itself suggests the awkwardness of attempting to apply literary parameters to the history of comics. Spurgeon's introduction suggests that the history of the comics medium has been obscured by the serial and temporal nature of its publication, but that a proper approach would be to convert these temporal texts into what Beaty and Woo describe as "plausible texts" (14). TCJ imagined comic strips and serials as permanent, historical documents like the great novels of the literary canon. This project is echoed by the extended reprint lines released by Fantagraphics and other comics. The final list, however, reveals how difficult it is to apply this framework to comics. The list includes graphic novels, individual comics stories, the entire run of newspaper comic strips, a certain period of monthly issues, the entire careers of magazine cartoonists, the collected output of one publishing company in two genres, and even sketchbooks. The list's definition of what constitutes a "comic" seems frequently arbitrary - for instance, an entire decade of American Splendor is listed as one entry, while multiple individual stories from similar single-author anthologies such as Love and Rockets and Dirty Plotte receive their own entries (Spurgeon Et. Al 120). There is a healthy dose of self-interest here for Fantagraphics in establishing the seeming ephemera they had released such as R. Crumb's sketchbooks as crucial parts of the comics canon. Overall, 
however, the categorical confusion of the list reflects the fact that it borrows its idea of a literary work from print literature, and specifically the print novel. The more frequently serialized and temporal medium of comics is mangled in the attempt to translate it to a different aesthetic scheme, forced into arbitrary portions and told that even its most outrageous and lurid stories are actually only great because they aspire to some humanistic truth. The assumptions of the Journal's list of the best 100 comics, that great art can be objectively recognized and reveals fundamental truths, are the same as those expressed by Harold Bloom in his own work of listmaking, The Western Canon. But eighteen years earlier, Bloom was forced to define his project as a reaction against critical trends that devalued a white male canon, while in 1999 TCJ presented a similar project as revolutionary. Of course, the extant cultural value of even Maus, Peanuts and Krazy Kat was radically different than that of the works Bloom discussed, but it is clear that Groth's beliefs in an autonomous literary canon would have been old-fashioned at best in the literary world which he so desperately aspired to.

By the time the Journal began its crusade, the ideas of literary genius and prestige it drew on were already seen in other circles as old-fashioned if not altogether outdated. Postmodernism and left-wing cultural politics were in the process of undermining the modernist-influenced critical orthodoxy that $T C J$ desperately aspired to be a part of. The ideas of autonomy and tradition that motivated modernist theorists such as Eliot and Pound were called into question by theorists who focused on the social and linguistic construction of meaning as well as postmodern fiction writers whose work sought to describe a world where individual agency was effaced. Postmodernism was usually treated with suspicion if not outright contempt by $T C J$ writers, with the postmodern love of kitsch in particular lambasted. ${ }^{12}$ Carter Scholz, for instance, wrote a

\footnotetext{
12 Note that Dwight MacDonald also described kitsch as the foremost form of cultural degradation ("Masscult and Midcult" 66).
} 
column describing mainstream comics as "postmodern" as a way to explain their poor quality (41). The attempt at establishing a canon also gestured towards an older theory of literary aesthetics and not more contemporary attempts to introduce marginalized groups into the canon as an extension of social struggle (Guillory 483). In attempting to gain status for comics, these writers aligned themselves with what were at the time conservative literary ideals, in particular the idea of true art as autonomous and disinterested in the political and material worlds and a strict hierarchy between art and genre work. The differing contexts of the two mediums certainly matters, but it is hard to ignore the ways in which Groth and the other writers he published embraced an outmoded idea of literary greatness and appealed to established cultural guardians such as mainstream bookstores to open the gates for a select group of comics artists. The publication of Maus and a few other adult-oriented comics by mainstream publishers at the end of the 1980s would suggest that this strategy bore at least some fruits. But it is at least worth noting that, for as much credit as alternative comics get for being revolutionary and disruptive, in the 1980s the periodical that was their biggest champion could be quite old-fashioned in its thought.

\section{"Erotica for the Juvenile Mind!"}

The anti-comics crusade of Fredric Wertham occurred within living memory for the original Journal writers and most of the creators they described. For many readers and fans, Wertham became a villainous figure responsible for the fall of the more diverse and rewarding comics world of the 1950s (Beaty, Fredric Wertham 197). Critics such as Paul Lopes and Joe Sutcliff Sanders have argued that the history of comics must be viewed through the lens of the stigma created by the association of comics with juvenility and perversion (Lopes 1, Sanders 
161). The stigma was certainly influential on the writers of The Comics Journal, who attempted to dispel the image of comics as juvenile trash. But the idea of comics as deviant, dangerous and illiterate has more influence on the Journal than a simple target of opposition, shaping the way the Journal's writers discussed comics even as they attempted to scrub away the medium's filthy connotations. In many instances, they would turn to the language of deviance and normalcy that Wertham had introduced in order to further their cause.

Despite the complexity of Wertham's psychiatric practices, the more mythological image of Wertham as censor dominated accounts of comics history in the world of fandom (Beaty, Fredric Wertham). The Comics Journal's presentation of the past was no exception. Early issues of TCJ featured multiple columns praising and mourning EC Comics, spurred by Russ Cochran's efforts at reprinting the company's output, with a representative example being R. Fiore's lament for the company in issue No. 60 entitled "And Then Some Idiots Turned Out The Lights!" Fiore credits E. C. publisher William Gaines with creating an environment of artistic freedom, allowing adult-oriented work and flouting censorship. This description more closely resembles the values of $T C J$ than those of EC, whose comics were still genre pieces aimed at a young audience. The imposition of the Comics Code as a result of the crusade Wertham supported is figured in Fiore's account, as in many others, as comics' original sin, responsible for the relegation of comics to formulaic writing for children. Dwight Decker even cited the censorship of comics, along with the rise of television, as the cause of declining literacy, imagining the 1930s as a lost paradise where "people read more" and specifically "every kid read comics" ("Doc's Bookshelf" 76). Perhaps because of the legacy of the Comics Code, TCJ was a fierce and vituperative opponent of censorship in any form, covering any instance of censorship from the big companies or obscenity suits directed against publishers and retailers with detail and 
fierce rhetoric. ${ }^{13}$ In the background was always the fear, sometimes raised but usually denied, that another wave of comics censorship was on the way, spurred by a 50s-like gap between the decade's mainstream conservative values and the increasingly adult nature of comics.

However, this emphasis on free speech was not the only response to Wertham. The central character of The Seduction of the Innocent, the child warped and stunted by comics, made surprisingly frequent appearances in the pages of the Journal. The exact character of this warping differed depending on the writer. The comics fan was sometimes described as a misunderstood genius and sometimes a demented man-child. These two approaches to the comic fan are both present in the first issue of The Comics Journal entitled as such. Dwight Decker writes about "The Dilemma of the Adult Comic Fan," stating bluntly that "comics are for kids" and that reading comics into adulthood requires a carefully-constructed worldview (11). Decker goes on to detail a number of self-justifications ranging from the practical to the delusional, and ends the list with a mix of all of them - the "Decker" ("Dilemma of the Adult Fan" 12). Articles like this periodically appeared in the first decade of The Comics Journal, offering an anatomy of comics fans and often casting them into various types and extremities. Most striking is an article by David Stallman diagnosing the "Cult of the Superhero" and offering a range of severities of superhero obsession from "browser" to "freak" and "junkie" (107-109). Stallman explains that his purpose for writing is to "get [superhero fans] to examine their participation [in the 'cult'] more closely and consider how worthwhile their support of that genre is, and if their interest and money could be better invested elsewhere" ("Cult of the Superhero" 109). There is an element of insider humour to these classifications, with both Decker and Stallman concluding by diagnosing

\footnotetext{
${ }^{13}$ Representative Journal articles on the topic of censorship from the late 1980 s alone include "Censor/Censure" (The Comics Journal No. 109 p. 36), "Protection vs. Censorship" (The Comics Journal No. 116 p. 29), "Obscenity and Freedom" (The Comics Journal No. 122 p. 127) and "Gutlessness and Greed" (The Comics Journal No. 130 p. 3).
} 
themselves under the schema they provide. But these articles, especially Stallman's statement of purpose, suggest that the comics fan and particularly the superhero comics fan was to the writers of The Comics Journal a pathologized subject, one prone to irrational manias and childishness. This also surfaces in numerous Groth editorials berating comics fans for their poor tastes and underdeveloped morality The Journal's adult comic fan is certainly less violent than Wertham's children, but he (and it is always a "he") is no less disturbed.

Running immediately after Decker's “Dilemma” in Groth's first issue is a column by Jim Wilson, written in response to a letter from Decker. Wilson describes members of fandom as "gifted and talented young people" who often have trouble adapting to a "hostile environment" (13). He draws on the familiar trope of the high-school misfit, writing that "the gifted are forced to go to schools where they must $[. .$.$] associate with average and below-average children whose$ minds are as alien to them as the mind of an alien might be" and comparing this situation to a “snooty cheerleader" being forced to attend a comic convention every day (14). This experience, Wilson argues, traumatizes gifted youth and fills them with alienation and self-doubt. The "gifted child" is perpetually stuck in the kind of heavily gendered high school drama popularized, ironically enough, in Archie and other teen comics - complete with a revenge fantasy against the presumably entirely un-nerdy and unintelligent cheerleader. The developmentally stunted fan is again a central figure, but here he has been hindered not by fandom itself but by the stigma against it. Like Wertham, Wilson portrays children as being psychically vulnerable to these early influences and calls on adults to protect these children by enacting reform. The comics fan is, once again, a tragic victim of society. This was not a common argument among Journal writers - indeed, mainstream comics fans were more likely to be painted as the popular kids stifling the truly gifted. Nevertheless, numerous letter-writers said 
that they identified with Wilson's account, and the Journal retained a recurring interest in the education of the gifted. Mel Gilden would echo Wilson's account a few issues later with an article that described comics fans as "born weird" and "divine madmen" (49). Over a decade later, Kenneth Smith wrote a lengthy article attacking the education system for failing to promote true learning, an article that $T C J$ published despite it seemingly having little to do with comics, showing a surprising continuity with earlier arguments ("Dramas of the Mind" 119). The Journal's long-form interviews often began with several questions about the subject's childhood, and in some cases the interviewer actively suggests a narrative of troubled childhood genius, as in interview with Wendy Pini where Decker asks "Were you pressured to conform" and "Did you run into any sort of flak for your unusual interests?" ("From Poughkeepsie to Elfland" 127). In its desire to portray itself as an intellectual bastion amidst an increasingly non-intellectual culture, The Comics Journal reached to the narrative of the stunted child.

More often, however, the childishness of mainstream comic fans was presented as not fragile genius but indulgent stupidity. In a review of the sci-fi anthology 1984, Raymond Orkwins uses the book's poor quality as a prompt to imagine the comics industry, and society at large, as nothing more than a dystopia of cheap entertainment and the idiot manchildren who loved it. Orkwins writes “Television, drugs, organized religion, comic books, Star Wars, Star Trek Close Encounters, pornography, disco music... All candy. All cheap titillation of our jaded desires. Holes in our sweet tooth, holes in our candy-flossed heads" (31). Orkwins goes on to compare this world of mind-numbed consumers to Orwell's famous dystopia, from which Warren's now-forgotten cheesecake mag drew its name. Here gluttony and perversity are tied together in one string of stupefying entertainment, and the candy analogy, along with an editorial illustration by Dennis Fujitake in which 1984 is read by children and subtitled "Erotica for the 
Juvenile Mind!" suggests that it is children in particular who are the audience for this entertainment. In fact, the cartoon could have served as a cover illustration for Seduction of the Innocent, with figures bursting out of the seemingly innocent comic including a naked woman, phallic tentacles, and a ray gun shooting a suspiciously semen-like blast from out of the book and onto the child's seat. Sex, violence, and monstrosity are all of a piece in this illustration, and all three represent both a literal and symbolic assault on the reader, who does not make meaning from the comic pages but rather has it forced upon him. The child's eyes are covered by the hands of a father or older brother, who is in turn intently staring at the comic - perhaps an example of developmentally maladjusted adults that such fare created. This tone of panic is even more notable considering the obscurity of Warren comics in the late 1970 s - bad comics, even if not popular, represented a potential source of social decay.

Superhero fans' childish consumption was described as not just bad taste but a kind of perversion, with the language both judgemental and sexual. Mainstream comics were repeatedly described by different critics as "incestuous," ostensibly due to the fact that writers of the comics were mostly former fans and wrote stories that only appealed to those who were already fans, but with distinct connotations of the sexual deviance and maladjustment associated with comics since Wertham. Reviewer Stewart Hopen writes that superhero comics "aimed at appealing to the hidden dream life of the male fraternity," a turn of phrase that mixes the adolescent sexual dysfunction of the wet dream with the hint of homosexuality (79). In a review of Love \& Rockets, Kenneth Smith accused mainstream comics of "the American fetish of colossalism, obsession with gigantic quality - in everything from mega-architecture to mega-tits" and state that these comics are "epiphenomena of the life of [...] pathetic fantasy, private escapist fantasy," en route to arguing that comics have contributed to an oppressive culture of alienation, 
"necrophilia and atrophy" ("Shaggy Shapes" 40-43). As in Wertham, the decadence of comic books reflects the sexual illnesses of American society at large, and these illnesses can be addressed by removing bad comics. These comments are taken from reviews by different authors over several years, but together they reveal that the association between comics, sexual deviance and societal breakdown was present in the very language and rhetoric with which The Comics Journal argued that comics should become an adult medium accepted by the mainstream.

It was perhaps this anxiety about deviant sexuality that lead to a general disinterest in underground comix. The underground embodied many of The Comics Journal's principles autonomous creators expressing their own ideas and freedoms without commercial interest - but the Journal was hesitant to embrace its legacy. Early issues contained a regular column on the underground, and the Journal would go on to maintain a similar level of coverage throughout the next decade, with most issues containing one or two pieces relating to the underground. Outside of these articles, however, underground comics were rarely singled out for praise or comment, and underground artists outside of R. Crumb were usually not included in the annals of comics greats. ${ }^{14}$ In part this disinterest is due to the fact that the underground boom had more or less petered out by the time The Comics Journal began, but I would suggest that it was due to a larger discomfort with the counterculture on the part of the Journal and its readers. In an interview Ted White, then-editor of Heavy Metal magazine, talked about the importance of drugs in his creative process to a startled and seemingly uncomfortable Groth ("A Life on the Fringe of Comics" 65). Several readers wrote in to complain about White's permissive attitude towards drugs and enumerated their dangers ("Blood and Thunder" (1981) 42). Other articles openly criticized the

\footnotetext{
14 The 1999 list of the top 100 comics includes 3 underground works not by Crumb, less representation than even $T C J$ 's critical nemesis, the superhero comic.
} 
underground, as when Bill Sherman questioned whether the project of shocking "bourgeois sensibilities" was even still possible ("Lust Among the Ruins" 69). And, as mentioned above, the Journal had a distaste for the kind of politically committed work that the underground embraced. While undergrounds were already in decline when Groth began editing the Journal, the publication harboured little nostalgia for the age of sex, drugs, and rebellion and had little respect for its comics, however autonomous they might have been. This indifference can be attributed to differing attitudes on sex, politics, and mainstream cultural acceptance. The undergrounds seemed to relish living up to the negative cultural images of comics, attempting to actually be the smutty, seditious literature that Wertham worried about. For the Journal, which wanted to dismiss and repress the ideas of comics as deviant, openly deviant comix were anathema.

My argument here is not that Groth, Thompson and the rest were closet Werthamites, but rather that the legacy of the 1950s anti-comics crusade had so influenced the cultural field that in their attempt to better the place of comics in said field the writers of The Comics Journal drew on the very discourse that they outwardly opposed. When they wanted to denounce mainstream comics, the concepts used to denounce comics decades before were closest at hand. So superhero comics became once again markers of stunted development and sexual deviance. The comics that the Journal endorsed would have to be largely comics invulnerable to charges of prurience and perversion, closing off the possibilities of outwardly rebellious work such as the underground. This is not to say that the Journal avoided sexually or politically explicit comics entirely, as can be seen in the case of Journal favourites like the highly sexual Love \& Rockets and the violent American Flagg, but any objectionable material had to be justified as part of a larger artistic project. Purely prurient interest or rebellion had no place in the world of artistic comics, and in this we can see how even in the staunchest support of adult-oriented comics there 
is an echo of their most prominent opponent.

Perhaps it is best not to take the Journal's polemics entirely on their face. Rancor and resentment was The Comics Journal's brand, as can be seen in advertisements for subscriptions that proudly proclaim that the magazine is "More powerful than critical acceptance of commercial mediocrity" or market the letters column as "irascible" ("TCJ advertisement" (1982) 4, "TCJ advertisement" (1989) 61). As publishers of Fantagraphics, Groth and Thompson were willing to publish fanzines about the X-Men and later a line of erotic comics in order to finance their more highbrow ventures, and Thompson edited Amazing Heroes, a sister publication to the Journal which took a much more fond look at mainstream comics. Even without this context, it is hard not to smell a whiff of performance in the Journal's anger at mainstream comics. But performative or not, the Journal's editorial line likely reflected real ideas and had real influence on the comics industry and in particular the nascent alternative comics scene. As I have shown, these ideas are numerous but broadly fall under two themes: firstly, that comics can and should move towards something more closely resembling prose literature through the actions of autonomous artists and critics to establish a canon of unassailable texts, and secondly that comics which did not do so were stunted and perverse, worthy of the invective that had been mistakenly hurled against E. C. Comics in the 1950s. These ideas would be taken up by Harvey Pekar and Dave Sim as they made their own attempts to shape the emerging field of alternative comics.

\section{Grub Street, USA: Prestige and Literary Realism in American Splendor and Beyond}

Harvey Pekar's attachment to comics-as-literature seems almost inherent in his position as one of the few major names in underground and alternative comics to not draw his own work. Pekar's most famous work, American Splendor, is autobiographical, but the artwork is provided by an 
assortment of artists working to Pekar's script. This process confounds some of the common ways of discussing both alternative comics and autobiography. Critics such as Hilary Chute and Jared Gardner have associated the genre of graphic autobiography with a kind of self-reflexivity that is directly tied to the physical process of drawing, citing artists such as Justin Green, Aline Kominsky-Crumb, Phoebe Gloeckner, Lynda Barry, Art Spiegelman and Alison Bechdel - all of whom both write and draw their own work. Gardner, who describes the "autographer's craft" as "combining words and images," concludes that "it is the graphic memoir that best allows for this simultaneous claim of autobiography and fiction, and for the simultaneous demand on the reader for both distance and identification" $(10,22)$. It is at least initially difficult to figure out how Pekar fits into this schema - if he is just a writer, does he really match Gardner's neological category of "autographer," and how can he achieve the duality of word and image that Gardner and Chute evangelize about? Gardner does include Pekar in his "origin story" of autography, arguing that the multiplicity of artists and art styles in American Splendor destabilizes the subject position by presenting us with no clear, official image of Harvey Pekar (15-16). This argument is more fully developed by Thomas A. Bredehoft in his article "Style, Voice, and Authorship in Harvey Pekar's (Auto)(Bio)Graphical Comics.” Bredehoft argues that Pekar's use of multiple artists and hence multiple representations of the autobiographical subject creates heteroglossia in the normally univocal world of autobiography (99).

This argument may very well be true, but it is not how Pekar conceived of his own work. In both print articles and American Splendor, he identifies himself as a realist and argues for the superiority of literary realism to genre fiction. When Comics Journal critic Leon Hunt praised him for telling stories in a way that subverts or calls into question realism, Pekar objected in an essay a few months later: "What Hunt does is cite stories of mine he likes, stories about 
experiences and things I've seen, and then claim they're not realistic because of the way they are told. His attitude seems to be, 'if it's good, it can't be realism'” (The Comics Journal No. 130 130). One can easily imagine him having a similar response to Gardner or Bredehoft's assessment of his own work. This is not to say that Pekar is the last word on American Splendor, but it does seem important to me to understand Pekar's own aesthetic beliefs, especially since he vociferously argued that these aesthetics were necessary for the advancement of the comics medium. Rather than evaluate Pekar's work through a postmodern critical rubric, I would like to briefly examine Pekar as an actor in the cultural field of alternative comics in the 1980s and 90s, an actor pushing towards a rubric inspired by social realism.

The most explicit presentation of this rubric can be seen in Pekar's above-mentioned Comics Journal article, an essay that inspired vociferous response from readers and a long exchange between Pekar and R. Fiore that was notorious for its venom even among the normally rancorous tone of the Journal letters page. ${ }^{15}$ Pekar begins by establishing that, as he has repeatedly stated in American Splendor and elsewhere, "Comics are as good an artform as any in existence" ("Comics and the Genre Literature" 129). Given this, Pekar attributes the poor quality of comics to the low standards of fans who simply want "escapist, pulp-derived stuff" but cannot openly say "I know this stuff is junk, but I like it" ("Genre Literature" 129). These fans with low standards apparently include the critics of The Comics Journal - a new type of fan who "have accumulated large vocabularies and claim to have read Ulysses" ("Genre Literature" 129). The mention of Joyce is a telling jab at the Journal's modernist aesthetic criterion and suggests Pekar's preference for social realist literature. Pekar goes on to defend the realist tradition as

\footnotetext{
${ }^{15}$ In 2011 the editors of TCJ, now largely an online publication, republished the Pekar/Fiore argument as an example to more recent readers of the "grand tradition of the flame war," likening it to both modern internet trolling and the eighteenth-century written debate between Jonathan Swift and Mary Wortley Montagu. The debate was also advertised on the cover of The Comics Journal No. 132 (1989).
} 
being more versatile and complex than its critics give it credit for, and defines his own work as realist stories with various aims, from the didactic to the meditative. He goes on to critique popular alternative artists such as Art Spiegelman and Los Bros Hernandez, whose work fails Pekar's realist aesthetic standards. Pekar accuses Spiegelman's Maus of being self-aggrandizing and portraying Spiegelman's father in a needlessly negative light, making the story "artificial, contrived, and pseudo-intellectual" ("Genre Literature" 129-130). Pekar insists that he does not object to anthropomorphization as a device, but the clumsy way in which Spiegelman handles it. To Pekar, Maus - which was on the way to being a cornerstone of the nascent comics canon was popular among fans because it took the form of funny animals in "an adventure story involving Vladek's attempts to keep himself and his wife alive," allowing genre comics fans to "[have] their cake and eat it too" ("Genre Literature" 129). Pekar levels a similar charge and Gilbert and Jaime Hernandez's Love and Rockets. He admits to liking the brothers' work, but writes that it too panders to comics fans' taste for genre pleasures by focusing on "young and good looking women [the readers] can fantasize about, full of young people of both sexes looking for adventures or having adventures, so that you forget some are supposed to have jobs" ("Genre Literature" 133). For Pekar, Gilbert "owes too much to genre literature," and hence doesn't reach the heights of literariness which comics are capable of.

This argument rests on a distinction between "genre stuff" and naturalist literature, one that upholds the latter as being the fundamental goal of true art. Pekar describes genre fiction as "commercial" writing that "rely for their appeal as contrived, tricky plots, sensational adventures in which the world is at stake, idealized protagonists, too-good-to-be-true heroines, and other stereotyped characters" ("Genre Literature" 129). Pekar acknowledges that "fine art" writers can create great works out of these subjects, but that fans of genre literature take little interest in 
these works, and in fact many genre works can be described as an adulterated version of fine art. The result is "schlock writing" and, in Pekar's eyes, "almost all comic books are schlock" ("Genre Literature" 129). The critique of the Hernandez brothers is particularly telling, as Pekar suggests that fans of Love $\&$ Rockets are motivated by the sexual desire to see attractive young bodies, drawing on the history of comics being targeted as sexually lurid "schlock." The comment about Hernandez's characters being "supposed to have jobs" suggests that for Pekar the world of work is an essential topic of literature, aligning him with the social realists of the late nineteenth century and their more directly political successors in the early twentieth. Pekar seeks to reinforce the divide between genre fiction and literature even more than Groth, casting aspersions on any non-realist elements. He is responding to the critical project of The Comics Journal and adapting it into his own, with a different set of literary referents. Pekar takes Groth's central promise that comics are bad but could be made good by autonomous creation, only adding more specifics as to what "good" means.

Pekar, then, was another conscious actor in the world of artistic comics, purposefully pushing alternative comics towards realist stories and away from their past as genre fiction. As with Groth, the promised reward for this shift was mainstream respectability, that comics would be widely seen as "a medium as good as any other" if only readers grasped the fine art/genre distinction that Pekar presents as widely-acknowledged in the realm of print fiction. American Splendor itself was a key part of this project, and several stories can be read as statements on literary prestige, artistic integrity, and working-class realism. Put cynically, a key element of Pekar's comics is convincing the reader of Pekar's ideas and Pekar's genius, functioning less as the warts-and-all confessional of underground comics and more as self-aggrandizement. Put more generously, part of the artistic mission of American Splendor was to establish a space for a 
realist comics tradition that had not truly existed before.

The literary focus of American Splendor can be seen in its basic formal elements. Pekar relies entirely on his words to establish his artistic authority - and as a result, there are a lot of words. Formally, no matter who the artist is, it is the words that dominate both the physical space of the comics page as well as, presumably, the reader's attention. The most striking example of this verbal dominance of "The Harvey Pekar Name Story," which features very little variation in the artwork as Pekar's autobiographical persona presents a monologue. As in a televised stand-up comedy special, the visual element is present but subordinated to the words being spoken by the subject. Many others are not so formally striking, but feature speech bubbles and captions that take up the majority of panel space. This is especially notable when one considers the reputation of several of the artists who illustrated American Splendor, including R. Crumb. In most stories, American Splendor formally presents Pekar's words as more important than the artwork. When Pekar began writing in the 1970s and 80s, comic book writers were generally seen as less skillful and important than artists, a state of affairs that would not change until the "British Invasion" of Alan Moore, Neil Gaiman, Grant Morrison and others. ${ }^{16}$ Virtually all of the underground comics that Pekar was influenced by were written and drawn by the same person, as were his alternative contemporaries like Spiegelman and Los Bros Hernandez. As simply a writer, Pekar had to foreground his contributions to attain a similar level of prestige and importance, both through the one-writer many-artists format of American Splendor and the formal dominance of text. It is not surprising that he turns to literary antecedents instead of the fine art world. This is a formal strategy repeated in parts of Cerebus

\footnotetext{
${ }^{16}$ For more on this shift, see Beaty and Woo, The Greatest Comic Book of All Time, Ch. 3 (pp. 53-64).
} 
and much later literary-inflected comics such as Fun Home. ${ }^{17}$

The style of these words are also striking, as Pekar takes pains to write in a casual MidWestern dialect instead of "proper" intellectual prose. This extends even to his prose writing, such as the Comics Journal essay mentioned above, whose gruff verbiage stands out in contrast to the verbose and melodramatic prose of writers like Groth and Thompson. As much as Pekar criticized the "genre stuff" of his contemporaries in the comics medium, appealing to traditional literary values, he also shows a distaste for academia and the New York literati, and certainly doesn't express a desire to be among their number. ${ }^{18}$ It should also be noted that while Pekar does place faith in autonomous art, he does not downplay material and financial aspects of life as unimportant in the way that Groth does. Numerous American Splendor stories concern the artist's quest for "bread" - even as he brags about having a cushy government job, the possibility of making a living, or simply more money, from his art looms as a never-attainable promise. In one later story, Pekar depicts numerous meetings with TV and movie executives, noting that "Man, would I ever like to sell out to them. [...] I'd cry all the way to the bank" (Odds \& Ends 4). On the cover of the same issue, Pekar depicts himself as a homeless man selling comic books out of an alley to a man in a limousine. If comics are an autonomous and worthwhile form of art to Pekar, they are also a kind of hustle, an endeavor that fundamentally belongs to the working class.

Pekar identifies himself as a "working class intellectual” (Odds \& Ends 4 ), and his struggle to make the two halves of this identity cohere are the topic of many stories in American Splendor. Several stories depict Pekar's difficulty in getting his prose articles published and

\footnotetext{
${ }^{17}$ It seems worth noting here that Bechdel illustrated a story in one of the later issues of American Splendor, and there is a continuity in the ambitions if not the styles of the two creators.

${ }^{18}$ See, for instance, his jaded portrayal of New York as "the city of art" in American Splendor No. 18 and the insults hurtled at academics in issue No. 22.
} 
Pekar's anxieties about his own intellectual reputation and self-satisfaction (e. g. "Grubstreet, U.S.A.," Music Comics). While Pekar sometimes takes pride in his practical job in the civil service, he also feels the need to write criticism as a way to "make [him] feel like more than a file clerk" (Music Comics 22). In one caption, he writes of himself that "He doesn't fit into any category. He regards most of the people he works with as ignorant and square and they think he's nuts [...] He's uneasy around academics, feeling that they think he's crude. He doesn't even fall into the hippy or junkie or wino category" (Pekar, "An Argument at Work" 19). Pekar is constantly upset at the cultural arbiters, most notably editors, who dismiss him but at the same time admits to being desperate for praise and recognition. At one point he bitterly complains of these editors that "These pitiful assholes could get through my stuff only if it had pictures" (Pekar, Music Comics 2) suggesting both the injustice of the divide between prose and comics writers and a hidden desire for print publication as an extrinsic validation that comics cannot provide. As a result of the conflict between his working-class lifestyle and his literary ambitions, Pekar begins to excavate a "category" into which he belongs.

Part of this search for a "category" involved reference to literary authors. In drawing a distinction between realism and shlock, Pekar follows in the footsteps of not just Groth and Thompson but also naturalist and social realist writers who ridiculed romances and promoted fiction that attempted to capture the texture of real life. His chief influence in this was turn-ofthe-century American naturalist authors such as Upton Sinclair, Theodore Dreiser and Frank Norris. Norris was starkly critical of the limited scope and repetitive tropes of his era's popular fiction, and derided "the aristocrats" and "the sensitive" who "will associate with your Romance only as long as she wears a silken gown" (925). Like Norris, Pekar positions himself as a working-class voice whose realism exposes the limitations of the upper class's favourite genres 
(although alternative comics critics make for a decidedly strange "upper class.") From Dreiser, he drew an emphasis on realism as the most important criteria of artistic evaluation; Dreiser once declared "The sum and substance of literary as well as social morality may be expressed in three words - tell the truth" (927). Pekar was willing to admit that non-realist work could be great, in a mostly hypothetical context, but he otherwise followed Dreiser's commandments, as well as his conflation of "literary morality" and "social morality." The literature referenced in American Splendor is varied geographically, including British, Irish, and Australian writers, but it is all work that falls within or close to the time period of American social realism and meets that movement's aesthetic criteria. While Pekar's ideas of the literary were just as dated as those of Groth, they came from a different portion of the turn-of-the-century literary world.

Pekar introduces these authors and their works into his autobiographical comics through direct intertextual references. In one story, he reads Theodore Dreiser's 1911 novel Jenny Gerhardt, and offers both a review-like commentary on the novel: "It turned out to be real good, way better than I expected" (Pekar, "Alice Quinn" 32). This assessment is followed by a brief plot summary of the novel, accompanied by a panorama of characters from Dreiser's novel. This image blends together the imagined faces of Dreiser's characters with those of the present-day people Pekar encounters in the text, most notably his old friend Alice Quinn. S. Carey's heavily cross-hatched art splits the difference between comics art and the kind of classical illustration popular in novels of Dreiser's period. Pekar stands in the centre of this panel, uniting the literary world of the past and the comics world of the present. Here Carey attempts to translate both Pekar's "decades' a faces ran through my mind" and the rapidfire series of deaths and other events that occurs at the end of Dreiser's novel into a montage. Pekar, this montage suggests, exists in continuity with Dreiser due to both subject matter and style. 
Reading is also a frequent way of introducing intertexts. There are full pages of American Splendor, and full stories, that just depict Pekar reading. This reading functions as a way of incorporating literary figures into the world of Pekar's mundane reality. The representation of these figures reflects the author's literary values. One story, "Memorial Day" devotes five pages to Pekar's reading of I. J. Singer's novel The Brothers Ashkenazi, with captions providing a plot summary and critique of the novel. In particular, Pekar criticizes Singer for sensationalizing Jewish culture and history, similar to the charges he placed against Spiegelman. Throughout American Splendor, especially in its later issues, Pekar discovers literary authors that could also fit into the category of frustrated working-class intellectual. Pekar explicitly identifies himself with 19th-century British author George Gissing, going so far as to title a story in which he attempts to sell out and laments the commercial pressures on his writing "Grub Street, USA." In "I'll Be Forty-Three on Friday," published in the same issue, Pekar depicts himself reading New Grub Street, and writes of Gissing and his fellow novelists that "These guys can't make any money unless they write commercial crap. They live hand-tomouth, they're looked down on by upper-class and middle-class people... Why should I think I'll wind up getting more recognition than them?" (23). For Pekar, Gissing is a compatriot - bitter at the world, unrecognized for his genius, and unable to find a wife that is his intellectual equal.

New Grub Street has particular resonance with Pekar's work. Gissing's novel chronicles a pair of writers: one, Edwin Reardon, is talented but frustrated by his lack of commercial success and the other, Jasper Milvain, is only interested in producing commercially viable work. This is the same dichotomy between authenticity and commercial interest we see Pekar draw in his writing for the Journal. In Gissing's novel, prestige and wealth are constantly entangled with romance: Reardon's marriage disintegrates due to the financial pressures caused by his literary 
struggles, while Milvain's romantic desires are blocked by literary feuds. Where Gissing differs from Pekar is that he portrays Milvain, the commercial writer, as being a kind person with a humble assessment of himself and perhaps a more healthy worldview than that of the depressive Reardon. This is a far cry from the cynicism and opportunism that Pekar attributes to Spiegelman, Hernandez, and seemingly everyone whose work is more commercially viable than his own. Thus when Pekar presents New Grub Street as being a narrative about the hard lot of the autonomous writer, it is something of a misreading, and a telling one. For Pekar, any failing of character must be on the part of the commercial writer, and the flaws that Gissing gives Reardon must be ignored. The character in New Grub Street that Pekar most resembles is in fact Harold Biffen, the strict realist whose comedically dull novels are portrayed by Gissing as the work of a well-intentioned fool.

In another story, Pekar is shown reading Katherine Mansfield, marvelling at her "flawless" stories and mourning her early death. This, in turn, produces his own anxiety about the meaningfulness of his work -- "Will anyone read my work after I'm dead? Will anyone wonder what kind of guy I was?" ("Christina Stead" 63). The second question, is, to me, more intriguing - so much of Pekar's worries are based on his apparent inability to fit into the mold of a literary genius, to adopt a respectable authorial persona. Pekar uses Gissing and Mansfield as points of comparison, suggesting to both himself and the reader that he is a modern successor to their writing - a succession that, to his frustration, does not come with status.

Perhaps to allay this anxiety, Pekar begins a project of canon-building. Just as Groth sought to establish a canon of comics that achieved greatness according to his modernist aesthetic criterion, Pekar presents a continuum of prose and comics writers working in the realist tradition who he argues have been unfairly neglected by cultural gatekeepers. This group 
includes Victorian and early twentieth century authors such as Mansfield and George Ade, who he presents in his Comics Journal article as proof that realist novels don't necessarily have to be formulaic (The Comics Journal No. 130 128). In the later issues of American Splendor, when Pekar was beginning to turn away from autobiography and towards a wider range of nonfiction comics, he writes several stories recounting the lives and works of authors he sees as unfairly ignored. Pekar repeatedly writes that "truth crushed to earth does not always rise," a reflection of his cynicism about the literary industry but also a rallying cry for his project of excavating minor artists. Pekar argues for the virtues and importance of mostly-forgotten realist and modernist authors such as Felipe Alfau, Daniel Fuchs and Olive Moore. He writes several similar stories about jazz musicians, focusing on both their music and their lives. ${ }^{19}$ The biographical elements of these stories are essential, as they present these authors as not just working in a similar style as Pekar but also living a mostly similar life as working-class artists trying to make ends meet and unfairly ignored by cultural elites. Perhaps the most comparable critical theorist would be Georg Lukacs, who advocated for social realism as a criterion of revolutionary art - although Pekar's politics were never explicitly Marxist. In terms of movement through the cultural field, the purpose of these stories is twofold: it associates Pekar with the prestige of "real" literature at the same as it resists the cultural hegemony of the modernist literary canon. American Splendor presents a hidden literary history in which its working-class realism is a natural progression from past works. In this history, the great works of modernism are a little less great and a little less original - Pekar argues, for instance, that many of the techniques James Joyce used to great acclaim are also found in earlier author George Moore (Odds \& Ends 13). Thus, Pekar's use of literary authors helps to express his simultaneous

\footnotetext{
${ }^{19}$ An example of these is his tribute to Sonny Berman in American Splendor No. 17.
} 
love and loathing of literary value, and forge a possible alternative.

Comics authors are of course also part of this canon, and Pekar sought to promote other artists who he saw as working in a similar mode. In the Comics Journal essay, he cites underground cartoonist Spain Rodriguez as an example of someone whose work is relevant to the real world and as such does not appeal to comics fans ("Genre Literature" 131-32). Pekar mentions only Spain's realist and biographical work here, although, as R. Fiore would note in a rejoinder to Pekar's essay, Rodriguez also created many comics that could be dismissed as “genre stuff” ("Blood and Thunder" (1989) 44). Through American Splendor, Pekar also evangelized for comics creators he saw working in similar modes, most notably journalist Joe Sacco. In one later issue, Pekar says offhand that Sacco's Palestine is “about five hundred times better than Maus" (Terminal 9). He also cites Palestine and the chiefly realist stories of Daniel Clowes as proof that comics are as good as any other medium (Odds \& Ends). In a broader sense, the rotating cast of Pekar's illustrators was a way for Pekar to introduce like-minded artists to his readers, with several of the American Splendor - including the above-mentioned Rodriguez, Sacco and Bechdel - also writing their own work in various realist or non-fictional modes. In addition to providing material support to fellow independent cartoonists, this canonbuilding perhaps serves as a way to assuage the anxiety about artistic merit that is a frequent topic of Pekar's comics. By establishing a shadow canon of work that has been mostly ignored by both mainstream cultural elites and comics devotees alike, Pekar suggests that he is not alone in his paradoxical identity of working-class artist and realist innovator.

The exact character of this artistic anxiety deserves further scrutiny. While many of Pekar's anxieties have to do with publication, respect, and financial matters, there is an undercurrent of sexual anxiety tied into them. Pekar's desire for respect from critics and editors 
parallels his interest in intellectual women, who he feels belittle and reject him because of his working-class background: "I realize th' kind of women I like are prejudiced against me 'cause I got a flunky job and plebeian characteristics" ("A Dialogue" 35). Pekar reads this rejection into the life narratives of many of his favourite authors, in particular George Gissing. He attributes the break-up of his second marriage to the fact that his second wife, a graduate student, looked down on him and wanted to live in a more intellectual milieu ("A Dialogue" 22). By contrast, his third wife Joyce Brabner (whom he would stay married to for the rest of his life, and also later a writer of nonfiction comics), pleases Pekar by identifying him as a writer and telling him to identify himself as the same. She asks him "Why do you always tell people you don't make a living as a writer? I always think of you as a writer, and you are one. I married a writer" ("The Garfield Monument" 56). This story is in fact Joyce's first appearance in the pages of American Splendor, and this line the first we hear of her marriage to Harvey. Thus, Joyce's recognition of Harvey as a writer is presented hand-in-hand with their marriage and is central to her character in Pekar's autobiographical narrative. Joyce knows Harvey through his comics, and is initially unsure of his appearance. As Bredehoft suggests, this scene highlights the arbitrary nature of the drawings (99), but it also highlights the absolute supremacy of Pekar's words as a way to attract romantic love. The images we get of their brief courtship are primarily literary ones - a twopage spread depicting the reading and writing of letters, Joyce stopping by Cleveland on the way back from her theatre work, all leading to a later series of collaborations between the two ("The Garfield Monument" 56). Pekar castigates writers like Singer and Gilbert Hernandez for seeking to titillate, and outside of the first few issues of American Splendor, avoids any overt sexual imagery. By tying romantic and artistic recognition so closely together, Pekar repeats the tangled relationship between literary prestige and sex found throughout comics-related discourse, but 
sublates the sexual anxieties of the 1950s comics purge into a plot of romantic recognition.

Pekar uses all of these devices to argue for and develop a distinct aesthetic throughout American Splendor as well as the paratexts surrounding it. This aesthetic is one that roots itself in literary realism and presents a subterranean canon of quotidian realism in both prose and comics concerning working class experience. Genre work is not outright forbidden, but almost ubiquitously betrays a lack of artistic sophistication and moral honesty. Under this aesthetic, the most valued creator is a working-class intellectual who is both aware of history and literature but deeply connected to his community. Pekar states all of this more or less explicitly, but also suggests it through the treatment of love, sex and artistic recognition within his autobiographical narratives. Seemingly singlehandedly, Pekar carved out an aesthetic rationale and tradition for realist comics, but it was one that relied upon conventional dichotomies of literature and genre and the conception of the autonomous artist.

\section{Modernism, Misogyny and Self-Publishing in Sim's Cerebus}

In the 1980s and early 1990s, Dave Sim and his long-running monthly comic Cerebus was an unlikely king of alternative comics. A fantasy series that had originally started out as a parody of Conan the Barbarian and its imitators, it later became an idiosyncratic fantasy drama featuring long-running dramatic storylines that used the titular aardvark to critique religion, politics, and the comics industry at large. It was one of the most acclaimed and discussed comics of the era (Beaty and Woo 123-124). Like Pekar, Sim was influential not only for his comics but his outspoken critical work. Much of this was contained within the pages of Cerebus itself. A typical issue of the comic contained an opening editorial note, 16-20 pages of comic story, several pages of letters, and possibly either a sample of a non-Sim independent comic or a prose 
essay by the author. Even the collected "phone book" editions of Cerebus storylines contained extensive commentary by Sim. Because of this, Sim's notes and the opinions expressed therein effectively became part of the text of Cerebus, shaping reader's opinions. Sim was also a notable contributor to The Comics Journal throughout the 1980s as letter-writer, editorialist, and interview subject. He advocated many of the positions endorsed by Gary Groth and $T C J$, such as the vapidity of mainstream comics and the importance of autonomous artists whose work could be compared to prose literature. ${ }^{20}$ However, Sim went even further than Groth in stressing the importance of authorial independence, arguing that alternative comics artists should all selfpublish as Sim did. ${ }^{21}$ This lead to a long-running disagreement with Groth, who was a publisher himself, which eventually turned into a full-blown feud. As with Pekar and his advocacy of other pillars of realism, Sim sought to form a canon of self-publishing artists. He advertised and included samples of their work in the pages of Cerebus and in 1994 launched a "Spirits of Independence" campaign with militant rhetoric promoting independent comics and denouncing publishers and distributors (Mothers \& Daughters 403 ). However, this campaign failed, and Sim gradually became ostracized from the comics community for his increasingly strident misogynist views (Beaty and Woo 125-126).

Sim also took the Journal's belief in the literariness of comics to an extreme. In a 1985 interview, he described his ambitions with Cerebus as being comparable to a novelist's (MacDonald, "Dave Sim" 144), and most of Cerebus's story arcs were subtitled with literary forms such as "High Society: A Novel" or "Melmoth: A Short Story." His formal experiments

\footnotetext{
${ }^{20}$ See, for example, Sim's letters to the Journal advocating that the magazine serve as a sounding board for the alternative press (The Comics Journal No.59 p. 24) and dreaming of a comic book shop focusing on alternatives and the properieter's own aesthetic judgement (The Comics Journal No. 123 (1988) p. 9).

${ }^{21}$ The roots of this conflict can be seen in Sim's 1989 Journal article, where he debates Groth on the role of the publisher (The Comics Journal No. 130 (1989) 87), or Sim's editorial broadside in Cerebus No. 162.
} 
with the comics medium tended towards the replication of the form of various prose genres, from the picture book in "Jaka's Story" to the novel in "Time and the River" to the magazine article in "Chasing YWHW." Sim's comics appeal to literariness by incorporating traditional literary forms, creating a hybrid of prose and comics. But the literary ambitions of Sim, and the peculiarities of his literary philosophy, can best be seen in the way he incorporates literary figures into Cerebus as characters. Cerebus was from the beginning rooted in references to other texts. Beginning as a parody of "barbarian" comics in which the titular aardvark hero mocked the tropes of popular comics, Cerebus made more or less explicit references to authors like Robert E. Howard and Michael Moorcock throughout. For example, Moorcock's most famous character Elric generated Sim's long-running supporting character and buffoon Elrod the Albino. Comics were also used as targets of parody, with a very thinly-veiled version of Chris Claremont showing up as another comedic character. Sim also parodied then-contemporary events in superhero comics through the parodic character of the Roach. As Charles Hatfield has noted, these parodies and metatextual knowledge rely on a presumed knowledge of the world of superhero comics and pulp fiction that often makes Cerebus inaccessible to later readers (Hatfield Ch. 1). These cameos do not really express a literary ideology other than disdain for mainstream comics. However, as Cerebus went on and became more serious, heavily serialized and critically acclaimed Sim did not abandon these references but began involving figures and characters drawn not from the world of fandom but that of high literature. These are almost all icons of modernism. The most notable writers to be depicted as characters within the fantasy world of Cerebus are Oscar Wilde, F. Scott Fitzgerald and Ernest Hemingway. Their appearances and the way they were depicted contributed to Sim's development of an aesthetics rooted in the idea of the autonomous male genius, and reveal the ways in which Sim attempted to 
rearrange the way in which prestige operated in the comics world.

The first writer who has a large presence in Cerebus is Oscar Wilde. Sim offers a split portrayal of Wilde that reflects his own ambivalent feelings towards the Victorian writer. Wilde would seem to be an obvious inspirational reference for Dave Sim's satirical ambitions as well as his advocacy of autonomous art (Goldstone), but things are actually a good deal more complicated than that. To begin with, there are actually two Wildes that appear in the pages of Cerebus, both referred to simply as "Oscar," both resembling the Victorian author without fully fitting his profile. The first Oscar appears in the Jaka's Story plotline, where he is portrayed as a roguish, untrustworthy, and more interested in upper-class cliques and flattery than literary greatness. He is an author of "reads," a genre of illustrated texts within the fantasy world of Cerebus that Sim uses to comment on the world of comics. Sim makes a point to distinguish this Oscar from the real-life Wilde as well as the version who will appear in Melmoth: in his first scene, the Jaka's Story Oscar comments on a meeting with "the author of that poisonous volume about a painting which grows old and hideous," who is also credited with some of Wilde's bon mots (Jaka's Story 7 5). The first Oscar becomes entranced with Jaka's erotic dancing and uses it as the basis of a sensationalist story about the land of Palnu. However, he is dismissive of Jaka in person, gently mocking Jaka's wife Rick for his affection (Jaka's Story 7 16). He is portrayed as generally being a poor author, with one sequence depicting him frustratedly staring at the same words for several panels (Jaka's Story 1112 ), While he is critical of the Cirinist ruling class during his first appearance, he flatters them and bends to their aesthetic demands. His bragging results in Jaka's illicit dancing being discovered and the nightmarish denouement to the story arc. This Oscar is nevertheless sentenced to two years' hard labour as punishment for his deviance by the dystopian-feminist Cirinist government, an echo of Wilde's actual biography. 
This version of Oscar seems to be the antithesis of Sim's concept of the virtuous author: a largely trivial flatterer whose interest in success leads to the breakdown of a successful society.

The second Oscar appears in the Melmoth arc immediately following Jaka's Story, and is a literary martyr who spends most of the story dying in bed. Sim again stresses that this is a different character by having him describe a "kinship" with the first Oscar "beyond our having the same given name" (Melmoth 2 3). In his early moments of lucidity, the second Oscar does offer a harsh critique of the society in which he lives, something that the previous version of Oscar couldn't do. In fact, the second Oscar criticizes a society based on literary cliquishness and likeability that would allow for the first one to succeed: "Once he's been approved as a 'jolly chap' who everyone and their mother has known from infancy, he could write a recipe book on the preparation and serving of 'Cirinist cutlets' and it would be of no interest to them whatsoever" (Melmoth 2 11). He also berates the public for allowing salacious and hollow art to succeed: "You've seen the average Reads customer, Robbie. Thin... nervous... myopic... spotted face... Does he strike you as being any threat? To anyone - or anything? Eagerly devouring some fabricated tale of blood-soaked mayhem... like a blissful suckling at his mother's breast" (Melmoth 211 ). This is a clear critique of the comic book industry, especially the shots at pimply-faced consumers who, in Sim's formulation of the "mother's breast," are not developed enough to resist the female power that defines both Cirinist society and corporate publishing. This Oscar, while still a bit of a dandy, is undeniably a threat. However, he later succumbs to his ill health and becomes an insensate victim, "incapable of desiring anything" (Melmoth 622 ). It is this loss of desire which, in Sim's moral universe, suggests his ultimate virtue. Oscar's death leads to a loss of his literary legacy as well, as he and his companion Reggie burn their correspondence as a way "to keep ourselves from breaking down" (Melmoth 10 18). The Oscar 
of "Melmoth" is a genius who can see the world as it is but is too weak to resists its power.

So, why the two Wildes? The most obvious explanation that Sim offers is his ambivalent feelings about Wilde's legacy. In an author's note before the penultimate chapter of "Melmoth," he writes that "The more I learned about Oscar, the more I resented his lack of productivity. [...] I resent the fact that most of his time was spent entertaining second- or third-rate intellectuals, or even worse, the aristocracy" (Melmoth 10 2). Splitting Wilde into two characters, then, is a way for Sim to imagine an ideal Wilde who is a genuine outsider challenging the feminine authority of his day, as well as excise the dilettantish qualities of Wilde that Sim feels are ill befitting a true artist. The quality of Wilde that Sim wants to excise is not his homosexuality but rather his decadence, the cheeky advocacy of sin that occurs throughout his works. At the same time, I suspect that Sim identifies just a little with the "bad" Oscar, who after all is writing a narrative he insists on calling "Jaka's Story" just as Sim is. We see pages of this story for several issues before Oscar is revealed as the author, so for a while it becomes quite plausible that the flowery prose is direct narration from Sim experimenting with the comic form, as he so often did. What's interesting is that the first Oscar - the superficial and obsequious one - reads distinctly heterosexual, describing Jaka in lusty tones in his novel and leering at her as she dances. By contrast, the latter Wilde - the "real" Wilde, perhaps - is both homosexual and homosocial, interacting only with the younger men who care for him in his dying days.

During the publication of this story arc Sim grew more and more vocal about his opposition to feminism, devoting numerous author's notes to his opinions. In the note before the second issue of "Melmoth," Sim proclaims that "I am not a feminist," and expresses a fear of reprisals for this statement (Melmoth 22). He claims here that it is mainly men who have chided and shunned him for his views on feminism, and that “the more intelligent women aren't 
feminists" (Melmoth 2 2). Sim concludes by writing "even if they made it illegal to not be, I still won't be a feminist," suggesting that he sees the authoritarian feminist dystopia depicted in his series as an imminent possibility (Melmoth 2 2). I suspect, then, that Wilde's homosexuality is a kind of fantastical desire for Sim - a way to resolve or at least simplify the combination of lust and contempt that composes misogyny. During this period Sim also wrote an editorial supporting gay rights and acceptance of homosexual men (Melmoth 11 2). Lesbians and other queer people were not mentioned. This opinion would later change, as Sim would come to bemoan the "homosexualist" agenda linked to feminism, but a version of gayness that excludes women from social life appealed to him. In an author's note towards the end of "Melmoth," Sim cites Neil Bartlett's biography of Wilde and writes that "The comic book world is so very like his description of the gay world" (Melmoth 22). The male-dominated homosociality of the comics world is thus something that Sim sees as a positive connection to the literary sphere. The bad Oscar is immersed in a feminine society, constantly at the beck and call of controlling women, including in one scene a nobleman in a dress (Sim, Jaka's Story 9 11-22). The good Oscar exists in an entirely male social milieu. By imagining a productive and subversive Wilde removed from any type of femininity, Sim creates a canonized authorial figure whom he can present as literary antecedent to his own work.

Dave Sim would only grow more vocal and more strident in his misogynist beliefs in the second half of Cerebus's 300-issue run, most obviously in the infamous 1994 "Reads" storyline. The comic pages of this story deals with a bloody battle between Cerebus and the leader of the Cirinist government, but the bulk of each issue consists of a prose story in which Viktor Davis, an author of reads, struggles with female editors and dreams of creating a work without images. It is clear that Davis is meant to be an alternate version of Sim who went down the path of 
traditional publishing: bound by conventional genres, unable to experiment formally, and bound by feminine authority. Like Sim, Davis has recently been divorced, and his attempt at reconciling with his ex-wife is described in terms of artistic creation: "The only materials at hand were those he had produced from within himself' (Mothers and Daughters 35 15). Even Davis's speech is described as a product of masculine exertion, compared to ejaculation and a hockey goal (Sim, Mothers and Daughters 35 12-13). The next issue, Cerebus No. 186, abruptly shifts to a prose account of a monologue given by Davis in which he argues for the superiority of the men as creators and leaders and denounces the idea of gender equality. There are occasional exceptions, specifically Sim's fellow independent cartoonist Colleen Doran (who Sim would later denounce), but the language starkly describes women as parasitical and manipulative, living off the benefits of male creativity and language. Through the device of a described monologue, Sim anticipates his reader's reactions, describing them first being shocked by such a taboo statement but unable to coherently argue against it. ${ }^{22}$ Sim suggests that in claiming the superiority of men he is only saying what his readers are afraid to, and in this he may not have been that far off.

Nicholas Thiesen has stressed the polyvocality of this issue, claiming that Sim's use of Davis as a stand-in challenges conventional ideas of authorship and makes it unclear whether this is his actual perspective. However, whatever deniability this device may have presented at first, Sim made clear in the editorial material of Cerebus that his opinions were identical to those expressed by Davis, and he would go on to defend the argument presented here against critics. ${ }^{23}$ If these issues do trouble the author function, they act against the intentions of Sim, who had a

\footnotetext{
${ }^{22}$ Sim argues against an imagined male reader in Mothers and Daughters 35 (17-18), and an imagined femal reader named "Exception" in Mothers and Daughters 36 (20-22).

${ }^{23} \mathrm{Sim}$ 's defense of the opinions on gender expressed in Reads begin in Mothers and Daughters 39, and continue periodically for the next seven year.
} 
very traditional idea of authorship. Indeed, authorship is central to the prose narrative of "Reads" and the misogynist philosophy presented therein. Davis/Sim argues that the male nature is "light" while the female nature is "void," meaning that men are capable of original creation while women can only neuter that creation by forcing it into social conformity. Feminism, along with communism, is the philosophy of "merged permanence" that seeks to force individual creativity into unambitious groupthink (Sim, Cerebus No. 186 10). By placing this monologue alongside a narrative of frustrated authorship, Sim suggests that his own self-publishing is an example of male light resisting the pull of the merged permanence of corporate comics publishers. In order to make this parallel, Sim has to distort the reality of mainstream publishers - Marvel and DC have always been editorially dominated by men, but in the "Reads" storyline Viktor Davis deals only with two female editors, both named after DC sub-editor Karen Berger. ${ }^{24}$ This was also a way of critiquing authors who had achieved great acclaim (certainly greater than Sim's) under Berger's Vertigo line, including Neil Gaiman, Grant Morrison, Garth Ennis and Warren Ellis. Implicit in Sim's narrative is a critique of these creators for allowing their natural gifts to be subordinated to the desires of both a woman and a large publisher. Seizing the creative potential of masculinity required self-publishing, and vice versa. Sim came to see gender and authorship as both being part of a larger struggle between individuality and collectivity, and as such his misogyny cannot be neatly separated from the rest of his artistic product.

As his own critical reputation waned, due in no small part to his open misogyny, Sim turned to canonical figures both as a way of validating his artistic project and demonstrating his

\footnotetext{
24 "Karen Potts" is identified as the editor of "Vertigo Horse," a fusion of DC brand Vertigo and major independent publisher Dark Horse, suggesting that she is a gateway to the world of prestigous comics. The last name "Potts" suggests Carl Potts, the editor of Marvel's parallel Epic line.
} 
views on creativity and gender. Several issues of the "Going Home" storyline involve Cerebus and his lover Jaka travelling by boat with famed writer F. Stop Kennedy, a thinly fictionalized version of F. Scott Fitzgerald. Sim referred to Kennedy as a "more ethical" version of Fitzgerald in his extensive author's notes, once again suggesting his desire to rescue canonical authors from their own misdeeds (Going Home 13 30). Kennedy is a well-known but frustrated writer endlessly revising phrases on female beauty (Going Home 10 7). Jaka, increasingly depicted as no longer an ideal woman but a vain and superficial one, treats Kennedy with passive aggression, but he continues to entertain and cater to her. This is later revealed to be an attempt to get Jaka to fund a writers' colony free from Cirinist oppression, an idea which she rejects (Sim, Going Home 13 9-10). In Sim's vision of a misandrist dystopia, this plotline represents the futility of attempting to maintain artistic autonomy without rejecting the dominance of feminism. However flawed his strategy may be, however, Kennedy is treated as a legitimate literary genius, one who knows the female gender better than women themselves. The flowering of this genius is an unpublished work entitled "Singularity," of which Sim includes several full pages, which operates as a more lyrical version of Viktor Davis's argument about the male light and the female void. This narrative is an autobiographical account of how Kennedy abandoned his masculine genius and was seduced by the promises of marriage and merged permanence. The link between the restriction of sexuality by marriage and the restriction of individual artistry is made clear: "though I still thought myself seductive, and all but ran through the streets unclothed, proclaiming my virility, it is never the dress that passion wears which does the business, but passion itself [...] Integrity was behind me, do you understand? I was grown" (Sim, Going Home 13 5-7). Here, Sim suggests, Kennedy comes close to revealing the truth of virile male genius ("the passion itself") neutered by female union ("the dress that passion wears"), but his 
work will ultimately not be published due to Jaka's failure to offer him protection from the matriarchal regime. This plot echoes the narrative of "Reads," and its implicit argument that Sim is able to tell the unpopular truth because he is not subject to a publisher. It also reinforces the connection between masculinity, autonomy and genius present throughout Sim's work.

These themes have resonances with Fitzgerald's work which may explain the efforts Sim took to incorporate Fitzgerald in both the content and form of Going Home. In particular The Far Side of Paradise, or at least an ideologically-informed reading of it, provides material that conforms to Sim's image of the clash of genders in art. Rosalind, Scott's fictionalized version of Zelda, admits to leading men on and subordinating them to her will (Fitzgerald 104). Her rejection of Amory, Scott's own persona, leads him to a personal, artistic, and moral crisis: “the problem of evil had solidified for Amory into the problem of sex" (Fitzgerald 163). For Sim, of course, evil and sex were always the same problem, with men abetting the evil of women out of a desperation for sex. This is represented in the larger Going Home story, in which Cerebus's trip home to visit his dying father is delayed by Jaka's insistence on purchasing new clothes every day. When he arrives at his birthplace, Cerebus discovers that his lust had lead him to succumb to feminine vanity and commit the evil act of abandoning his family patriarch, leading him to finally break with Jaka (Sim, Going Home 34). Of course, The Far Side of Paradise was written in the bitterness of youthful rejection, and Dave Sim extrapolates this momentary bitterness to a philosophical principle by including Fitzgerald in this storyline.

In the editorial material, which at this point in Cerebus's run included a prose article by Sim after the comic section of the issue as well as the opening note and several pages of letters, Sim suggests a parallel between himself and Fitzgerald as artistic geniuses hamstrung by women. Sim compares Fitzgerald's formal innovation of using screenplay formatting within a novel with 
his own technique of using pages of pure prose to tell parts of a comics story (Sim, Going Home 10 23). In the notes to the next issue, he suggests that Fitzgerald's Tender is the Night has unfairly been neglected because it is "factual" in portraying that "Zelda was insane and what was Scott to do about it?" (Sim, Going Home 10 23). The life story of Fitzgerald, to Sim, is a reiteration of his fundamental scene of artistic creation: a man working hard at literature and having to overcome the stultifying effects of women. In his notes on his research for the Fitzgerald story, Sim frequently discusses his own interactions with women, both past and present, and makes clear that he sees his past marriage and other relationships with women as just as disabling. ${ }^{25}$ Arguing for Fitzgerald as a literary predecessor is not only a bid for prestige, but also a means of demonstrating Sim's misogynist literary philosophy.

"Time and the River" is immediately followed by "Form and Void," a title which echoes the term of the infamous "Reads" issue. This storyline takes a similar approach to Ernest Hemingway, another modernist author who Sim believes was hamstrung and ultimately done in by a troublesome wife. Hemingway appears in the world of Cerebus as "Ham Ernestway," a famous writer now in a near-comatose state from Cirinist drug treatment. Cerebus idolizes Ham as an avatar of masculinity. "Form and Void" contains lengthy flashbacks to an African safari taken by Ham and his wife Mary (portrayed as an ugly butch woman with power in the Cirinist hierarchy) in which Mary is ashamed of her inability to shoot a lion (Sim, Going Home 25.) This reflects an acknowledgement of her ultimate nature as the titular "Void," unable to replicate the achievements of masculinity. Instead, Mary and the society she represents seek to subordinate Ham's masculine individualism into a "merged permanence" by means of electroshock therapy, reducing him to an empty shell. Hemingway becomes another way for Sim to demonstrate his

\footnotetext{
${ }^{25}$ For instance, Cerebus No. 245 (1999), pp. 23-25.
} 
theme of autonomous and masculine genius subordinated by female collectivism.

What makes Hemingway a curious choice is that Sim expresses a certain disdain for his actual literary work. In his notes to "Form and Void," Sim criticizes Hemingway's simple diction as "just typing" and cites the fable of "The Emperor's New Clothes" to describe the critical consensus built up around him (Going Home 1622 ). Ever the maximalist, Sim saw Hemingway's minimalism as simply fraudulent. So why devote several issues to a story lamenting the tragedy of Hemingway's later years? For one, the fate of Hemingway fits neatly into Sim's ur-plot of the male artist in a matriarchal world, at least if you blame Ernest's hospitalization and death on his wife Mary, as Sim does. But the prominence of Hemingway also highlights the signal importance of modernist figures and aesthetics in alternative comics: even an artist who Sim believes is a fraud appears as the most appropriate figure around which to marshal the theme of stifled genius.

The most obvious point of reference for "Form and Void" is Hemingway's "The Short Happy Life of Francis Macomber." In the story, inspired by Hemingway's own experiences on safari in Africa, the title character experiences shame over his inability to kill a lion. In "Form and Void," a flashback sequence set in an apparently non-fantastical Africa includes a genderreversed version of "Francis Macomber." In Cerebus, it is Ham's wife who fails to shot a lion, and feels shame over her feminine weakness (Going Home 25 7). She narrates that "It is lonely being the only incompetent here," a line which Sim glosses in his notes for the next issue: "a guy would never, ever, allow himself to think 'it is lonely being the only incompetent here' if he wanted to keep being a guy" (Going Home $26 \mathrm{np}$ ). Ham, in contrast to the effete Macomber, has no problem shooting and killing until he is subjected to Cirinist electrotherapy. Despite the obvious parallels with one of Hemingway's most well-known stories, Sim argued that his story 
was in fact based on the factual safari that Hemingway and his wife took in 1952. Sim wrote in the back matter for issue No. 256, the first installment of the safari flashback, that he wanted to write the story of the real-life safari in a "female Hemingway voice." He expressed this goal as a desire to counter Mary Hemingway's failed attempt to do the same thing in her diaries and autobiography, which Sim suggested were artificial documents meant to present a skewed image of her life. What they obscured was, presumably, the feeling that Mary's Cerebus doppelganger expresses: feminine weakness. Similarly, the fact that Hemingway's fiction dealt with failed masculinity was erased by Sim. Perhaps it was one more thing that Sim didn't like about Hemingway.

"Form and Void" offers a more literal translation of the ending of "Francis Macomber," where Macomber is shot by his wife, but suggests that this aspect of Hemingway's story was unintentional foreshadowing for the author's life. Throughout his notes, which were published in each issue alongside the story material, Sim expressed the view that Mary Hemingway intentionally left Hemingway's rifle available to him in hopes that he would kill himself, a longgestating plan revealed by certain hints in her own writing (Going Home $27 \mathrm{np}$ ). In this way, Sim argues, Mary was responsible for her husband's death and deserves to be thought of as a murderer but is not because of the feminist establishment. This view of events suggests why Hemingway was a crucial figure for Sim, despite his personal dislike. Hemingway's life story, or how Sim interpreted it, fit neatly into Sim's primal scene of the male artist constrained and ultimately snuffed out by a woman. Thus Sim presents a modified version of "Francis Macomber" in which the wife's murder of her husband is motivated not by disgust at his weakness but disgust at her own. In creating a canon based purely on virile masculine genius, Sim has to do quite a bit of interpretive work. 
Another prominent modernist, Gertrude Stein, appears in "Form and Void" as the cruel Cirinist inquisitor Gertrude. ${ }^{26}$ She is mentioned in the endnotes as being a perceptive critic of Hemingway, and the fact, in Sim's eyes, that she could give more than she got suggests Hemingway's ultimate weakness (Going Home 29, np). However, unlike Ham, the fictional Gertrude is not accorded any of her real-world literary reputation, and is portrayed as simply a foot soldier of the militant matriarchal cause. Her inclusion nevertheless suggests the importance of the modernist milieu as a setting for Sim's gendered drama of artistry.

In these two storylines, taking up over twenty issues of Cerebus, Sim uses the prestige of modernist literary figures both as a bid to shore up the rapidly falling prestige of Cerebus itself and as a way to demonstrate his misogynist aesthetic philosophy by playing out a gendered drama of genius and suppression. What critical writing there is on Sim often seeks to bracket off his incendiary views on gender or present it as part of a postmodern destabilization of authorship, as in Thiesen. However, as I have argued above, both Sim and Cerebus are very invested in a traditional notion of authorship, and the separation of people into "light" and "void" along gender lines is crucial to this philosophy. One cannot address Sim's authorial project and persona without addressing his misogyny - not because said misogyny renders his work completely void of merit, but because it is foundational to the artistic philosophy which Sim expresses throughout Cerebus in everything from the various parodies of mainstream comics in the beginning of the series to the theological treatises that conclude it. This philosophy is most evident, however, in the incorporation of canonical literary figures as characters. Sim presents these characters, particularly Wilde and Fitzgerald, as antecedents not only as great authors and satirists but also as kindred spirits due to their oppression by the female void. Ironically, in order

\footnotetext{
${ }^{26}$ Sim describes Stein in the author's notes to Going Home 29 as a leader of the "Moronic Art Movement" and responsible for Hemingway's inflated reputation.
} 
to channel these authors' canonical reputations Sim has to edit their personae and works into a form that fits his ideology, casting aside the contradictory bits of their biographies and aesthetics. In doing so, he articulates an aesthetic in which authorial autonomy and male supremacy are critical to the creation of great art - an aesthetic which resonated in the world of alternative comics throughout the 1980s and 90s.

\section{Comics and Literary Machismo}

Although prominent artists continued to associate with him after "Reads," including Alan Moore and the founders of Image Comics, Dave Sim eventually became something of a pariah in the alternative comics scene. His ostracism may have had more to do with his vituperative feuds with prominent figures such as Gary Groth and Jeff Smith, the latter of whom Sim challenged to a fistfight (Going Home 3425 ), as well as declining reader interest in the increasingly didactic and slow-paced Cerebus. The final issue of Cerebus, published in 2004, had an initial print run of only seven thousand, and came and went with barely a notice in comics fandom (Beaty and Woo 124) Certainly by the time Going Home (which includes the Fitzgerald and Hemingway plots detailed above) was being published, Sim was no longer an influential figure in alternative comics. However, we should not treat Sim's misogyny as alien to the comics scene in which it emerged. Sim took to an extreme the ideology advocated by The Comics Journal, which stressed authorial independence, adherence to literary modernist values, and the figure of the male genius oppressed by society. Cerebus made the sexism of alternative comics, including authors such as Groth who denounced Sim, explicit. In the 1990s comics market, objectified images of anatomically impossible women were a core commodity, from the mainstream work of 
Rob Liefield ${ }^{27}$ to independent comics such as Avatar focusing on "good girl" art to Fantagraphics' line of pornographic comics Eros. The male-dominated comics scene which TCJ helped to build was one in which Sim felt able to express his misogyny, and the lack of female cartoonists elevated to the status of artist allowed him to dismiss female artists as odd exceptions. Even Pekar, who celebrated numerous female authors, associated his writing and cultural positioning with male sexual triumph. Sim spoiled the party by saying what the polite left unsaid, and in the process revealed the misogynist aspects of the cultural politics and aesthetics central to alternative comics. This is not to argue that Pekar and Groth were just as bad as Sim they weren't - but that the misogyny of Cerebus is an extreme manifestation of the cultural logic common to all three.

Sim and Pekar are curious absences in each others' polemics. In his advocacy for selfpublishing, Sim repeatedly advertised self-published comics that he admitted to not liking, but never mentioned American Splendor, one of the most prominent self-published comics of the era. The only reference to Pekar in either Cerebus or its paratexts is an in-text mention of his "declaiming" and "droning" in F. Stop Kennedy's autobiographical novel, printed in the late 1990s after Sim had mostly given up on advocating other self-published works (Going Home 13 5). Similarly, Sim would seem to be a far more likely target for Pekar's rant about "genre stuff" than Spiegelman or Gilbert Hernandez, but he is not mentioned. It is hard to imagine that the two authors were not aware of each other during the 1980s, given their prominence in an insular alternative comics scene. Perhaps Pekar saw Sim and his anthropomorphic aardvark protagonist as beyond saving in a way that Spiegelman and Hernandez were not, and Sim could not overcome the ideological differences between himself and Pekar even in the name of promoting

\footnotetext{
${ }^{27}$ See Beaty and Woo, The Greatest Comic Book of All Time, Ch. 7.
} 
self-publishing. However, both were conversant with Groth, with each being interviewed with The Comics Journal and having heated disagreements with them over their aesthetic theories. Pekar and Sim built on and modified Groth's core arguments: that comics should aim for the standards of autonomous literature, and that mainstream superhero comics represented a kind of perverse arrested development for both the art form and its readers.

Both of these ideas drew on discourses that already existed in the broader culture. If canonical literature held up a mode of artistic production that was autonomous and shied away from genre, then this was the closest shore for comics to swim to. And if the critics of The Comics Journal wanted to criticize mainstream comics, the weapons closest at hand were the same ones used by anti-comics crusaders who associated the medium with unhealthy and deviant behaviour. The Journal's writers sought to create a new type of comics and a new way to discuss comics, but they did not do so out of their own materials, instead drawing on the discourses that were already present in the surrounding cultural field. This is an important example of the way in which attempts to alter the cultural field, in this case by increasing both the prestige and autonomy of comics, reproduce the field's ultimate logic. This logic affected the development of comics as a medium - the works that became a part of the emerging canon of comics, and the works that survived in a difficult alternative comics market, were those that could fit the profile of autonomous art that aspired to literary qualities. Other comics of the period, such as mainstream genre work, the undergrounds, and explicitly political work, were pushed to the margins of the canon if not out of it entirely. As one of the larger and longest-lasting alternative publishers, Groth and Thompson had the ability to ensure that works which adhered to this idea were more likely to be printed and re-printed.

Under the cultural field model, there are two ways of narrating this movement: as either a 
canny use of the rules of the game or as a slavish, unconscious adherence to the very tradition that marginalized comics. However one wishes to describe it, the Journal writers' strategy for creating a limited sphere of alternative, autonomous comics by appealing to existing literary values was ultimately successful. Sim and Pekar had less success converting broad swathes of comic fandom to their ideas - Sim's falling sales and slide into irrelevance speak for themselves, and the majority of responses to Pekar's TCJ editorials were negative. The Journal's 1999 attempt at canon-building may not match up exactly to the works available in a mainstream bookstore today, but it comes much closer than Sim and Pekar's putative canons of independent and realist comics respectively. While The Comic Journal's diatribes may come off as rank snobbery in today's poptimist age, in the context its writers were operating in such positions are not only understandable but perhaps necessary - there are few people today waxing nostalgic about the comics world of 1976, and the aesthetically rigid platforms of Groth, Pekar and Sim nevertheless provided key exposure for a diverse number of alternative artists. However, because The Comics Journal, Cerebus and American Splendor drew on existing social ideas to support their program, the spectres that haunted comics for decades - comics as low art and comics as perversion - were not swept away by the likes of Maus but lingered in the shadows of alternative comics, often twisting together in strange shapes. This was a legacy that future artists would have to slowly and carefully untangle.

But despite these differences, the commonalities between Sim and Pekar reveal an underlying belief that comics should be autonomous creations that aspire to literary values. This is the ideology advocated for by The Comics Journal, and while both Sim and Pekar upheld different ideas of value and criticized Groth repeatedly, they agreed with this core principle. This was a view that became only more strident over time. In 1976, when the first issues of Cerebus, 
American Splendor and The Comics Journal were all published, Sim was still taking commercial work from larger publishers and Pekar was widely seen as part of the floundering underground comics scene. As both authors became part of an emerging canon of alternative comics, they became more strident in their beliefs in artistic autonomy and their appeals to literary authority. They did so through largely similar tactics, cultivating a canon of past and present works and involving literary figures in their stories. Both also built upon the metaphor of literary maturity as sexual maturity central to the Journal's rhetoric, with Sim in particular using it to develop an explicitly misogynist theory of artistic genius. And so, despite their significant differences, Groth, Sim and Pekar both contributed to the guiding aesthetic philosophy of early alternative comics: that the ambitions of comics should be fundamentally literary. 


\section{Chapter 2: The Groundlevel and Canonical Remixes}

The campaign for comics as literature did not take place entirely within the alternative press. As Julia Round's work on DC Comics and their Vertigo imprint has shown, superhero publishers cultivated their own version of the literary comic through specialized imprints that focused on more adult-oriented work by writers with a greater degree of creative freedom (24). As Round states, "these elements have shaped the medium by bringing the graphic novel closer to the aesthetic of the literary text" (15). DC's twin successes of Watchmen and The Dark Knight Returns, dark superhero narratives that were popular not just as limited series but as a collected bookstore product, had proven that the comic market could reward such work. The early Vertigo comics echoed this by putting obscure DC-owned characters into grim narratives that defied genre conventions (Round 16). British writers Neil Gaiman and Grant Morrison were among those who garnered prestige by authoring comics with an aesthetic (and sometimes a politics) not seen before in commercial American comics. In return, Vertigo and the discourse around it helped to develop the status of the comics writer as auteur, a historical shift from the artistoriented nature of early comics fandom (Round 21).

Gaiman and Morrison were following in the footsteps of their countryman Alan Moore. Moore first became known to American fans for his work on the series Swamp Thing, but is most famous for Watchmen, which used thinly-disguised versions of Charlton Comics characters to tell a story that critiqued superhero comics with references to authors such as Nietzsche and Shelley. In his later career, however, Moore moved away from DC after a series of disagreements and began to produce work that was even more self-consciously involved with the literary. In The League of Extraordinary Gentlemen and Lost Girls, Moore uses characters from numerous Victorian texts to both tell genre narratives and develop an idea of anarchist sexual 
liberation. These comics remix canonical characters, simultaneously channeling and undercutting the prestige associated with prose fiction. Moore's work of this period, I will argue, represents a shift away from the reverential approach to literature taken by Gaiman, Morrison, and their alternative-comics contemporaries, and towards a relationship that allows for literary play heedless of canonicity and literary ideology.

Gaiman, Moore and Morrison were part of a movement within mainstream comics known as the "British Invasion," a group of writers who worked largely for DC and later for various independent houses. ${ }^{28}$ These writers, influenced by British science fiction comics such as 2000 A. D., brought a distinctly different idea of the genre comic to America, one that involved adult themes, formal experimentation, and a wider range of genre tropes. Their work never hit the sales heights of contemporaneous superhero titles, but each maintained a cult following and received acclaim from both the comics and mainstream presses (Round 18). The space they occupied has sometimes been referred to as the "groundlevel," located between the underground and the mainstream. ${ }^{29}$ Groundlevel comics assert an aesthetic independence like alternative comics, but offer more conventional genre pleasures than the typically mimetic or surrealistic work of alternative artists. Moore in particular is a figure that has travelled between large and small publishers and whose work has been praised in The Comics Journal as well as magazines targeted at superhero fans. ${ }^{30}$

These writers' understanding of literature is different from that of their predecessors in the world of alternative comics. To Gaiman, Morrison, and Moore, literature is a form of myth,

\footnotetext{
${ }^{28}$ Other key figures include Warren Ellis, Garth Ennis, and Peter Milligan.

${ }^{29}$ See Beaty and Woo's chapter on Moore in The Greatest Comic Book of All Time.

30 The Comics Journal gave Moore prominent place as early as 1984, when they published a special issue on Swamp Thing (No. 93), and later included four of his works on their 1999 list of the greatest 100 comics ever (No. 210). Wizard listed six Moore titles in their 2009 list of the top 100 graphic novels (No. 212), five within the top 16.
} 
one that is valued precisely for its ability to create images, narratives and phrases that resonate throughout history. Authors are vessels for these ideas, but ultimately less important than the symbols that the text leaves in broader culture. These three authors use genre tropes to depict these archetypes as being literally magical, suggesting that the work of Shakespeare or Bram Stoker are the origin point for the fantastical devices of Sandman or The League of Extraordinary Gentlemen respectively. Gaiman and Morrison begin to introduce these ideas, but are not fully able to part with the concept of the canonical author. Moore's later comics Promethea, The League of Extraordinary Gentlemen and Lost Girls present a more radical vision in which literary characters and plots are divorced from their origin point and are free objects of textual play.

It is clear, then, that a history of alternative comics must also give at least some consideration to the groundlevel, even if that work cannot be comfortably classified as alternative in itself. In particular, Moore and his contemporaries are highly relevant to the changing relationship between comics, the literary and cultural prestige. Moore's writing was often used as a key piece of evidence in the argument for comics-as-literature, and his later work would initially appear to be an obvious instantiation of the concept of the literary comic. However, these literary remixes take a more critical approach to the canonical than the earlier works of Gaiman and Morrison, ultimately challenging the cultural hierarchies that separate comics and prose fiction. Moore seeks not to emphasize the distinction between literature and commercial comics but rather their continuities, and in doing so turns the psycho-sexual development narratives of his predecessors on their head. Ultimately, Moore presents a free and non-hierarchical flow of texts and characters as a way of envisioning new, utopian sexual and political arrangements. 


\section{Canonical Genius in The Sandman}

Perhaps the most celebrated single issue ever published by Vertigo was the nineteenth issue of The Sandman, "A Midsummer Night's Dream." This issue shifts the setting of the series from the contemporary United States to Elizabethan England, and tells the story of William Shakespeare putting on the titular play in front of an audience of fairies and spirits, including the real Robin Goodfellow. The story was widely acclaimed and won a World Fantasy Award for Best Short Story. It was the first comic to win the award and, in a much-repeated bit of lore about the discrimination comics face, the rules were changed immediately afterwards to prevent such a thing from happening again (Round 26). While largely ancillary to the series' main storyline, “A Midsummer Night's Dream” became so associated with The Sandman that Gaiman returned to Shakespeare for the series' seventy-fifth and final issue. In this story, Gaiman uses Shakespeare's writing of The Tempest to express his own feelings on the ending of his series.

Why did these stories become the chief evidence for The Sandman as literature, and by extension the possibility of a DC Comic to be literature? Gaiman's adroit writing certainly has something to do with it, but it was no more in evidence for these issues than for many other issues of the series. What is unique to Gaiman's Shakespeare stories is a textual argument that presents The Sandman as being an artistic creation in some ways comparable to Shakespeare's plays, the most canonized works of English literature. To make this argument, Gaiman necessarily reaffirms Shakespeare and the literary in general as an instance of transparent and autonomous genius.

"A Midsummer Night's Dream"31 imagines Shakespeare's faery comedy as history

\footnotetext{
${ }^{31}$ Quotation marks will be used for the Sandman stories, and italics for the Shakespeare plays they are named after.
} 
watched by the supernatural characters featured in the play. The plot also presents Dream, the divine protagonist of The Sandman, as Shakespeare's patron who has commissioned the bard to write a play as a gift for the fairy court. In return, Dream grants Shakespeare his lyrical genius and artistic immortality: "Through him [the great stories] will live for an age of man, and his words will echo down through time" (Gaiman, "A Midsummer Night's Dream" 20). In this way, Gaiman's creation is not just associated with the canonical genius of Shakespeare but actually responsible for it. The comic goes on to directly mimic the conclusion of A Midsummer Night's Dream, with Robin Goodfellow giving his famous monologue declaiming the events of the story as meaningless dreams. This is not to say that readers came away from the text literally thinking of Gaiman as superior or equal to Shakespeare, or that this was Gaiman's intention. Rather, the inversion of the source-inspiration relationship between Shakespeare's play and Gaiman's comic as well as the identical endings suggests that the two texts are both part of a single artistic lineage.

"The Tempest" furthers this identification between Gaiman and Shakespeare. The placement of the issue at the very end of the series suggests a parallel between Gaiman's act of writing his final Sandman issue and Shakespeare's act of writing his final play. Gaiman's comic contains multiple page-length illustrations of the events of the play, captioned with direct quotations in a font that mimics that of an Elizabethan folio, resulting in a text that not just thematically but also physically resembles the canonical drama. Shakespeare describes his final play as a way to lay down "the burden of words," a description that has obvious resonance with Gaiman's situation ("The Tempest 38). Prospero then emerges as both a parallel for Gaiman and a fantasy figure for Dream, a magician who is able to give up his magic powers - or, in a comparison the issue hammers home, a writer who is able to give up the pen. There's an implicit 
comparison between the role of the comics writer and the playwright, both of whom provide a verbal framework for an act of visual creation by others (the illustrator and actors respectively). Shakespeare is left to compose the final monologue without Dream's gift, just as Prospero is left with "all my charms o'erthrown" - and, perhaps, just as Gaiman is leaving images behind ("The Tempest" 38). Following this story, Gaiman would focus on prose writing without the "charms" of illustration, with only occasional returns to the comics form.

For this device to work, Shakespeare's plays must be invested with their own nearmagical power. Gaiman does work to demystify the man himself in his comics, highlighting that Shakespeare's creative decisions were often based off practical concerns or simple laziness. The in-text Shakespeare says of his own writing "I see no art, just artifice" (Gaiman, "The Tempest" 22). Gaiman also depicts Shakespeare as being distant and cold towards his family, seeing them as only material for stories ("A Midsummer Night's Dream" 14). However, Shakespeare's own work has all the transformative and eternal qualities that the literary canon commonly attributes to it. Shakespeare's estimation of his own work is shown to be overly humble, in a scene where he casually coins the traditional Guy Fawkes rhyme in a conversation with Ben Johnson and dismisses it as doggerel ("The Tempest" 16). "The Tempest" continually compares Prospero’s magic to Shakespeare's words, suggesting the power of the Bard's poetry as supernatural. The talent given to him is described by Dream as "the power to give men dreams that would live on after you were gone" ("The Tempest" 32). And his portrayal of the faery world is enough to earn approval of even Oberon and Titania themselves. Gaiman's Shakespeare possesses the ability to transmute the physical material of the world around him into eternal art, as with the death of his son Hamnet, who is depicted in "A Midsummer Night's Dream" as a neglected 
child. $^{32}$ Gaiman thus develops a separation between the playwright, a decent man with mortal concerns, and the mythic power of his plays. This portrayal of Shakespearean verse as mythically great was one that cultural authorities and guardians, from awards committees to librarians, could happily sign off on.

Gaiman's focus on the work and its ability to affect future generations marks a shift from Groth's idea of art as an expression of the artist's passion and moral character. The Sandman was known for its use of imagery and characters with cultural resonance ranging from Norse mythology (the three Fates) to contemporary toys (Ken and Barbie in “The Dollhouse.”) Shakespeare's value to Gaiman is precisely as a progenitor for so many such iconic characters and images, which have as much power to affect the supernatural world in which the story is set as medieval gods. ${ }^{33}$ It is not that Shakespeare's artistry is unimportant to Gaiman, but rather that his most important quality is that he "sees the world as a story," as Hamnet notes ("The Tempest" 14). Being fluent in mythic imagery is more important to Gaiman than Pekar or Groth's idea of art as truth-telling. Shakespeare the man, as depicted by Gaiman, is usually concerned with prosaic matters, but the iconic significance of his work transcends his own mortal existence. This is not a particularly novel or progressive view - indeed, in emphasizing the importance of work over author Gaiman comes closer to the 1950s New Critics than even Groth. But this view marks a significant difference between The Sandman and its more firmly alternative brethren.

There are hints here of a broader connection between comics and mythology. Much has been written about the parallels between superheroes and classical gods. For instance, in The Mythology of the Superhero Andrew R. Bahlman interprets the superhero through structuralist

\footnotetext{
32 The Sandman No. 19. Gaiman heavy-handedly calls attention to this process by having Hamnet remark that if he died his father would make a play of it.

${ }^{33}$ Gaiman would take this approach even further in his print fiction, particularly American Gods.
} 
ideas of myths. Bahlman suggests that there are clear parallels between superheroes and mythic characters in both the narrative content and the way in which such stories draw on a common repository of tropes (4-5). Ben Saunders makes a more direct comparison in Do the Gods Wear Capes, suggesting that superheroes not only draw on classical mythology but fill a similar social role. This comparison is certainly present in The Sandman, particularly its early issues, but Gaiman imagines a much wider range of cultural icons who are all conversant with and equivalent to divine myth. Shakespeare, or more precisely the iconic images generated by his work, are thus no less mythical than Samson or Superman. Comics, a visual medium that is less directly representational than film or photography, is a way for Gaiman to trace the lineage between these iconic characters.

The Sandman represents dreams and narratives as having genuine power to shape the world, an argument Gaiman has in common with Moore and Morrison. Ascribing narrative with the power to shape the real world can be a postmodern tactic, but it can also be a canonizing one, and The Sandman takes the latter tack. Gaiman identifies his own writerly ambitions and career, as well as the powers of his central character, with Shakespeare. In doing so he necessarily portrays Shakespeare as not an artist given prime placing in a canon determined by historical forces but as one possessed of literally supernatural gifts to create transcendent art. Gaiman's work is certainly more sophisticated than the mid-century Classics Illustrated, but they both assume that the works of the English literary canon represent a transcendent greatness, and that the means of creating artistically worthwhile comics will involve a version of this greatness. The gatekeepers of prose fiction such as the World Fantasy Award operated under a similar assumption by making "A Midsummer Night's Dream" central to the elevation of The Sandman from comics to literature. 


\section{Romantic Rebellion in The Invisibles}

Grant Morrison also came to prominence in American comics by reworking long-defunct DC characters - in this case the Doom Patrol - under the Vertigo imprint. But whereas Gaiman attained popularity through a work with gothic or fantastic style and liberal politics, Morrison offered a more irreverent and self-conscious style with that loudly boasted of political radicalism. This is no more evident than in The Invisibles, a series about a mystical society rebelling against a corrupt world. The series acted as a kind of alternative superhero narrative, with the protagonists being a cell of five mystically-inclined anarchists combating various government conspiracies. The series explored anarchism and the occult, obsessions that Morrison shared with his countryman and rival Alan Moore. ${ }^{34}$

Morrison is a proponent of the comics-as-mythology idea, arguing for it in his prose nonfiction book Supergods. He suggests that superheroes, like the gods of classical myth, are Platonic embodiments of human traits (Morrison, Supergods 9). Morrison retells the creation of iconic superheroes such as Superman and Batman in a mock-epic style, suggesting that these icons and their origins have a kind of divine symbolic resonance, as when he described the creation of DC's iconic duo as a "grand separation of light from dark, is from isn't, this from that, up from down, in a kabbalistic, Hermetic symmetry" (Morrison, Supergods 35). His creation of The Invisibles could be seen as an attempt to accomplish a similar feat, creating a set of superheroes that could embody anarchy and resistance. Morrison's tendency towards mysticism lead to strangely literal interpretations of comics writing as a divine act of creation: in one infamous incident, Morrison asked readers to masturbate at a particular time in a ritual to help save the series from cancellation. Morrison here lays claim to the reputation of comics

\footnotetext{
${ }^{34}$ See Phil Sandifer's ongoing The Last War in Albion for an exhaustive treatment of Moore and Morrison's relationship and intertwined careers.
} 
readers as being isolated sexual deviants and comics themselves as being a form of masturbatory maladjustment. By associating the fate of his series with magical rituals, Morrison also affirms that comics writing is essentially magic in nature, and tied to sexuality.

Morrison also drafted members of the literary canon into his radical version of the superhero team. In "Arcadia," a four-issue arc published early in the series' run, Morrison sends his protagonists back in time to meet the Marquis de Sade, who is revealed to be an agent of the Invisibles. The storyline also contains several otherwise unrelated scenes of dialogue between Lord Byron and Percy Shelley discussing art and politics, and it is suggested that they were also members of a historical Invisibles cell. The overall effect is to recast literary authors into a tradition of anarchist artistic rebellion that would in turn include the writing of Morrison.

The Invisibles most explicitly suggests this tradition through the discussions of Shelley and Byron. In these dialogues Shelley generally presents an idealistic thesis and Byron responds with cynicism that nevertheless suggests a faith in political radicalism. In the opening scene of the arc, Shelley advocates a utopian mode of poetry: "As poets, it is our duty to turn our face up from the mire, to look up and tell our fellow men that we have seen a better world than this" (Morrison, "Arcadia Part 1" 5). Byron counters by bringing up the failure of past utopian schemes by Coleridge and Southey (Morrison, "Arcadia Part 1" 5). Morrison depicts the two poets as eloquent but marginal; Byron describes the pair as "atheists, radicals, perverts, a pale vegetarian and a club-footed sodomite" ("Arcadia Part 1" 5 p. 6 ), suggesting that despite their canonical status they are not all that different in status than the rag-tag group of anarcho-punks who are the protagonists of Morrison's series. Nevertheless, Byron goes on to argue that their poetry will outlast their meagre human existence and have a much greater effect, ultimately reaffirming Shelley's concepts of poetry as politically powerful. This also suggests the same 
split between the mortal artist and the transcendentally powerful art that is present in Gaiman's version of Shakespeare.

Through Byron and Shelley Morrison establishes an uncertain ethos for his most explicitly political series. In venues such as his autobiography Supergods, Morrison has depicted his career as defined by the tension of his own artistic and political beliefs and the commercial nature of the medium. Byron and Shelley's debates serve multiple purposes in attempting to resolve these tensions and create an autonomous space within the world of commercial comics. By associating himself with these two canonical authors, Morrison establishes his ambition as serious and literary, and by highlighting their political radicalism, Morrison suggests that he follows them in a tradition of not just literature but also anarchist literary world-making. Byron and Shelley's in-text discussions about the possibility of utopian art suggests that The Invisibles follows this tradition, imagining in its Invisible cells a culture free of gender roles and hierarchies and suffused by mysticism. The goal of the group is a similar utopianism, to "pull off a trick that'll result in everyone getting exactly the kind of world they want. Even the enemy," as expressed by leader King Mob in this story arc ("Arcadia Part 4" 7). At the same time, Byron's cynicism suggests that this radical optimism is tempered by reality, as reflected in stories like "Best Men Fall" that call into question the morality of the Invisibles.

Morrison also includes Mary Shelley as a character. She does not take part in the philosophical dialogues of her male peers, but does comment that poets "steal the power of creation from the gods" and "remake the world with the words and images of their dreams" (Morrison, "Arcadia Part 3" 21). However, she does not identify herself as a poet, but as "the rest of us" who "must live in it" (Morrison, "Arcadia Part 3" 21). Much of Percy Shelley's actions in this story arc are motivated by his anguish at the death of his infant son, an anguish 
which he transforms into art. However, Mary does not seem to feel similar angst, instead suggesting that Percy needs to move on (Morrison, "Arcadia Part 3" 21). This ignores her own famous work of grief-stricken art, Frankenstein, and indeed Morrison references her literary career only in the first scene she appears in. This absence suggests that for Morrison there is something particularly masculine about his idea of literary world-making. Indeed, while the majority of the five-person Invisibles cell the series follows are female, the two male characters King Mob and Jack Straw - receive by far the most focus. As much as Morison championed the fluidity of gender roles through the characters of Lord Fanny and Boy, the role of the author is still coded as masculine.

The Marquis de Sade does not comfortably fit into the ruggedly masculine idea of authorship valued by Sim and Pekar, nor the vision of the rebel author put forward in Morrison's depiction of Byron and Shelley. His plays are more infamous than canonical, associated more with the sexual subculture that includes his name than literary classrooms. Nevertheless, Sade plays an important role in both the plot of "Arcadia" and Morrison's concept of authorship. His transport to the present is the impetus of the storyline's plot. Sade is depicted as overweight and cowardly, but still subversive enough to warrant membership in the Invisibles. Morrison goes on to explore Sade's work as containing the potential for both social violence and revolution.

The potential for Sade's work to be used as a tool of violence by the powerful against the oppressed is first evident in his role as a judge in Revolutionary France, which Morrison portrays in a very negative light. ${ }^{35}$ Sade himself is disgusted at the conditions in which the citizens live, and pales before actual violence (Morrison, "Arcadia Part 2" 13, 17). "Arcadia Part 3," subtitled "100 Days of Sodom," mostly chronicles a version of the infamous Sade novel acted out by a

\footnotetext{
35 "Arcadia Part 2" begins with a shot of the guillotine, which is followed by an extended conversation with a cab driver who describes the horrors and intellectual poverty of the Revolution to the Invisibles.
} 
cabal of shadowy elites in a dream state while the author himself watches. Morrison emphasizes the political elements of Sade's pornographic fantasy, in which the four torturers all hold positions of societal power, while their victims are the poor and helpless. Discomfited by the reality of his work, Sade criticizes it as reflective of broader social hierarchies: "Authority and submission. There's civilization for you. Man is a mad animal" (Morrison, "Arcadia Part 3" 14). The Invisibles suggests that the dominant/submissive dynamic has the potential for hierarchical violence which would appall Sade himself. Regressive literature here is not harmless venting of fantasies, but a vital threat against real people.

Nonetheless, Morrison leaves open the possibility for a revolutionary Sade. The author's criticisms of violent and hierarchical implementation of his ideas suggests that Morrison reads Sade's work as not a blueprint for social violence but as a critique of it. When brought forward in time to witness consensual BDSM in modern-day San Francisco, Sade is delighted: "I sought an unmarked grave [...] Yet look! I have become immortal!" (Morrison, "Arcadia Part 3" 5). Ultimately, the Invisibles call upon Sade to design "a blueprint for the future of humanity," inspired by both his social criticism and the example of polyphonic sexuality which Morrison ascribes to San Francisco (Morrison, "Arcadia Part 4" 7). A progressive mode of Sadeian literature - say, a violent anarchist comic book series - is necessary for the creation of a new world. This, again, treats literature as a force with literally magical power.

"Arcadia" presents art as powerful but unstable, containing the possibility of both Byron's cynicism and Shelley's optimism. It follows The Sandman in highlighting the ways in which literature's iconic and popular qualities can give it a significance beyond the mortal and flawed motives of the author. Here, Sade is an irresponsible aesthete and Shelley a poor husband overwhelmed with grief, but their work has a larger supernatural significance. What Morrison 
adds is the political significance of literary icons, who appear here not as guardians of a conservative canon but as fodder for revolution. Morrison is keen to highlight the ways in which poetic world-making can go wrong through his depiction of Revolutionary France and the elite use of 120 Days of Sodom. But it is also, in the end, only art - and specifically criminalized, perverse art - that has the potential to save the world and create the utopia that the Invisibles (and The Invisibles) champion. Like Gaiman, Morrison depicts literary writers as both figuratively and literally magical, capable of transcending their own mortality and the worldly affairs in which they are enmeshed. By aligning these authors with his own fictitious superheroes, Morrison places himself into a tradition of radical literary authors.

Ultimately, "Arcadia" was not nearly as critically or commercially successful as "A Midsummer Night's Dream." Readership dropped off heavily from the first four issues, and the series was in danger of cancellation. Morrison would go on to express regret for the placement of the arc, although fans would repeatedly claim it as their favourite. "Arcadia" was, however, significant in the cultural work it did. Like Gaiman's Shakespeare stories, it advocated for comics as literary by explicitly relating its contents to prose literature. In order to do this, literature has to remain a stable and familiar referent, consisting of familiar authors enmeshed in their historical surroundings who possessing transcendent power. Morrison does begin to move away from familiar literary symbols by incorporating the pornographic writer Sade into his vision, but it is a limited step. While Gaiman and Morrison seek to separate work from the author, arguing that it is only the former that has mythic resonances, the author nonetheless remains a vital figure in their work, able to wrench the entire narrative away from its ostensible protagonists. The contradiction between the urge to biography and the urge to a more mythical view of literature is one that "Arcadia" does not fully resolve. Perhaps it is not surprising, then, 
that Morrison's attempt to marry this conventional idea of the literary to the radical politics of The Invisibles was ultimately unsuccessful.

\section{Metafictional Magic in Promethea}

In 1999, Wildstorm (itself an imprint of Image Comics) ${ }^{36}$ established a sub-imprint entitled America's Best Comics, after a 1940s superhero publisher. The imprint consisted of a series of interlinked titles created by Alan Moore, the British writer most famous for penning Watchmen a decade earlier. After spending most of the preceding decade on the historical graphic novel From Hell, Moore used the ABC imprint to indulge his interest in the history of genre fiction, from the pulp heroes of Tom Strong and Top 10 to the Victorian weird fiction of The League of Extraordinary Gentlemen. All of these titles reflected a broader ethos that emerged from Moore's interests in postmodern metafiction and mysticism. At the beginning of the decade he had declared himself a "practicing magician." Promethea is the text in which Moore most explicitly laid out his new worldview, one that maintains the primacy of fiction as a means of world-making while eroding the power of the author and hierarchy of genres that Gaiman and Morrison left intact. As Matthew J. A. Green argues, "the transformations of Sophie and the other Prometheas offer a dramatization of Moore's own understanding of the processes and potentials of his art" (739).

The plot of the series concerns a college student named Sophie Bangs researching a character named Promethea who has appeared across history in various genres, including an Elizabethan romance, a Little Nemo-esque comic strip, a pulp novel series, and of course a series of superhero comics. Promethea turns out to be a transcendent spirit that inhabits Sophie,

\footnotetext{
${ }^{36}$ Wildstorm was later sold to $D C$, and $A B C$ along with it, meaning that these comics straddle the independent/mainstream divide both in form and in publication history.
} 
turning her into a mystical superhero (or "science hero," in the terminology of Moore's retrofuturistic setting). After Sophie encounters past incarnations of Promethea in the afterlife, she ultimately turns out to be the key to "ending the world" by eliminating the barriers between the living, dead, and fictional. However, Moore frequently strays from this plot in order to express his views on magic and the role of fiction. Moore himself described the text as having "a bit of a Trojan horse element to it," smuggling mystical and metafictional concepts into what initially appears to be a superhero serial (Khoury 187).

Like Gaiman and Morrison, Moore invests fiction with a magical ability to change the world. Fiction and reality are depicted as two separate but interlinked planes of existence. Promethea's hosts summon her through acts of creation, such as Sophie writing a poem (Moore, The Radiant Heavenly City 22). Humans are described as "amphibious" creatures that move between the two planes (Moore, Weapon for Liberty 13). Sophie skeptically summarizes this belief by saying that "everything in our culture, including language and art, arose from the drugged-out insights of the first magicians" (Moore, The Magic Theater 10). Art, then, is an extension of the practice of magic and has magical properties. This belief in literary creation as magic and the fluidity between reality and fantasy is contrasted with scientific rationality and domination, represented by the Tarot symbol of The Sword and by the agents of the government who feel threatened by Promethea (Moore, A Warrior Princess of Hy Brasil 19). Using his characters as mouthpieces, Moore argues that ultimately this materialism is a dead end that resulted in the horrors of the twentieth century (Rocks and Hard Places 20). Ultimately, then, the argument Promethea makes about fiction and magic are also arguments about the nature of humanity and its history.

Moore's literary philosophy is not, however, simply a more dramatic version of Gaiman 
and Morrison. Those two contemporaries attributed the magical power of literary world-making chiefly to canonical authors. These figures are absent from Promethea - instead, it argues that the most crucial modern fictions circulate through items of low culture. All of the fictitious texts in which Sophie finds Promethea are obscure and mostly come from low-cultural forms such as comics and the pulp novel. The poetry with which Sophie summons Promethea is never published, let alone canonized. The lowbrow, the obscure and the personal are the means by which Moore presents modern myths such as Promethea circulating - as one of Sophie's guides remarks "gods used to be in tapestries, now they're in strips" (Mercury Rising 5). Moore here baldly expresses his allegiance to the concept of comics as mythology. Gaiman and Morrison could not be accused of looking down on low cultural forms and genres, having spent their entire careers working in them, but they expressed their ideas of literary genius and creation through canonical figures - a move that Moore resists in Promethea.

The name itself is a reference to Helene Cixous's The Book of Promethea, perhaps the most unlikely text ever to be adapted into a comic book series. The Book of Promethea is a quasi-novel in which the narrator expresses her love for an abstract and possibly fictitious entity known as Promethea. Its form is elliptical, always promising to get to the "real story" after the latest digression or poetic ode to the titular lover. The Book of Promethea is an instantiation of Cixous's theory of ecrituire feminine, a form of writing against masculine power that is feminine but can sometimes be practiced by men. In her theoretical writing, Cixous identifies reason with phallocentrism and masculine domination, an idea Moore echoes in his depiction of The Sword, and argues that ecrituire feminine is writing that abandons patriarchal reason and the strictures of plot in favour of a more fluid, affective mode of narrative ("The Laugh of the Medusa" 879). Writing is a way for women to "return to the body which has been confiscated from them" 
provided that it occurs "in other areas than those subordinated to philosophico-theoretical domination" (Cixous, "The Laugh of the Medusa" 880 \& 883). In other words, Cixous stages an opposition between masculine writing that stems from Enlightenment reason and ecrituire feminine that recovers the role of the body and the female voice, of which The Book of Promethea acted as an example.

Moore's Promethea is a translation of these ideas into the plot-driven medium of superhero comics. In Promethea, women's writing serves as a way to literally commune with female creators of the past who have been obscured by patriarchal history. Sophie's quest begins as an academic inquiry but quickly becomes a mystical one, marking the rejection of masculine reason in favour of experiential knowledge. Sophie's friend Stacia becomes lovers with one of the spectres of past Prometheas, acting as a literal translation of the metatextual lesbianism of Cixous's Book of Promethea. However, Moore's series cannot be said to be an act of ecrituire feminine: like a conventional comic-book narrative, it is driven by a mechanistic progression of the plot and the supernatural powers within are carefully defined by their effect on the real world. Like Cixous' novel, it is digressive, but there is no obvious autobiographical or self-reflexive element, and the digressions take the form of lectures on the occult instead of emotional expression. As Chris Eklund has written, rather than doing magic Promethea settles on explaining it (11). Rather, ecrituire feminine operates in Promethea as a mystical force that can be gestured towards and observed but never quite captures. The series sets out the schema for a literary mission that Moore would never quite be able to realize, although Eklund argues that Lost Girls is at least a valiant attempt. However, Annalisa di Liddio has argued that Moore's formal experiments do convey the kind of transcendence that the comic lacked as a script: "images freely come one alongside the other and are almost always spread in a continuum" (89). 
For instance, a page in which Promethea and her companion Barbara shift from crude stick figures through the phases of creating a comics panel suggests a parallel between the artistic process and the emergence of divinity (di Liddo 93). The artistic plane, then, allows Moore to come closer to his ideals than the verbal one.

Even beyond the explicit debt to Cixous, Promethea also presents authorship as much more feminine than past attempts to introduce literature to comics. The various characters who inhabit Promethea are all women, including a man who comes to identify as a trans woman through the experience, and two of the texts that give Promethea life were authored by women. Promethea herself acts as an ersatz history of women in comics, tracking the transition from imaginative early newspaper strip to formulaic pulp narratives and the marginalization of femaleled books in a male-dominated medium. ${ }^{37}$ This celebration of female writing comes, of course, in a comic written and drawn by men operating from a prestigious position in a patriarchal comics industry. But while Promethea is not an unqualified victory for feminist aesthetics, it does suggest a broader conception of authorship than other literary comics.

The emphasis on female authorship, and particularly Cixous's ecrituire feminine, reflects the centrality of sexuality and gender in Moore's conception of both authorship and magic. Green argues that Moore associates the female body with "a power that is at once primordial and horrific" and has a "messianic potential" (742). It is a sexual encounter between Promethea and the magician Jack Faust that provides the first of Prometheas' exegeses on magic and reality. Faust explains that magic involves "becoming hermaphrodite," transitioning through both male and female roles (Moore, Sex, Stars and Serpents 9). These roles are, in turn, established through stories: Faust describes mythic quests as a form of masculine conquest, while Sophie

\footnotetext{
${ }^{37}$ Moore highlights this history in "The Promethea Puzzle" in Promethea No. 1 (p. 31-32), a fictitious prose piece on the character that discusses her difficulty reaching a male readership.
} 
learns on her quest through the sphere in the story The Wine of Her Fornications that the female form of God is composed of various images of woman ranging from Madonna to whore. In the series' finale, the apocalyptic shift of spiritual being that Promethea ushers in is marked by an acceptance of sexual transgression (Green 740). Promethea expresses the interlocking roles gender, magic and fiction play in Moore's corpus.

Other than the Cixous book, Promethea is scant on explicit references to real-life authors and texts. Rather, it uses fictitious texts, which include both the magical progenitors of earlier Prometheas as well as satirical works such as the "Weeping Gorilla" character that depict the dead end of contemporary irony (di Liddo 99). While there are real-world parallels to many of these works, they most obviously function as generic examples that can be used to create a framework of anarchistic meta-fictional play that Moore would use in contemporary and future projects such as The League of Extraordinary Gentlemen and Lost Girls. This framework would uphold the faith in creation expressed by Gaiman and Morrison, as well as their conception of literature as icon and myth, but actively struggle against hierarchies of gender and genre.

Promethea presents a literalization of the common comparison between superhero narratives and mythology, suggesting that popular fiction makes up a contemporary mythology whose symbols can be used for progressive world-making (di Liddo 89). In other works, Moore would deal more directly with the texts he saw as making up this mythology.

\section{Perverse Victoriana in The League of Extraordinary Gentlemen}

Launched alongside Promethea in 1999 was The League of Extraordinary Gentlemen, a genre mash-up that did not share the setting of other America's Best Comics titles but did share much of their philosophy. This series would prove to be the most commercially successful and 
longest lasting of Moore's ABC titles, receiving a (disavowed) film adaptation and ultimately outlasting the $\mathrm{ABC}$ imprint to continue at Top Shelf Comics. In League, Moore assembles a group of characters plucked from Victorian popular literature, with H. Rider Haggard's Alan Quatermain and Bram Stoker's Mina Harker (now referred to by her maiden name of Mina Murray) serving as protagonists and constants throughout the various permutations of the team, which span over a century of popular fiction. Later installments in the series become less focused on an adventure narrative and more invested in constructing a narrative edifice in which all fiction can exist simultaneously. The comics overflow with references to various texts, with an "unofficial guide" by Jess Nevins widely circulated among fans that has become long enough to warrant three stand-alone books. In short, it is perhaps the most thorough plundering of literature for material in comics history.

The objects of reference, however, are again different from the high literature used by Sim, Pekar, Gaiman and Morrison. While Moore mixes texts from a variety of genres and languages, the ones with pride of place are those from Victorian authors of adventure novels and “weird fiction.” Haggard, Stoker, H. G. Wells, Robert Louis Stevenson and Jules Verne provide the members of the initial team, who come up against villains devised by Arthur Conan Doyle and Sax Rohmer. These writers have a certain amount of prestige due to their long-lasting fame and place in the canon of science fiction and fantasy (to the extent this genre can be said to have a canon), but they are certainly no Shakespeare. The conspicuous absence of Frankenstein, likely the most canonized of the early science fiction novels, suggests that it is not prestige that Moore is after. Rather, Moore suggests an alternate vision of literary history, one in which popular narratives of the fantastic are central. This again points to an iconic conception of literature, one in which the most vital texts to address are not the ones that best embody writerly 
skill but the ones which create characters and settings that resonate in the popular imagination.

This is an universe which has room for literary fiction, but also has room for comic books.

Through League, Moore opens up a space of literary play that disregards the hierarchies of genre.

The presentation of The League of Extraordinary Gentlemen, particularly in its original serialized issues, does much to suggest a continuity between Victorian popular literature and contemporary comics. The issues of the first volume contained extensive paratexts, including fake advertisements, prose fiction, and an in-character letters column. The advertisements, designed to mimic a nineteenth-century periodical, include various questionable products and in one issue even a sex toy disguised as a "vaginal syringe" (Moore, Some Deep, Organizing Power 31). These advertisements recall the notorious promotional material from classic superhero

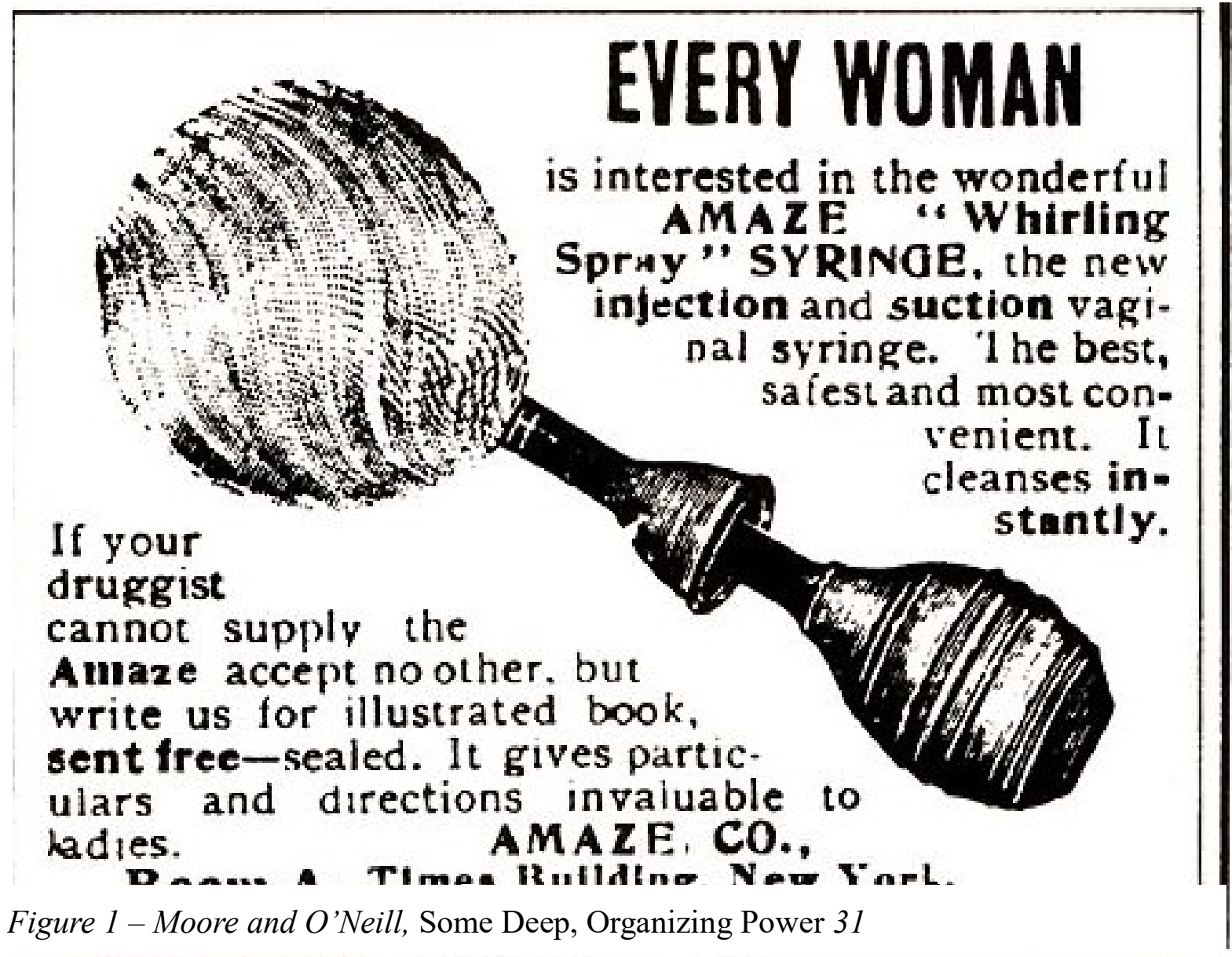


comics, which shilled for sea monkeys, muscle-enhancing cream and pyramid schemes. It also suggests that the Victorian characters, far from existing in an autonomous space of high culture, were in fact deeply implicated in the most crass and commercial ventures of their day. But from the beginning, League highlights precisely the unprestiguous, nonautonomous nature of Victorian literature, including the dubious periodicals in which they circulated. Moore's author credit is in one issue captioned "Writing for Ruffians," suggesting the unprestigious audience of these texts and his own lack of interest in cultural respect (Gods of Annihilation 2). This presentation serves to remove whatever literary residue these texts may have accumulated over the years, restoring the context of societal disdain and shameless commercialization. It also serves to liken the history of literature to that of comics, suggesting that the two forms have a continuity not because comics have the potential to be literary, but because literature has the potential to be comic-like: mercenary, dubious, but undeniably fascinating.

Moore's presentation of his Victorian heroes is often drawn from interpretation and paratext as much as the texts themselves. For instance, Mina Harker plays a secondary role in Bram Stoker's novel, but feminist criticism has accentuated the unusual amount of agency Stoker gives Mina and the ways in which it reflects Victorian anxieties about gender roles. ${ }^{38}$ Moore builds off this interpretation to create a Mina who, rather than simply aiding the male monsterslayers in their research, abandons her husband and confronts dangerous things directly and in heedless defiance of Victorian gender norms. The fact that the new Mina bears a different last name seems like a clear marker of her difference from the Stoker's version of the character, one that fits Moore's desire for a strong female hero (di Liddo 109). Similarly, League’s Captain Nemo is an explicitly anti-colonial character, an Indian in constant conflict with the British

\footnotetext{
${ }^{38}$ Ex. Charles E. Prescott \& Grace A. Giorgio, "Vampiric Affinities," Victorian Literature 33.2 (2005) pp. 487-515.
} 
empire. While this interpretation of the character does have basis in Jules Verne's writing, this basis is not in 20, 000 Leagues Under the Sea but in the lesser-known The Mysterious Island, and even that text is rooted more in anti-Englishness than anti-colonialism. Mina and Nemo both show a level of reinterpretation on Moore's part to fit the anarchist politics of his work.

In the later volumes of League, Moore goes on to highlight the sexual undercurrents of these characters. Mina and Alan Quatermain become lovers, revealing their bodies as shaped and scarred by their various adventures: Mina bears a neck covered in fang marks, while Quatermain's body is visibly old and worn down (Moore, All Creatures Great and Small 20). The linkage between their monstrous bodies and the events of Dracula and King Solomon's Mines suggests that the sexual nature of these characters was always implicit in the texts Moore draws on. The sex scene is explicit and lengthy, skirting the boundaries of pornography (that most stigmatized of genres) in a way that prefigures Lost Girls. ${ }^{39}$ The revelation of Mina's "hideousness" in the aftermath, the red marks of her wound standing in contrast with the dark blue shade of the rest of the panel, suggests that sex has become a way of revealing and reconciling inner monstrosity. This proves to be only the beginning of sexual exploration for both characters and author. The Black Dossier, a graphic novel that served as a sequel to the two serialized League adventures, includes among its many textual imitations an openly pornographic "lost chapter" of eighteenth-century erotic novel Fanny Hill. Fanny is also revealed to have been a member of an earlier incarnation of the League, suggesting pornography as both a vital part of literary imagination and a fellow traveler alongside the genres of science fiction and fantasy. The free-wheeling sexuality of the chapter arouses Mina and causes her to seek out Alan, demonstrating the potential of texts to enhance sexual relationships. In the

\footnotetext{
${ }^{39}$ Although, given that portions of Lost Girls were published in 1993, perhaps it would be more accurate to describe this and subsequent sex scenes as a continuation of that project in a more broadly-read text.
} 
Century graphic novels, Mina and Alan revealed to be in a three-way relationship with the gender-fluid Orlando, a creation not of Victorian pulp but of literary modernist and feminist Virginia Woolf. Moore here plays on the association of comics with sexual deviance and perversion, suggesting that this too is continuous with literature. By portraying literary characters as perverse and deviant themselves, and suggesting that this perversion was latent in Victorian fiction, Moore again suggests continuity between literature and comics not in the highcultural associations of the former but in the low-cultural associations of the latter. The positive portrayal of this sex contributes to the polyamorous utopianism that Moore develops throughout this period of his work, culminating in Lost Girls.

However, not all of the sex in The League of Extraordinary Gentlemen is so utopian. Moore is known and criticized for the frequent use of rape in his plots, but the omnipresence of sexual assault in what might otherwise seem a light-hearted crossover project is striking. ${ }^{40}$ The first issue of the first volume sees Mina Murray facing numerous sexual threats, from an attempted gang assault by men in Cairo to an encounter with the rapacious Mr. Hyde (Moore, Empire Dreams 9 and 24). Wells' invisible man is depicted as a sexual predator, first appearing using his powers to peek at a girls' school and later attempting to molest Mina as he betrays the League. He is, in turn, violently raped by the monstrous Hyde. In The Black Mossier, Moore portrays "Jimmy Bond" as an imperialist, somewhat dim-witted rapist. The first volume of Century largely concerns the attempts of Janni Dakkar, Captain Nemo's daughter, to survive as a sex worker in turn-of-the-century Britain, culminating in her taking up her father's submarine to take revenge on the men who abused her and her peers. For as much joy as the women of

\footnotetext{
${ }^{40}$ For example, Moore was questioned about his use of rape in a 2016 Vulture interview (http://www.vulture.com/2016/09/alan-moore-jerusalem-comics-writer.html), with both interviewer and Moore treating this complaint as familiar.
} 
League find in consensual sex, they are under constant threat from the men around them.

There's undoubtedly a prurient and possibly even exploitative aspect to these plots, drawing as they do on the titillating role of sexual assault in Victorian thrillers such as Dracula. But perhaps more important to Moore's vision is sexuality as a site of struggle between the forces of liberation and control. Sex is not liberatory in itself - The Black Dossier includes an example of fascist pornography created by the Big Brother government - but is rather a practice through which patriarchal domination can be both reinforced and resisted. This is why survivors of sexual assault, most obviously Mina Murray but also Janni Dakkar, play central roles in the series. Janni's violent revenge against the johns of London represents the most obvious form of resistance against patriarchal control of the female body, but Mina's free-flowing sexuality could also be said to represent a reclamation of the bodily agency that is so often threatened. Through this struggle between rape and radical consensual sex, Moore simultaneously acknowledges and opposes the patriarchal tropes of the text he draws on. This perhaps does not justify the prevalence of rape across his entire body of work, but within this particular series the prominence of sex both consensual and not resonates with the body of fiction that League adapts.

This treatment of sexuality functions as a microcosm of the political content of The League of Extraordinary Gentlemen. Moore re-imagines the protagonists of Victorian literature as empire's outcasts, summed up by the first volume's epigraph which states "The British Empire has always encountered difficulty in distinguishing between its heroes and monsters" (Empire Dreams 6). Di Liddo has argued that this is most strongly represented in the dual characters of Dr. Jekyll and Mr. Hyde, with Moore using the character to depict the violence underlying Victorian civility (di Liddo 107). The League begin as servants of the British Empire, but quickly come to learn that their enemies are intertwined with the state they serve. By the end 
of the first volume, it's revealed that the League's shadowy boss is in fact the villainous Moriarty. Moriarty explains that the British state created him, and that the heroes' efforts for it amount to mere "shadowboxing" (Moore, Organizing Power 10). After the second volume, Mina and Alan abandon the service of the Empire after witnessing the horrors of its war against Mars. The rest of the series, which is now the majority of League material in length, features the now-immortal Mina and Alan as rebels against an oppressive state represented by Ingsoc and Jimmy Bond, the latter of whom tellingly describes them as "anarchist." Moore personally identifies himself as an anarchist, and one of the strands of the series is the political education of Mina Murray, who begins the series idolizing the colonial adventures of Alan Quatermain and believing the propaganda set against Nemo's anti-colonial campaign but gradually learns of the horrors of the state. League is not an uncomplicatedly anti-colonial text, as it often reproduces the colonialist and racist texts it draws on in characters such as Fu Manchu or the Golliwog. However, its most explicit argument is an anti-imperial and anti-State one, articulated in the early volumes through the character of Captain Nemo and in later ones through Mina and Allen.

As with Moore's depiction of sexuality, there is also an utopian quality to the politics of The League of Extraordinary Gentlemen. The back material of the second volume, an atlas of Moore's fictional world which plots out the ways in which all fictions fit together, suggests that the tradition of British fantasy that the League draws on contains the potential for political utopias. The series' mythical landscape contains "Commutaria," an utopian town allegedly founded by Merlin, as well the South American island of Utopia (Moore, Phases of Deimos 24 \& And the Dawn Comes Up Like Thunder 25). These spaces are held in contrast to the bleak "Realism Island," suggesting that these spaces of political possibility are not to be found in the canonical literature that motivated previous creators of alternative comics (Moore, People of 
Other Lands 24). These societies suggest that Moore sees in British mythology and fantasy not just imperial violence but also a potential source for radical politics. Within the comics, this utopia is found in the Blazing World, a metaphysical plane which Mina and Alan escape to at the end of The Black Dossier. The Blazing World scenes are printed in 3D, requiring glasses packaged with the book (in an ostentatiously un-literary touch) to read and suggesting that they literally transcend both the mundane and violent world of the rest of the text and the twodimensional world of text itself. It is a place of constant revelry, and also where Mina and Alan are reunited with Orlando for the first time in the series, ${ }^{41}$ associating the Blazing World with the opportunity to escape from monogamy and gender roles. This section, as well as the graphic novel as a whole, ends with a monologue by Shakespeare's Prospero that mirrors the conclusion to The Tempest but evidently does not have the suggestion of finality that either the original play or Gaiman's story of the same name have. The monologue refers to a "radiant synthesis" of "figures" and "arabesques," a metatextual comment on the synthetic nature of League. Artist Kevin O’Neill's depiction of Prospero, with his long white beard, is one that closely resembles Moore himself and perhaps suggests that this space of hope and transcendence is one in which the author locates himself.

The utopia of the Blazing World, only briefly glimpsed, is one in which the rules of geography and empire are transcended - it is literally a place that cannot be found on a map. The textual mixing of The League of Extraordinary Gentlemen suggests a similar approach to authorship, that the series represents a world where all fictions exist together and are common property not demarcated by authorship. In the early volumes, this is literally true, as all of the characters were drawn from the public domain, but the cavalier use of characters from popular

\footnotetext{
${ }^{41}$ In order of publication, although not chronology.
} 
fiction continues into the volumes of Century set in more contemporary periods as Moore integrates thinly-veiled versions of characters such as James Bond and Harry Potter. Moore treats literary style in much the same way, creating numerous pastiche of period styles in the prose pieces accompanying the various volumes of League. This is especially true of The Black Dossier, which contains imitations of authors from Shakespeare to Kerouac. Century also disrupts literary periodization by incorporating characters from various periods and traditions into a contemporary plot. In the final volume of Century, set in 2009, Mina comments that contemporary society seems "very Victorian," suggesting not only the continued relevance of Victorian literature but also the essential falseness of the narratives of progress that sustain periodization. The sexual liberty of Moore's protagonists are mirrored by the textual liberty which he grants himself to transgress the boundaries of genre, authorship and period. Jackson Ayres has argued that Moore participates in a modernist dialogue about the nature of copyright (Ayres 144). Ultimately, Ayres suggests that League operates as a critique of corporate authorship, with its "revived" and updated characters standing in contrast to the "zombified" and static figures of superhero comics and other works which depend on corporate ownership of intellectual property. The League of Extraordinary Gentlemen, then, not only imagines political utopias but an utopian form of text in which capitalistic ownership of popular characters can be ignored.

This textual mixture is not without its problematic elements. There is certainly an element of contradiction in Moore using versions of copyrighted characters in ways that defame them, making James Bond a rapist and Harry Potter a vessel for the antichrist, while continually protesting the use of his own characters (particularly those of Watchmen) by DC Comics and various film studios. Nico Dicecco attempts to explain this by arguing that Moore's adaptations 
are self-reflexive in a way that the Hollywood versions of his comics are not (Dicecco 124).

Moore's use of racist and sexist texts and characters as grist for an adventure narrative trusts that his own radical politics have the power to transform these texts into parts of a revolutionary narrative, a particularly questionable assumption for a white British man, however radical his own politics. In particular Moore's use of the golliwog as a character in The Black Dossier drew considerable controversy and criticism from readers of colour who did not see the racist caricature as an image that could be rehabilitated or disrupted by Moore's work. ${ }^{42}$ For the most part, these tropes are not explicitly contested within the text: the Arab rapists who threatens Mina in the first issue are, in the end, just Arab rapists, quickly dispatched by a virtuous white man. While Moore honours anti-colonial resistance through the character of Nemo, League retains from its sources the image of the colonized world as a playground for the adventures of British heroes. The atlas of the mythic world published alongside League's second volume includes chapter on Africa, Asia and the Americas that consist mostly of material European writers have written of these continents and not stories and texts indigenous to the area. The abovementioned frequency of rape can be viewed in a similar light, as an attempt to use the tropes of misogynist fantasy to challenge the hierarchies of those fantasies. Moore's radical politics suggest a kind of assurance that this text, guided by the work of a white male genius, can successfully rehabilitate the images of racist and sexist fantasy and even turn them against the society from which they came. While League disregards the mythology of individual authorship in general, it fully upholds the mythology of Alan Moore.

We can see more limitations in Moore's treatment of Virginia Woolf's Orlando. Outside of Shakespeare's Prospero, Woolf's Orlando is the most canonical figure to appear in League,

\footnotetext{
42 Perhaps the most extensive fan treatment of this controversy was on the And We Shall March blog (http://andweshallmarch.typepad.com/and_we_shall_march/the_black_dossier/index.html).
} 
and is central to the plot of the post-Wildstorm graphic novels. In Woolf's novel, Orlando is a seventeenth-century male dilettante who eventually becomes a woman who lives for centuries (though still slowly ages) through a largely uncommented-upon magical device. In League, Orlando is a millennia-old character who loves battle and sex. Orlando becomes, for Moore, a way of tying the history of literature together into one narrative as well as the ultimate pulpadventurer character. This reflects League's conception of fiction as an ongoing trove of popular adventures. The series gives no suggestion, however, of the ways in which Orlando is in itself a metatextual work in which the title character's longevity allows Woolf to comment on the literature that matters to her. In his male incarnation, Orlando acts as a parody of the proliferate romance writer, producing countless useless texts but never publishing them, and overlooking the genius around him (Woolf 38, 27). As the centuries past, Orlando's unproductive literary career parallels and parodies the development of English literature, becoming a minimalist, a friend of the eighteenth-century satirists, becomes affected by the creeping "damp" and bloating of the Victorian period and the phallic "shrinkage" of the Edwardian, and eventually is revived by the seeming magic of modernity (Woolf 117,152 ). Woolf treats these shifts as not the results of epochal genius but of frivolous fashion, as represented by the critic Greene who sees Elizabethan playwrights as talentless when he is living among them but later sees them as a golden age which later literature is but a degradation of (Woolf 44, 142). This gentle parody is nowhere present in Moore's Orlando, a perpetual hot-headed youth, nor is much of the literature that Woolf highlights. Woolf's conception of literary history is feminine, filled with love affairs and momentary fashions, compared to Moore's masculine world of battle and rebellion.

All of the characters Moore uses are stripped of their surrounding context to one degree or another, but the context which Orlando uses seems particularly startling. In part, this move 
helps to reinforce the general disdain which Moore shows towards the literary canon, translating his most literary hero into a dramatically different version who is concerned only with the stuff of boys' adventure novels. But it also suggests that, within League, Moore has a certain kind of monopoly over the ability to assess the broad sphere of literature and make metatextual maneuvers. In taking characters from other authors' texts, Moore is suggesting in some ways that those fictions previously existed in a naïve state and must be transformed into a contemporary, progressive adventure series by the genius of Moore. There is thus a contradiction in Moore's work between the dismantling of others' authorial primacy and the implicit presentation of Moore's own textual privilege. To acknowledge the ways in which authors such as Woolf were canny and metatextual in their own way would disrupt the authorial primacy that Moore seeks to assert despite his desire to remix other authors' works.

The League of Extraordinary Gentlemen would appear, at first, to be of a piece with "A Midsummer Night's Dream" and "Arcadia" in marshalling the images of literary fiction to grant comics the same kind of respectability. Like those works, it focuses on literary characters and symbols instead of authors, and presents these symbols persistence as a product not of material conditions but of some innate, mystical quality in the literary. However, there are crucial differences which mark League as an important shift in the way literature was used within comics. Authors do not appear as characters, but only their creation, with no credit given within the text or its immediate paratext. The works drawn on are not the most canonized, but a wide spectrum of respectable and unrespectable texts, with the incorporation of literature not suggested as an elevation of the comics medium but as the realization of a continuity between comics and genre fiction. League says a number of very nice things about stories, but sees their point of origin as essentially unimportant, placing all of fiction in a "great structure" within 
which it can be played with and manipulated as one wishes. In doing so, it often overestimates the power with which such literary play has to transform reactionary images and tropes. However, the turn from reverence to play is an important one, and one that would be heightened in Moore's follow-up work.

\section{A Literary Pornography: Moore and Gebbie's Lost Girls}

Moore's 2006 graphic novel Lost Girls is another textual remix, placing characters from popular fictions into an unfamiliar and somewhat unsavory genre. Again, the primary works cited are well-known without being altogether canonical, this time heralding from the world of children's literature: Peter Pan, The Wonderful Wizard of $\mathrm{Oz}$ and Alice in Wonderland. However, while Lost Girls is presented as a comic, the genre which Moore set out to comment on was pornography. The three-volume graphic novel stars adult versions of Wendy Potter, Dorothy Gale, and Alice, who meet in Hotel Himmelgarten in Austria during the weeks before the outbreak of World War I and begin a series of sexual explorations with each other. In the process, the three women tell each other the stories of their individual sexual awakenings, which mirror the stories the characters are taken from but replace the fantastical elements with pornographic ones. For example, the Lost Girls version of Peter Pan is a young male prostitute who introduces Wendy and her brothers to the sexual world of the streets. As in The League of Extraordinary Gentlemen, Moore re-mixes well-known characters and imitates prose styles in order to offer a heightened, metatextual version of a degraded genre. The use of pornography only calls further attention to the relationship between liberated sexuality and textual play in Moore's ABC period.

Shortly after Lost Girls' release Moore published an article in the British magazine 
Arthur which, while not mentioning the graphic novel by name, clearly lays out the theory of pornography that informs it. "Bog Venus Versus Nazi Cockring" presents a history of pornographic art from the titular Venus of Willendorf to the present. Moore presents pornography and sexual liberty as having accompanied societal progress while facing constant repression by the forces of power: "sexually progressive cultures gave us mathematics, literature, philosophy, civilization and the rest, while sexually restrictive cultures gave us the Dark Ages and the Holocaust" ("Bog Venus.") Moore upholds the traditional view of Western history, with classical Greece and the Renaissance as high points of creativity flanking the barren Dark Ages, in order to suggest that this has also been the history of sexuality. "Bog Venus" goes on to detail a canon of artistic pornographic works, including literary authors such as William Blake, Aubrey Beardsley, and the Beats as well as comics such as the infamous "Tijuana Bibles" and the works of Harvey Kurtzman and R. Crumb. As in Sim, the prosecution of Oscar Wilde operates as a signal instance of the power and cruelty of artistic repression. As is evident from this history, Moore is a full-throated proponent of the "repressive hypothesis" which Foucault famously critiqued in his History of Sexuality. Even while admitting that porn is "now a part of mainstream culture," Moore maintains that its poor quality and adherence to patriarchy is still a result of social repression ("Bog Venus.") While porn has been accepted as a business, Moore argues, actually consuming it is still an act that brings shame, in part due to the low quality and questionable morality of porn. With the eradication of pornography being impossible, Moore suggests that the solution is "good porn" in which both creators and consumers can take pride. Once great artists and authors have created pornography of this type, "The erotic might be elevated from her current status as a hooker everyone keeps chained up in their cellar but nobody talks about, unmentionable but available, back to her previous position as a goddess("Bog 
Venus.") This metaphor again shows Moore's tendency to use sexual violence against women as a means of making a point, but also recalls the mythology of Promethea, in which sexual learning is key to restoring the position of the goddess within society. Lost Girls, released as a glossy and expensive three-volume set, is clearly Moore's attempt to create this good porn.

We can also see Lost Girls as a form of rebellion against the comics form' history of censorship. Attempts at comic censorship from Wertham to the present used the image of the innocent child corrupted by their exposure to illicit material. Moore deliberately plays up the pedophilic associations of this narrative by incorporating characters associated with children's literature into a pornographic work that includes sexual imagery of children. Shrink wrap or not, Lost Girls is precisely the sort of work that the anti-comics movement feared. However, Moore argues through the comic that the obscene was already present in children's media, highlighting the psycho-sexual subtexts of seemingly beloved and wholesome stories. We see again an instinct not to dissociate with the debased history of comics but rather to highlight the continuity of debasement between comics and literature. Moore is also flaunting his autonomy from the corporate control of comics -- it is hard to imagine DC or even Image allowing any of their subsidiaries to publish a work like Lost Girls, vulnerable to controversy and censorship. For Moore, the explicitness of Lost Girls is a means of spitting in the face of the long lineage of comic censors.

Like League, Lost Girls presents an utopian vision of sexuality leavened by the acknowledgement of rape and patriarchal oppression. Hotel Himmelgarten is eventually revealed to be one designed after the fantasies of erotica, with staff who will indulge the clientele's every sexual need, “A place outside our normal lives, where we can be who we are in secret" (Moore, Lost Girls Vol. 3 32). This formulation suggests the hotel as a psychogeographic 
location that allows for the release of desires otherwise restrained. The relationship between the titular women forms a kind of utopian sexual experiment akin to the relationship between Alan, Mina and Orlando in the later volumes of League in that it imagines a free-flowing sexuality devoid of possession and restriction. Bisexuality and polyamory are seemingly universal. By the third volume, the hotel has been closed to new customers due to the outbreak of World War I but Moore's heroines remain in a space removed from the worlds of both commerce and violence. While the staff are prostitutes, their removal from the economy seems to only stimulate their activity. Not all of the sex in the book takes such an utopian tack. All three women are subject to sex used as violence or control by men: Alice was molested as a child, while Dorothy experienced incest and Wendy is both pursued by the pedophilic Captain Hook and repressed by her stifling husband in later life. As Zoe Brigley-Thompson argues, the arc of the text amounts an overcoming of "the nullity of their desires" felt by each protagonist due to their traumas (85). It is precisely in order to escape from this use of sex for violent and patriarchal purposes that the sexual exploration which Lost Girls chronicles is necessary in order, as Alice said, to not let the young girls who were the victim of sexual violence to become "lost" to their adult self (Moore, Lost Girls Vol. 3 72). The sexuality of Lost Girls is thus both utopian and commemorative, honouring the desires born of a violent and patriarchal society without submitting to them uncritically.

Narrative is also a critical part of this remembering, in a way which suggests the more general link between fiction and sex in Moore's work. Rougeur explains in the third volume that he established the hotel as a place in which "everyone can act the way people do in fiction. In romances," thus imagining the fictive as a space of utopian pleasure which can only be imitated (Moore, Lost Girls Vol. 3 32). Much of the plot of Lost Girls consists of storytelling, with the 
three protagonists taking turns revealing lurid elements of their pasts. These stories serve as a way of exorcizing repressed memories, but they are also a form of erotic play, with the other two women often questioning the speaker and expressing their arousal. ${ }^{43}$ Pornography also serves as a frequent text-within-a-text, in the vein of the authorial imitations in The Black Dossier. In this case, the diegetic text justifying these imitations is a book of pornographic frauds which Rougeur places in every room, mimicking writers such as Wilde, Beardsley and Apollinaire. Wilde is here treated as a decadent wit, with emphasis placed on his perversity, in contrast with the Wilde presented in Sim's "Melmoth" whose sexuality is de-emphasized in favour of his potential for social critique. Rougeur's book of forgeries allows Moore and artist Melinda Gebbie to participate in their own form of play, imitating and perverting canonical turn-of-the-century authors and painters respectively. But whereas the pornographic renderings of popular children's' narratives serves to parody and desacralize their familiar comments, the hotelier's book serves as a way of introducing the repressed canon of artistic pornography that Moore chronicles in "Bog Venus," including Wilde, Beardsley and Apollinaire. This body of work functions like Pekar's shadow canon of social realists, integrating the comic work into the history of prose fiction. In this way, Moore makes the same argument he does in The League of Extraordinary Gentlemen, that the canonical and the degraded are part of a common literary heritage and are more similar than different.

Even when not imitating specific painters, Gebbie's art contributes to the way in which Lost Girls portrays sexuality and artistic creation. Most of Moore's work, including Promethea and The League of Extraordinary Gentlemen, are illustrated in the classical comic book style -

\footnotetext{
${ }^{43}$ See, for example, the way in which Alice and Wendy goad Dorothy into admitting that the "Uncle" figure in her story is actually her father (Vol. 3 p. 71-72).
} 
broadly realist pencil drawings accented with ink and colour. ${ }^{44}$ Gebbie's illustrations are done as watercolours, suggesting the prestige of fine art - the high-class, respectable pornography that Moore set out to write. Compared to the skinny, angular characters that Kevin O'Neill illustrates in League, Gebbie's figures are soft and permeable, with a less striking division between figure and background than in conventional inked comic art. Her chief influences are Impressionism and Art Nouveau, art movements roughly contemporary to Lost Girls' 1914 setting, which adds another layer of intertextuality and imitation to the graphic novel (di Liddo 141). As Charles Hatfield writes, "her characters aren't simply fleshy, they're downright ruddy" (“A Review and a Response" 14). Gebbie's style is the antithesis of the jagged angles and bare-bones dialogue of the Orwellian pornography in Black Dossier. This difference conveys Lost Girls' polyphonic sexuality: it does not believe that pornography should be reserved for a certain definition of beauty, a refusal conveyed by the plump Wendy and the aged Alice, nor that sex should stop at even the border of the self. Gebbie's well-known status as Moore's wife also suggests the graphic novel as an act of love, its perversity nevertheless sanctioned by the marriage bed. Gebbie's artwork is integral to both Lost Girls' image as artistically respectable pornography and its thematic embrace of sexual freedom.

Moore treats this sexual freedom as coextensive with imaginative freedom, with pornography functioning as a means of sex. This is certainly the Rougeur's intent in leaving his book of pornographic imitations in the room of his residents, spurring even the most prudish to sexual inspiration, as in the scene where Wendy's repressed husband is moved to masturbation by images that strongly resemble Gebbie's art (Moore, Lost Girls Vol. 2 18). In the utopian space of the hotel pornography functions not as a commodity or a purveyor of ideology but as an

\footnotetext{
${ }^{44}$ One significant exception is the photo- derived artwork in Promethea No. 7, which uses the style of Italian fumetti or "photo-comics" to depict Sophie's alienation upon returning to the physical world.
} 
imaginative space for sexual liberation. Moore most clearly expresses this during the Rougeur's monologue in the midst of an orgy. The speech takes place all in one panel, one whose image is a wide shot of the hotel orgy, suggesting that Rougeur's words are his ultimate comment - and perhaps Moore's final comment - on the entire spectrum of human sexuality. Gebbie's watercolours, abandoning any sense of realism for a splash of blues and purples, also implies that we have moved into the realm of abstraction. The panel also contains a man ejaculating on a book, a literal vision of the fusion between textual and sexual. He comments that "Pornographies are the enchanted parklands where the most vulnerable of all our many selves can safely play. They... oh, your cunt. So warm" (Moore, Lost Girls Vol. 3 26, italics in original). The suggestion of an "enchanted parkland" housing multiple selves recalls the iconography of Promethea, while the interjection of commentary on the sexual acts the speaker is partaking in suggest that this space is fundamentally a yonic and maternal one. The space of sexual imagination created by pornography is a vagina: internal, safely private, and feminine. Gebbie has spoken of the prevalence of rounded and asymmetrical shapes as a means of returning to natural and feminine growth (di Liddo 142). All three of Moore's protagonists are cisgendered women, ${ }^{45}$ and the hotelier uses the yonic imagery of "secret gardens" and the "wet, blinding gateway of our pleasure" to describe the location of inner fantasy (Moore, Lost Girls Vol. 3 26). Orion Kidder notes the primacy of lesbian activity and female bisexuality in Moore's advocacy for sexual liberation, a primacy which Kidder argues tends towards fetishization more than mere representation (187). It is telling, then, that even in a scene of phallic penetration the vagina continues to act as a symbol for scopophilic pleasure. As in League, Lost Girls offers up this sexual liberation as a political alternative to the destructive nature of capitalist society, as

\footnotetext{
${ }^{45}$ Curiously, the encyclopedic panoply of sexual perversions and identities in Lost Girls does not include any transgendered characters.
} 
represented by the outbreak of World War I. Rougeur describes the world of fantasy as "the palaces of luxury that all the policies and armies of the outer world can never spoil, can never bring to rubble," while Alice describes war as a "perversion" where "boys will be dying in mud when they should be fucking in bed" (Moore, Lost Girls Vol. 3 26, 92). By contrast, an embrace of inner fantasy allows access to a kind of transcendence that even fiction cannot: "things may be expressed in a language that is beyond all literature, beyond all words" (Moore, Lost Girls Vol. 3 26). Moore again reverses the typical hierarchies of genre by suggesting that pornography has more artistic and political possibility than literature.

So, why does this argument about the potential of pornographic exploration require the use of characters from well-known children's novels? One aspect is surely the shock of taboo that comes from placing such symbols of childhood in sexual situations, a perversion that is literalized in Lost Girls' multiple explicit depictions of child molestation. Indeed, all three women's backstories include childhood or adolescent sex with older men, echoing the textual work which Lost Girls does with the lore of childhood. But the mixing of texts also suggests that the sexual licentiousness of Rougeur advocates parallels the textual licentiousness which Moore takes in his later work. Lost Girls advocates for unfettered play and exploration in both sex and writing. Rougeur plays a role in the text remarkably similar to Moore, imitating others work for the purpose of stirring up sexual arousal and liberation. His monologue about the value of pornography is essentially a more poetic presentation of Moore's argument in "Bog Venus." In Lost Girls, the creation of an utopian sexual space requires the breaching of the boundaries of literary property and propriety and the same anything-goes attitude that Moore's protagonists adopt. And while the titular lost girls overcome the taboos of Georgian society to live out their own sexual fantasies en route to untangling their pasts, Moore presents himself as having 
overcome the ultimate literary taboo, plagiarism, in order to fulfill his artistic fantasies en route to furthering the cause of freedom.

The use of well-known children's literature also allows Moore to continue exploring the perversity of the literary tradition. Through flashbacks to the central characters' lives, Moore and Gebbie present pornographic versions of popular stories, in the tradition of the Tijuana bibles of the 1930s. The suggestion is that the sexual desires and traumas that affect the lost girls are latent in the texts from which they're drawn. For instance, Kenneth Kidd has argued that Alice's molestation in the first installment of her story "aggressively courts" readings of Alice in Wonderland that accuse author Lewis Carroll of pedophilia and the text of being an expression of his desire for a real pubescent girl (2). On a plot level, Moore's Alice begins her adventures into drugs and lesbianism after the attentions of a pedophile, but the conclusion of each flashback with a full-page panel depicting a pornographic version of the fantastic scene from the original text (such as, for instance, Dorothy copulating with an actual Tin man), suggests that this is less an addition of perversion and more an explication of the perversion already present in children's literature. Similarly, Moore's adaptation of Peter Pan also draws on the "discourse of pedophilia" surrounding the author, and the libidinal impulses of the original play of novella (Kidd 8). In Moore's hands, scenes such as Wendy teaching Peter what kissing is or the Lost Boys fervently wishing for a full-bodied woman to mother them are taken to their logical conclusion. As Kidd notes, this is a very Freudian reading of these texts, suggesting that their seemingly innocuous and frequently nonsensical plots can be read as coded sexual desire (7). The suggestion, as with The League of Extraordinary Gentlemen, is that seemingly wholesome literary traditions were already perverse and degraded.

What is not explicated in Moore's translation of these works is the political valences of 
the children's texts that Moore draws on. L. Frank Baum's The Wonderful Wizard of Oz has been read in light of the author's interest in Populist and nativist politics, perhaps most famously through Henry Littlefield's reading of the text as being a metaphor for US monetary policy. Moore's presentation of the text as a Freudian drama of sexual exploration and incestuous lust, with Dorothy's desire to return home translated in displaced desire for her father, discloses on such readings. Similarly, while Carroll's Alice in Wonderland contained numerous jokes about and references to what were then contemporary British politics, in Moore's comic it is entirely an expression of pedophilic desire. This is not to say that Lost Girls depoliticizes these texts - as noted above, Moore has his borrowed characters critique sexual repression and militarism in between sexual dalliances. But in Lost Girls, as in League, the politics is all Moore's and obviously so, with other texts presented as naïve fantasies whose perversions can be decoded by the contemporary author. As di Liddo has noted, all three of these texts have been re-interpreted numerous times by authors and filmmakers, but Moore does not acknowledge these past reinventions or incorporate them into his metatextual world (di Liddo 138-9). Again, in Moore's metatexts there is little room for authorial agency other than his own.

Lost Girls has the curious distinction of being both a beginning and a conclusion of this period of Moore's work. Its early chapters were serialized in 1993, and the work stayed incomplete until its publication as a three-volume graphic novel in 2006. The serialization of Promethea and The League of Extraordinary Gentlemen as part of America's Best Comics occurred between these two dates. Lost Girls is Moore's most whole-hearted attempt at laying out the principals theorized in Promethea and gradually introduced in League, emphasizing continuity between the canon of Victorian popular fiction and the seemingly degraded and commercial world of comics and pornography. Like those previous two texts, Moore uses 
intertexts to present a literary and political argument advocating the abolition of both sexual repression and societal hierarchies in general. His project of constructing a literary canon around iconicity reaches its apex in a work that makes sex itself an interaction between icons (di Liddo 151). This graphic novel, then, is the most uncompromised and provocative statement of Moore's predominant themes in this period of his work.

\section{Iconic Resonance}

The literary aspirations of ground-level comics produced within the mainstream comics industry are even more unlikely-seeming and hence more desperate than those of alternative comics. As such, they reach back to even older and more canonized texts such as Shakespeare and the Romantic poets. They may have also seen these works as predecessors in using images of the fantastic to literary ends. Gaiman and Morrison use the fantastic devices of their series to imagine literary authors as not just distant antecedents of present-day works but active participants in it who interact with comic-book heroes. In doing so, they uphold the literary canon's claim to self-evident greatness. This is why the shift that takes place around the beginning of the 21 rst century is so important. The works of Alan Moore, perhaps the biggest name in ground-level comics, took an approach to literary fiction (albeit less canonical works) that saw the past as a box of tools to be used at will instead of a set of ancestors to be paid respect. The League of Extraordinary Gentlemen and Lost Girls tell genre narratives that are in many ways highly conventional, but also draw on a complex web of intertexts that are often used in perverse and unorthodox ways. Gaiman and Morrison use literary intertexts to argue that comics can be, like literature, autonomous and intellectual; Moore uses intertexts to argue that literature can be, like comics, commercial and perverse. 
What are the origins of this iconographic conception of literature? It is easy to imagine how writers working for DC Comics, a publisher known much more for its ability to create culturally-resonant characters than any mastery of form or expression of interior genius might come to argue that cultural resonance is the most important aspect of the literary. Or, to reverse causality, authors who already thought of literary characters as part of a shared set of myths were more willing to associate themselves with the publishers of superheroes, comics' most enduring myth. In terms of literature antecedents, the iconographic approach has elements in both Jungian criticism and postmodern metafiction without fully committing to either. It owes perhaps just as much to New Age spirituality, which offered a hybrid of many past belief systems. Both Morrison and Moore committed to this hybridity spiritually as well as aesthetically.

Perhaps Moore, as one of the most canonized comics figures, had the freedom to cast away literary aspirations in the way that Gaiman and Morrison, who wrote the above-mentioned stories early in their careers, did not. In any case, Moore's work on America's Best Comics, while not nearly as popular or influential as his 1980 s deconstructions of the superhero, represents a turning point in the way comics considered literature. With the literary comic being no longer a seeming contradiction or an aspirational horizon, space opened up for a reconsideration of the values invested in the literary by the early proponents of alternative comics discussed in the last chapter. At his most political and idealistic, Moore treated the intersection of comics and literature as not simply a space to advocate for artistic liberty but also sexual and political freedom.

This shift is not a straightforward overturning of conservative attitudes in favour of revolutionary ones. Imagining the world of art as a place free of any intellectual or moral restrictions, as Moore does, is a component of the art-for-art's-sake ideology that also drives 
canonization. Moore's belief in his abilities to use elements such as racist imagery and child sexual abuse in liberatory ways may ultimately re-affirm an idea the author as a superhuman figure who stands aside from the flow of history and moral considerations. Rather, what is significant is the shift from a unidirectional view of the literary based on reverence to a complex approach based on the concept of play. In this period a parallel evolution was taking place within alternative comics, with queer artists exploring the literary as a space of play. 


\section{Chapter 3: Queer Reading Strategies in Schrag and Bechdel}

As shown in previous chapters, the discourse of legitimation at work in alternative comics imagined the author as not just male but vigorously so. By contrast, the mass audience was imagined as effeminate and sexually deviant. As I have argued, this echoes the argument of Fredric Wertham, who used a medicalized discourse to argue that comics such as Batman promoted homosexuality. As the mainstream comics industry responded by grafting heterosexual quasi-families onto their characters, critics like Gary Groth (who, it must be noted, explicitly argued against homophobia in The Comics Journal as early as the 1970s) used the terms of this critique to argue for a disruption of the comics mainstream. Thus the queer reader, never mind the queer writer, remained an abject figure within comics discourse. In the previous chapter, I have showed how Grant Morrison and Alan Moore gestured towards sexual diversity and a feminist critique of the literary but nevertheless drew on a predominantly male canon. Moore and Morrison, both heterosexual men, could also introduce gender-fluid characters such as Lord Fanny and Orlando without losing the status of virile masculine genius.

The queer author of comics approaches this discourse from a very different position. Gay and lesbian comics date back to the earliest days of underground comix, from the confessional work of Howard Cruse to the political lesbianism advocated in parts of Wimmen's Comix. However, they have rarely been given pride of place in the argument for comics as literature, and more often ignored. Even Alison Bechdel, who would become part of the comics canon, spent two decades penning a syndicated strip largely ignored by fans of both alternative and mainstream comics. Queer comics were doubly marginalized, as queer art and as comics. We can see Schrag and Bechdel reaching back towards the literary canon, and in particular the queer and deviant authors of the canon, as a form of resisting or mocking this marginalization. 
However, these works do not flout the canon in the intentional, iconoclastic mode of Alan Moore. Both, instead, lead the reader and autobiographical subject towards a renewed appreciation of canonical literature as a source of meaning and pleasure. The canon's value in Likewise and Fun Home stems from its potential as an object of empathy leading the reader towards greater self-understanding. Schrag and Bechdel's approach in their graphic memoirs could be placed in the context of contemporaneous trends towards a therapeutic approach to literature, encouraged in everything from postmodern life writing to Oprah's Book Club, but once again the double marginalization of the queer comic complicates matters. What emerges, at least in Fun Home, is not a simplistic sympathy with characters based on shared experience, but rather a careful and partial appropriation of literary tradition in order to compose a hybrid text that is both critical and autobiographical. The work of Schrag and Bechdel is thus simultaneously part of an individualist trend towards literature as therapy as well as a queer rethinking of reading methods and philosophies.

In its own way, this gesture represents a reconciliation with the literary canon. The list of texts referenced by Bechdel - Joyce, Proust, Wilde - is as comfortable and familiar a modernist canon as those invoked by Groth and Sim. However, the canon appears here not as a standard of excellence to which the author's own efforts must aspire, but as a common set of reference points which the young protagonist must establish their own highly personal relationship with. If in both Groth and Moore the literary is fundamentally a site of struggle, in Bechdel and Schrag it is chiefly a space of personal growth. That growth here takes place not through the lineal arc of development from child to adult, but in a halting and frequently frustrated struggle to establish a relationship between the queer body, the literary text, and the world. 


\section{Likewise and the Crises of Identity and Authorship}

Ariel Schrag became a presence on the alternative comics scene at a young age, selfpublishing the first of her autobiographical comics in tenth grade. These works were relatively unheralded in even the alternative comics scene, but gathered a cult following as part of California youth, punk and queer subcultures. This initial book, Awkward, would be followed by three more, each detailing a year of Schrag's high-school life and with each comic created directly after the year depicted. As a result, the comics become increasingly self-referential, with the story of each comic becoming more and more about the creation of the previous one. This trend reaches its peak in Likewise, the final volume. Throughout Likewise, Ariel considers and doubts her own role as an artist and the ethics of autobiography. This theme is paralleled with her ambivalence about her own lesbianism and in particular her tortured relationship with her exgirlfriend Sally. Throughout Likewise, Schrag's comics authorship is depicted as fundamentally libidinal, and in many ways a more authentic expression of her sexuality than her fumbling relationships. However, this self-expression is by no means a purely positive act, and in many ways Ariel's attitude towards her art is no less confused and contradictory than her attitude toward sex.

The involvement of Ariel's lesbianism in her comics work and vice versa is established repeatedly in Likewise. The reading or writing of "the comic," as Ariel's narration refers to it, frequently precedes sexual attraction or masturbation (Schrag 257). Many of Ariel's love interests offer themselves first as literary interlocutors: she longingly reads the poetry of exgirlfriend Sally, discusses literature with friend Mary before kissing her, and reads aloud the poetry of a potential male suitor (Schrag 261, 265, 273). By contrast, Ariel takes her short-term girlfriend Mabel's disinterest in the comic as proof that they shouldn't be together (Schrag 142). 
As she says to Sally, "I realized I'm like - not attracted to people who don't get my comic" (Schrag 141). The tape recorder Ariel uses to record dialogue for the comic is described in her narration as "stuck out like an eager dildo with no play," again suggesting symmetry between art and masturbation (Schrag 229). Even the production of the comic involves close mimicry of sex acts for reference (Schrag 224). Likewise continually establishes Ariel's comics work and her sexual activity as being closely linked.

It would be easy to look at this correlation and conclude that Schrag sees her comics authorship as a way of validating her lesbianism and challenging a heteronormative world. Indeed, as Emma Maguire argues in her study of Potential, Schrag's life writing presents a challenge to heteronormative conceptions of girlhood (Maguire 55). However, this ignores the profound ambivalence which Ariel experiences about both her sexuality and her art. The former doubt is expressed in a Likewise plotline where Ariel attempts to find a biological rationale for homosexuality, refusing to accept cultural explanations as to why she is not simply defective. She is reluctant to embrace triumphant cultural narratives of coming out and queer rights common to her Bay Area locale, in one scene expressing disgust at the "fucking freaks" who would attend a gay pride parade (Schrag 10). This may too be part of the "queer art of failure" that Maguire, citing Judith Halberstam, uses to describe Schrag's work (Maguire 58). Ariel fails to adhere to either straight or gay norms, even sleeping with men in both Likewise and Potential. This failure does not bring her a sense of transgressive triumph, but rather greater anxiety and self-awareness.

Identifying as an artist initially seems to be much more palatable to Ariel. On the opening page, taking place before the narrative even begins, Sally jokes that "you might as well just call the next book 'writing Potential."' As predicted, Likewise includes numerous scenes of 
the artistic process, including a breakdown of Ariel's after-school "working hours" (Schrag 95, 154). Ariel believes that this process provides a constancy that her tumultuous love life does not: "love is like this thing you can be totally obsessed with and your life revolves around it, but only if art is like this stable thing that's kept behind it, which means it's really the most important thing" (Schrag 277, underlines in original). This lengthy and fervent statement, in a casual conversation with her mother, suggests Schrag's dedication to art as simultaneously an emotional anchor and a neurotic fixation. Similarly, after an emotional fight with Sally, Ariel narrates "I thought about how all that mattered, in all entirety, and all I wanted, and all I could see anything worth being anything for, was being a writer" (Schrag 229). The repetitiveness of this statement again suggests both ferverence and desperation, with the identity of "writer" as a shield against emotional attachment.

Much of Ariel's concept of artistic creation comes from the idea of "It" that her and her friends develop early in Likewise. "It" is an ineffable quality akin, but not identical, to artistic inspiration and charisma. Writing is suggested as a prominent way to show "It," but this concept has more to do with personality and interest than creation: "I think it's just like the stuff you talk about and what you're interested in that shows your It" (Schrag 33). Ariel and her friends disagree on what particular items and subjects are imbued with "It," but all agree that this ineffable quality exists and is important, with Ariel even thinking that "It" defines her life (Schrag 35). This concept does not relieve Ariel's artistic and sexual anxieties, and if anything increases them: “I'm sure Sally doesn't think I have It? She thinks my comic has It!" (Schrag 33). The ambiguous concept of "It" is the glue that fastens Ariel's activities as writers and artists so closely to her idea of selfhood.

However, Ariel's belief in the stability and importance of her art is challenged throughout 
Likewise. She frequently experiences anxiety about both the creation of her work and its reception. For instance, Ariel worries that her art is too ugly and that the people she is depicting will find it insulting (Schrag 76). She also worries about being identified and pigeonholed as a queer female artist. This is seen in a sequence where Ariel experiences anxiety about an upcoming interview with a feminist magazine, imagining that the interviewer will draw out her unorthodox thoughts about her own gender and sexuality as well as grilling her about the infrequent representations of black people in her comic (Schrag 79). Here Ariel's failure to conform to a coherent gay narrative and embrace progressive politics extends into her feelings about the comic. Ariel's fixation on the reception of her comic makes it a source of anxiety instead of stability.

The ethics of Ariel's autobiography is also challenged by other characters within Likewise, most notably Sally. Sally refuses to model for Ariel's comic-book recounting of their now-ended relationship. She phrases this objection as one of bodily autonomy: "It's my body. I decided you don't own me and you can't make me do things I don't want to" (Schrag 88). She also criticizes Ariel for her depiction of a classmate in Potential as annoying and mentally disturbed (Schrag 212). The comic book is often a spectral presence that influences the characters, as multiple people worry about their representation in the comic or ask Ariel not to include events, a request which by its representation implicitly has been denied (Schrag 286). These scenes highlight the ways in which Schrag's autobiographical work is not entirely creative and benevolent but in fact relies on the bodily participation of numerous people whose attitude towards this participation is frequently ambiguous. This realization in turn challenges Ariel's status as an autonomous artist.

The anxiety surrounding the creation of Potential and Likewise as well as the connected 
struggles with her relationships and self-identity leads Ariel to a mental crisis. This crisis is depicted through a breakdown in comic form. This is most evident in a section at the end of Part I of Likewise in which the page numbers - the most conventional formal device to suggest progression - abruptly stop at 224 and resume at 225 eighteen pages later. These pages, like the pages proceeding them, use a constant two-by-three grid of equally-sized panels, but several squares in the unnumbered pages where panels would be expected are blank white space. Schrag also shifts styles within these pages, sometimes even from panel to panel. Her usual sketchy artwork that uses thin lines and a lot of white space is replaced with artwork filled with shadow and dark lines that suggest three-dimensionality. It is literally a dark period. The lettering, usually a steady handwritten lower-case script, goes to extremes in this section, in some cases being a wild scrawl and in other places affect-less typing. The chronology of this sequence is also jumbled, skipping between different points in times, sometimes without any textual notification. This emotional crisis, which makes up the climax of Likewise, is depicted as a crisis of representation in which the devices of the comic form used to mark the passage of time are rendered meaningless. That Ariel's crisis of identity and self-belief is reflected through a breakdown in the comics form suggests that the comic is ultimately coterminous with that identity.

The latter two parts of Likewise are largely about finding a way out of this crisis. While the personal events of Ariel's life do not necessarily get better, there is never again a disjunction in the narrative such as the unnumbered section. The art style continues to shift in moments of stress and disassociation, sometimes becoming a childish scrawl and other times a mechanical assemblage of dark shapes, but by the end of the section it has returned to normality. These parts of Likewise struggle to hold the comics form together but succeed. This reflects Ariel's partially 
successful attempt at reconciling her queer artistic identity with the necessities of sociality.

In part this attempt involves the acknowledgement of the creation of the comic as a collaborative process. Ariel is reminded of how her drawing initially started as a social activity, spurred by art classes and friendships (Schrag 300). Attending a gala for a lesbian magazine places her in a welcoming literary world. This is signalled by four silent panels of Ariel meeting and talking with others, a rarity in such a thoroughly-narrated graphic novel. The final panel of the page sees Ariel walking home with the simple caption "future?" (Schrag 287). Ariel begins to realize that there is a literary world, even a queer literary world, in which she can fit.

The most important of these relationships is between Ariel and two of her high school teachers, Ms. Salt and Ms. Nocatz. The two teachers, both lesbians, act as mentors for her and provide feedback on the comic. They are the only characters for whom Ariel expresses uncomplicated love and admiration. The final lengthy scene of Likewise, and hence of the entire series, consists of Ms. Salt driving Ariel, drawn as a child, home after her graduation. Ariel tells her "You really were my best friend this year" and "I love you" (Schrag 357). When she returns home, a smiling Ariel looks in the mirror and notes "This is the most important year of my life and this is what I do with my time" (Schrag 359). This line was previously used as a way of admonishing herself, but here it becomes a moment of self-acceptance due to the positive connotations of the white space absent from previous pages and Ariel's smile. The experience of mentorship and collaboration leads Ariel back to a measure of self-acceptance.

Ariel also uses modernist literature, most notably Joyce's Ulysses, to piece together a narrative mode that can accurately represent her experiences. Ulysses is a constant companion over the length of Likewise, making up a part of Ariel's work schedule alongside working on the comic and scientific research (Schrag 94,154$)$. Upon deciding to read Ulysses, a large caption 
reads "Ulysses or die!," echoing Ariel's frequent proclamations that "the comic is life" (Schrag 75). Joyce becomes both inspiration and aspiration for Ariel. In a late-night phone conversation, Sally says that "people should get a cult together to read your book, like Ulysses" (Schrag 136, underline in original). Ariel sees Joyce as the embodiment of "It," an example of a personal work of genius to which she can aspire.

Formally, Likewise can be described as an attempt to translate the modernist techniques of Joyce, most notably stream of consciousness, to comic form. The language of Schrag's captions frequently mimics Joyce's prose. For example, while Ariel prepares for a college interview, the captions read "lone girl traverses with Ulysses and glasses. Have interview and girl is jaded by lesbianism. Reed just perfect for Sally! Personification? So perfect! Mr. rakes went, mood, de-press, string bean all over it. Vegan muffins” (Schrag 93, underlines in original). The mention of Joyce immediately transitions into prose that, through its frequent and unprompted changes of subject, sentence fragments, and strings of verbs and nouns outside of grammatical order, is distinctly Joycean. Schrag directly depicts this inspiration. While reading a passage of Ulysses, Ariel visualizes the scene in comics panels. These are panels-within-panels conjoining the captions that contain Joyce's text, a formal invention that visually presents the translation between word and image (Schrag 186-187). After reading this, Ariel begins speaking into her tape recorder in a stream-of-consciousness manner, perhaps unknowingly beginning the preparations for Likewise and the style it will take (Schrag 188-189). Schrag's shifts between various visual styles depending on mood are also comparable to Joyce's mimicry of different genres and styles in Ulysses. Joyce provides Schrag with not just a general artistic inspiration but a specific style which she attempts to adapt to the comics form.

Drawing comparisons between one of the ur-canonical texts of English literature and a 
comic book drawn by a teenage girl may seem odd, but that is precisely the point of Schrag's usage of Joyce. The prominence of Ulysses in Likewise acts as a bid for literary validation, not just for Schrag but for the comics form in general. The low-culture status of comics obviously bothers Ariel, and this surfaces in a conversation with male love interest Derek. After an offpanel snub to the comics form, a wild-eyed Ariel goes on a rant about how "there's no reason why pictures and text together should be any less than writing and paintings" (Schrag 271). While she initially cites Maus as proof of her argument, Ariel ultimately yells "I'm going to change comics they will see" (Schrag 271). The punctuation-less presentation of the station suggests it as a kind of rushed statement made out of overheated emotion, but its ambitions nevertheless align with the various ambitious formal experiments that Schrag undertakes in Likewise. The creation of a comic that could legitimately be described as Joycean would definitely serve the purpose of elevating the medium.

The narrative of Likewise can be described as one of dual crises: a crisis of sexual legitimacy, marked by the drawn-out break-up with Sally and Ariel's search for a biological justification of homosexuality, and a crisis of artistic legitimacy, marked by the challenges to her autobiographical voice and a breakdown in comic form. These two crises are closely linked. Sally and Derek act as antagonists in both narratives. Sally challenges both Ariel's conception of their relationship and her depiction of it in Potential, while Derek questions the artistic potential of comics and Ariel's denial of heterosexual attraction in the same scene. To the extent that either crisis is resolved within the narrative of Likewise, it is done through the guidance of the two lesbian teachers at Ariel's school, Ms. Salt and Ms. Nocatz. The conclusion of Likewise, Ariel's tearful parting with Ms. Salt after a lackluster graduation, represents not a resolution of the questions raised by Sally and Derek but at least a measure of self-acceptance. 
The importance of Ariel's comics to her conception of herself is evident throughout the graphic novel. Likewise, openly comparing itself to a canonical work of literary modernism, presents itself as the fulfillment of Ariel's vow to change the public perception of comics. While we see very little of the actual production of Likewise, its very publication suggests a resolution of the struggles of artistic production that consume Ariel in her final year of high school. It is less clear if the creation of Likewise also represents a resolution of Ariel's crisis of sexual identity. But Schrag so closely parallels her autobiographical protagonist's twin crises that it begins to seem as if a resolution to one is a resolution to the other. In other words, Schrag's work of authorship legitimates her both as a queer artist and as a literary one.

Schrag certainly fits into the alternative comics scene, particularly the trend of melancholic autobiographical or mimetic work which came to prominence in the 1990s such as Joe Matt, Adrian Tomine and Chester Brown. At the same time, due in large part to her age, Schrag was not in conversation with her alternative comics peers in the same way that Harvey Pekar and Dave Sim were, and her works were not taken up as an exemplar of the genre. Certainly there is something of the modernist concept of genius in Likewise, described by Ariel and her friends as "it." But "it" is democratized, belonging not just to writers but also to schoolteachers and friends. And while the act of creating is certainly important to Ariel, what interests her in Joyce, Spiegelman and other authors is not their own acts of creation but rather their significance to her own as well as her development into a mature artist. Here there is something of Eliot's idea of "tradition," where authors build their works on the greats of the past. There is also something new, a form of approaching literature which privileges reading over writing and the individual reader over both the author and society as a whole. Likewise is thus a transition point between the aesthetics of the 1970-80s alternatives, represented best in The 
Comics Journal, and a new conjunction of comics and literature. That conjunction would be fully realized in Alison Bechdel's Fun Home.

\section{Queer Reading Strategies and Identification in Fun Home}

Alison Bechdel's graphic memoir Fun Home is a story that revolves around reading and interpretation. The comic tells the story of Bechdel's relationship with her father and her attempts to come to grips with his death, which she believes is a suicide stemming from his repressed homosexuality. Using frequent digressions and leaps back and forth in the narrative's chronology, Bechdel weaves her father's story together with her own coming of age and lesbian awakening, as well as numerous literary allusions. An important strand of the narrative is the development of Alison, a child reader, aping her father's ideas, into Bechdel, a narrator capable of deep and complex analysis. ${ }^{46}$ Over the course of this development, Alison eventually arrives at a queer erotics of reading that encourages a free play between the personal, the fictional, and the semiotic. In order to do so, she must ultimately reject her father's mode of interpretation, which fixates on reader identification and authorial persona. This allows her to disengage from hierarchical modes of reading and ideas of literary authority which resonate beyond Bechdel's individual story.

Given this focus on reading, it is not surprising that Fun Home has been a hit with the academy. Since its publication in 2006, it has been the subject of dozens of academic articles and appeared on countless syllabi, quickly becoming one of the most-studied comics ever (Beaty and Woo 7). There's a certain irony to this explosion of academic study, given how dismissive

\footnotetext{
${ }^{46}$ I will use "Alison" in this essay to describe the young character depicted in the panels, and "Bechdel" to describe both the older narrator and the author herself, or at least the author-function, two voices which the memoir presents as identical.
} 
the graphic memoir is towards academia and its methods of analysis. Despite enjoying her father's high-school English classes, Alison is alienated by her encounters with literary analysis in university: "I didn't understand why we couldn't just read the books without forcing contorted interpretations on them" (Bechdel 200). This is punctuated by a caricature of a frustrated professor (who bears a strange resemblance to myself) sketching crudely on the board and barking "Get it? Marlow's steamer? Penis. The Congo? Vagina" (Bechdel 200). Alison eventually abandons a critical establishment that tells her that her very words are wrong, and vows to never take another English class as long as she lives (Bechdel 202). She is eventually forced to take a small seminar on Ulysses, and while this seems to be a less painful experience, she still finds criticism "a suspect activity" (Bechdel 205). Alison's earlier education by her father, with his more traditional mode of reading literature, undoubtedly biased her against academia's paranoid critiques, but the comic exaggeration of this scene hardly suggests that Alison only needed to read the right theorist to understand her life. In Fun Home academic close reading is quickly dismissed, portrayed as comically narcissistic and pedantic. If this critique is not developed as length, it is only because Bechdel sees it as self-explanatory. If Alison is looking for a mode of reading and interpretation that will make sense of her own life, she does not find it in the university's classrooms, but rather in obscure corners of the library and her campus's queer student group.

Bechdel's distrust of the academy would find sympathy within the academy itself. Over the past two decades, numerous prominent theorists have expressed just as much frustration with an academic method devoted to interrogatory close reading and the hermeneutics of suspicion. Theorists have attempted to develop numerous alternative modes of reading and analysis. The most pertinent comparison for uncovering Bechdel's own critical project originates in Eve 
Sedgwick's article "Paranoid Reading and Reparative Reading," which signaled a turn in Sedgwick's work away from the symptomatic interpretation of early works such as Between Men and Epistemology of the Closet and towards the study of affect and queer modes of interacting with texts. In place of the routine academic exercise of what she deems paranoid reading, Sedgwick urges a more reparative method of reading, one that might pay attention to "the extremely varied, dynamic, and historically contingent ways that strong theoretical constructs interact with weak ones in the ecology of knowing" (145). In her work from the later period of her life, Sedgwick would explore ways to read "non-dualistically," focusing on affect and sensory experience. For Sedgwick, queer readers require different interpretive skills to use texts to repair relations damaged by a violent and heteronormative society. We can see comparisons here with the project of Fun Home, which sets out to heal the trauma of Bruce's death by reconstructing him as an object of analysis.

Rita Felski develops a similar project at greater length in her book Uses of Literature. For Felski, a central problem with the hermeneutics of suspicion is its diminution of reading as an activity - she asks rhetorically "Do we gain nothing from what we read?" (3). In order to answer "no," Felski examines four different goals of "everyday" reading - recognition, enchantment, knowledge and shock. Felski's project is more descriptive than prescriptive, analyzing how these approaches function and what makes them appeal to readers, but she argues against any reading that would see these goals as simply illusory or deceitful. Ultimately, Felski suggests that these approaches are both more democratic and offer more radical potential for queer affect. In this, both of their projects can be compared to Alison's approach to reading in Fun Home, in which a moment of exhaustion with academia provides an opportunity to develop a new mode of reading. 
In grouping Bechdel's memoir with these theoretical projects, my goal is not to vindicate or praise Bechdel. Fun Home is more than a simple illustration of the ideas that Sedgwick, Felski, and many others have developed. The genre of academic prose tends towards prescription and combative debunking of what has come before, a tendency that Sedgwick and Felski do not fully escape from. Sedgwick herself notes the paradoxical elements of attempting to describe deviant reading: "A lot of voices tell us to think nondualistically, and even what to think in that fashion. Fewer are able to transmit how to go about it, the cognitive and even affective habits involved, which are less than amenable to being couched in prescriptive forms" (Sedgwick, Novel Gazing 1). Perhaps the graphic memoir, with its descriptive but non-mimetic form and its focus on remembrance instead of argument, offers a better chance for transmitting "how to go about it" than the academic monograph. Bechdel provides us with not a model for queer reading but rather a personal example, one from which more general ideas can only be extrapolated. As character, Alison's journey is sometimes a familiar narrative, but always infused with the ethos of queer narrative. Bechdel's attempt to do so is an imperfect but valuable example of a graphic narrative approach to the question of queer reading.

\section{Bruce Bechdel and Identificatory Reading}

There is an important difference in context as well as genre. Whereas Sedgwick and Felski depict their theories as working in opposition to the suspicious close reading they saw as dominant in academia throughout the 1980s and 90s, Bechdel positions her methods as opposing readerly identification that accepts canonical authority, a method identified with her father Bruce. Throughout the narrative, Bruce acts as simultaneously an instructor and a foil to Alison. Bruce's approach falls somewhere in between the type of "everyday reading" Felski valourizes and the 
conservative "theocratic" approach to literature she opposes. The character of Bruce Bechdel and his reading practices is thus critical to understanding Bechdel's critique of contemporary, hierarchical reading strategies. The queer reading that Alison develops stresses the physical, the sensory and the erotic, and has as much to do with the bedroom as the printed page - something that differentiates it from the more abstract formulations of Sedgwick. This contrast demands a close reading of the reading practices of both of Fun Home's central characters, which I will provide in the body of this article. This examination will show the ways in which Fun Home establishes the repressive effects of conventional identificatory reading and the liberating effects of queer reading, and in the process demonstrate that Bechdel deserves consideration not just as a cartoonist but also as an important theorist of queer reading.

Estranged from her college English class for the reasons detailed above, Alison takes to calling her father for "coaching" (Bechdel 201). After receiving an extensive lecture on The Sun Also Rises, Alison tells Bruce that the next book on the syllabus is $A$ Portrait of the Artist as a Young Man. Bruce comments "Good. You damn well better identify with every page" (Bechdel 201). If Alison and Bruce's relationship is heavily mediated through books, then her father's controlling nature is reflected in a prescription of certain reading practices. In critic Ariela Freedman's terms, "the demand for identification becomes a commandment instead of an invitation" (133.) But why the practice of identification in particular? Bruce is not forcing a particular meaning on the text here, but rather demanding a certain affective response from Alison. But why the practice of identification in particular? Bruce is not forcing a particular meaning on the text here, but rather demanding a certain affective response from Alison. The word "identify" here seems to be inevitably slippery and partial, considering how unstable the concept of identity is throughout Fun Home. But the command to identify betrays both the 
violence and the longing of Bruce Bechdel's way of reading, buried beneath the authority of the canon. Throughout Fun Home, Bruce's approach to literature is treated as indicative of both his domineering nature and his closeted sexuality, and hence the reading practices he foists on Alison can be seen as functionally hierarchical and heteronormative.

Rita Felski describes identification, or recognition in her terms, as "perplexing and paradoxical [...] Simultaneously reassuring and unnerving, it brings together likeness and difference in one fell swoop" (25). Felski presents recognition as an ethical practice, part of what she calls "an exhortation to look at, rather than through, the literary work" (20). For Bechdel, however, the politics of recognition are distinctly mixed. Despite his investment in the practice of identification, Bruce remains someone who, as Bechdel narrates, has an "awesome capacity for cognitive dissonance" (199). If reading is a form of self-fashioning for Bruce, the self that it creates is a presentation of normalcy that represses queer desires. In his position as a high-school English teacher, Bruce's ability to read text and present those readings as authoritative is directly linked to both his presentation as an upstanding citizen of Beech Creek and his secret affairs with teenage boys. Given this, Bruce's commandment to identify suggests a reading practice that is hopelessly caught up in the suppressed complexities of his own identity, and suggests that Bruce himself may be the object of a similar commandment from a heteronormative society. This is a point where we can see Bechdel diverging from Felski and Sedgwick, largely due to her object of critique. Felski, seeking to counter the academic assumption that any form of identification with literature is always a case of misrecognition, argues that recognition can nevertheless be powerful and productive (46). Bechdel, engaging with more conventional modes of reading, presents dangers of misrecognition that are more difficult to sweep away and, in the case of Bruce, may literally be fatal. 
In Bruce's early life, identification with literature emerges as a way to create a heterosexual identity. After his death, Alison discovers a trove of letters between a young Bruce and his future wife that reference F. Scott Fitzgerald's autobiography The Far Side of Paradise. It's clear that Bruce relates to Fitzgerald's work through the device of identification, which Bechdel describes as "seeing himself in various characters," writing to Helen that "[Fitzgerald] reminds me of myself, especially the old 'emotional bankruptcy"' (62). This is an ironic detail, given that such recognition rests on the idea of a stable and authentic self: it is precisely Fitzgerald's anxiety about a lack of genuine self that Bruce identifies with. Rather than using Fitzgerald's work to identify an inner truth, such as his own queer sexuality, Bruce uses Fitzgerald's literary style to create a mask of heterosexual desire, crafting love letters that Bechdel notes are "lush with Fitzgeraldesque sentiment" (63). The excerpt of one letter that Bechdel crops in the panel below takes pains to announce itself as a declaration of love, betraying a self-consciousness about its nature as a performative action: "Do you know I love you. That made me feel so good I'll say it again. I love you I love you I love you, you crazy wonderful girl" (63). Bechdel goes on to imagine a point of readerly identification between her father and Jay Gatsby, Fitzgerald's most famous character. Again, this is an identification based precisely on the ability and desire to create an artificial self using textual materials - Gatsby's fake books and Bruce's real ones (84-85). Bechdel makes the importance of performative identity to the comparison explicit by writing that "Such a suspension of the imaginary in the real was, after all, my father's stock in trade" (65).

It is fitting that Bruce becomes interested in Fitzgerald through his autobiography instead of his more well-known novels, as the personal life of authors is central to his reading strategy. For Bruce, the object of identification is not just character but also author, with the text 
functioning as a kind of conduit for a relationship of recognition and mutual understanding between reader and writer. Bechdel believes that "what was so alluring to my father about Fitzgerald's stories was their inextricability from Fitzgerald's life" (65). When we do see Bruce presenting a reading of a text, it is a strictly biographical one with no room for invention or ambiguity. Instructing Alison on The Sun Also Rises, Bruce says that "Jake is Hemingway. Cohn was a guy named Harold Loeb. Brett is a Lady Duff Twysden” (Bechdel 201). What draws Bruce to literature is the chance for a connection with a romanticized author figure. In the midst of his phone lecture on the novel, Bruce seeks to draw a tenuous personal connection between himself and Hemingway: "You know, Andy, the best man at our wedding, saw Hemingway in Pamplona the year before we were married" (Bechdel 201). As Bechdel suggests in her narration, Bruce's reading habits are a way to participate vicariously in the life of the author, just as his instruction of Alison is a way to participate in her life as a student $(65,201)$. Suspecting his daughter's lesbianism, Bruce gives her Colette's Earthly Paradise, saying that "You should learn about Paris in the twenties, that whole scene" (Bechdel 205). This shows both Bruce's literalism and his insistence on reading as a way to access famed literary "scenes." Even when done in the name of queer recognition, as in Alison's readings detailed below, identification as depicted in Fun Home is always an identification with not just a character or a text but with the literary persona that created it.

This phone conversation is a microcosm of the ways in which Bruce claims literary authority. The tenuous personal connection with Hemingway plays its part in this claim, as does his ability to supply a huge amount of historical information. Bruce's language here is definitive, using the assured "is" instead of "based on" or "similar to" to describe the resemblance between Hemingway and his protagonist. It also resembles the "Marlow's Steamer? Penis" insistence of 
the professor on the facing page. The preceding panel shows Alison complaining about her professor writing “wrong word” on her paper: “'Is'? How can 'is' be wrong?” (Bechdel 201). If, as Bechdel has said, "the book is just an expansion of my freshman English paper" (Chute 181), then this moment takes on epistemological importance. This panel is ironically sandwiched between two clear examples of "is" being wrong, with both the professor and her father phrasing their interpretive statements as matters of fact. The top panel of the facing page shows Bruce using similarly definitive language in a moment of direct identification: "Faulkner IS Beech Creek. The Burdens ARE Bechdels" (Bechdel 200). Fun Home calls attention to Bruce's casual use of the definitive "is" through capitalization, repetition, and her professor's comment, as a way to show how even in his basic grammar Bruce has a kind of literary authority that she lacks. Bruce's gender and heterosexual presentation also gives him an ability to claim identification with virulently male canonical authors such as Fitzgerald and Hemingway that Alison lacks. Bechdel spends the rest of the page illustrating Alison receiving the lecture, gradually sitting down and growing disenchanted as Bruce's word balloons overwhelm the panel. Bechdel writes that "Eventually, his excitement left little room for my own. And by the end of the year I was suffocating" (201). The failure of Bruce's lecture suggests that its reading strategies are ultimately flawed and exclusionary. In Fun Home identificatory reading, at least as practised by Bruce, is not part of a politics of recognition but rather part of the process of domination and authority.

The problematic implications of Bruce's reading strategy plays its part in the celebrated sequence in which a young Alison's attempt to keep a diary begins a descent into OCD. Numerous critics have commented on this scene, including Hillary Chute, Julia Watson, and Jared Gardner, but what is often ignored is the way that the act of reading frames the production 
of Alison's diary and her subsequent doubts about its authenticity. Bechdel suggests that she "picked up" many of her compulsions from reading Dr. Spock and other child-rearing books and fixating on its details, an example of the dangers of unquestioned identification with a text (135). When Alison first receives the diary, Bruce gives her a head start by writing "Dad is reading" in his own handwriting, leaving Alison to fill in the title of the book (Bechdel 140). Alison's epistemological crisis literally begins with "Dad is reading," and her father's act of writing the first words in her own diary show that his reading practices are both a way of connecting with and understanding his daughter and also a way of controlling and defining her. She comes to see her language as being too certain for her highly subjective viewpoint, commenting that "My simple, declarative sentences began to strike me as hubristic at best, utter lies at worst" (Bechdel 141). This forces her to insert parenthetical "I think"s and later inscrutable marks in order to signal her lack of authority to an unknown reader. Alison lacks the "hubristic" certainty in her own identity that allows her father to simply write "Dad is reading." The marks she makes over her own words presage her professor's criticism, both in shape (a squiggle instead of "W. W.") and in their attempt to point out the way in which "is" can be wrong. The young Alison's attempt to persist in a singular and straightforward self-narration, as compared to the complicated and ambivalent self-narration that is Fun Home, ultimately leads her close to mental breakdown. Part of her recovery involves her mother writing her diary entries for her, leaving out the marks of uncertainty (Bechdel 143) - a rejection, in the end, of paternal authority. The diary is, among other things, a failed attempt to imitate the certainty of her father's critical strategy. But of course, Bruce's certainty in itself only masks a deep confusion about his own sexual identity, something that Alison doesn't realize until she is an adult.

The question of misrecognition haunts both Felski's defence of identificatory reading and 
Bruce's practice of it. Felski acknowledges the persistence of the misrecognition of self and others, but suggests that this does not eliminate the potential for recognition and empathy altogether (28). Rather, she argues that the unrecognizable nature of the postmodern individual allows for recognition to be self-forming as well as self-acknowledging. Felski writes that "Rather than blocking self-knowledge, language is our primary means of attaining it, however partial and flawed our attempts at understanding ourselves and others must be," a description that certainly fits the ways in which Alison uses reading to construct her own identity and make peace with her father's memory (Felski 38). But for Bruce, language is not just a flawed means of selfknowledge, but an actively counterproductive one. Bruce claims that his identification with Faulkner is based on rural setting and country dialect, but given the distance in both geography and culture between Faulkner's Mississippi and Bechdel's small town in Pennsylvania, the comparison seems somewhat strained. A more obvious point of identification would be the dysfunctional nature of both families, but this is clearly something that Bruce wants to repress. In the scene where he writes Fitzgerald-inspired love letters to Helen, Bruce uses literary language to construct a false identity that conforms to the affective demands of heterosexuality. But in Fun Home, such reinvention is never foolproof. Just as Gatsby can never fully banish his origins, Bruce's queer sexuality immediately escapes from his attempt at heterosexual selffashioning: looking at Bruce's copy of The Far Side of Paradise, one of his fellow soldiers jokes that "'s this your boyfriend? He's even prettier'n you" (Bechdel 63). Similarly, when Bruce borrows language from Joyce in his love letters, he tellingly misgenders the possessor of Joyce's "beseeching eyes" (Bechdel 28). In Fun Home identity, while clearly mediated through reading, retains some kernel of fundamental truth which literature can be used to suppress as well as express. If identification is central to Alison's self-discovery, it is also central to the ways in 
which heteronormativity acts against Bruce.

Bruce's wilful lack of self-knowledge contributes to the ultimate failure of his reading strategy. The first scene depicting his English classroom features Bruce teaching The Catcher in the Rye, in particular the relationship between Holden Caulfield and his teacher Mr. Antonelli. After a lacklustre student response, Bruce insists "He makes a pass at Holden. Did any of you twits read this?" Through captions, Bechdel points out that one of her father's teenage lovers was sitting in the class, and that her father possesses an "awesome capacity for cognitive dissonance" (Bechdel 199). However, Bruce is not entirely staving off identification in this scene - he clearly reads his own relationship with teenage boys into Salinger's novel, transforming a scene that is somewhat ambiguous in the original text into a clear homosexual advance. In this scene Bruce's suppressed inner desires and readerly authority complicate and ultimately undermine each other, creating a reading that both simplifies the text and fails to acknowledge the personal perspective he brings to it.

Taking her father's cue, the teenage Alison presents readings of The Catcher in the Rye and Pride and Prejudice that present Mr. Antonelli and Mr. Bennet as kindly father figures who maintain an egalitarian relationship with the novels' protagonists. Like her father's reading of Fitzgerald, this is a kind of identification that is ultimately aspirational, with Alison projecting the relationship she imagines establishing with her father through reading onto literary texts, and then using her readings of said texts as a way of winning her father over through her performance in class as "the only one worth teaching" (Bechdel 199). On Lizzie Bennet and her father, Alison comments that "They have this neat relationship. They're, like, friends" (Bechdel 199). This panel is captioned "The sensation of intimacy was novel," referring to the closeness between her and her father in the English class and punning off the literary novels that form the 
glue of this relationship. But Alison's aspirational identification is ultimately as flawed as her father's. In terms of the texts she reads, she is oblivious to the possibility that Mr. Antonelli's interest in Holden might not be entirely healthy or paternal: when Bruce asks the class: "And does he turn out to be a great guy? What happens?," Alison is just as silent as the rest (Bechdel 198). Her reading of Pride and Prejudice also ignores the suggestion that Mr. Bennet's friendly relationship with his daughter is a form of irresponsibility in the face of his family's potential ruin. These, in turn, are aspects of her father that Alison is not yet ready to confront: his suppressed homosexual desires, and his frequent recklessness in pursuing it. Alison's attempt to imitate her father's identification and win his praise leads to her using textual identification not to reveal new things about the world around her, as Felski suggests, but rather to suppress the unpleasant aspects of her father's life. This in turn presents skewed interpretations. This mode of identification becomes another way of dominating the text, of forcing it into a shape that reflects the life the reader would like to have.

Bruce's textual attempts at performing gender are also ultimately failures. Alison describes herself and her father as "inverts" of each other, a boyish girl and a womanish man (Bechdel 98). She constantly detects a failure of masculinity in him, one which she feels a need to compensate for (Bechdel 96). The term "invert," drawn from Victorian terminology for homosexuality, both suggests the duality of the graphic novel's two central figures as well as the antiquatedness of the gender roles Bruce attempted to fit his family into. Bruce's fussiness, such as the constant maintenance of his Victorian-era décor, aims to project an image of classical and refined masculinity - a "nineteenth-century aristocrat," as Bechdel describes it (60) -- but is read by the rest of his family as effeminate (Bechdel 13-14). In 1970s rural Pennsylvania, the markers of modernism are markers of a certain kind of dandyism. In his attempts to force Alison 
to dress in feminine clothes, Bruce reveals himself to be not an arbiter of gender norms but as the bearer of a characteristically queer obsession with fashion. Perhaps most crucially, his performance of gender does not convince the authorities, as seen in his arrest for giving alcohol to a minor - an arrest that clearly carries with it the suspicion of much more (Bechdel 161). While Alison is conscious of her own “inversion," Bruce's femininity is constantly leaking out of his performance of masculine identity. Again, Bechdel suggests a certain kind of sexual truth which performance can only obscure. In this she departs from Judith Butler and other theorists of queer performativity who see opportunities for play and empowerment in gender performance. As demonstrated below, there is plenty of room for play in Bechdel's idea of queerness, but it is play that takes place further away from the self. In Fun Home Bruce's effeminate performance of male literary authority is a marker of the failure of his reading strategy.

If all Bruce's identification was guilty of was distorting texts and removing ambiguity from them, it could perhaps be written off as a harmless flaw. But in Fun Home, reading is a life and death matter, as can be seen by Bruce's pre-suicide reading of $A$ Happy Death. Bechdel narrates that "It's not that I think he killed himself out of existentialist conviction. For one thing, he would have gotten to Camus's conclusion that suicide is illogical. But I suspect my father of being a haphazard scholar" (47). This last line is laid over a panel that suggests a reason for this haphazardness, a fraternity brother calling for a doe-eyed Bruce, which links Bruce's interpretive failures to his repressed sexuality. This panel introduces the idea that Bruce's readings may be flawed, and that in particular misinterpretation can be fatal. This link is also displayed in Bruce's letter to Alison in which he "does and doesn't come out" (Bechdel 230). Bruce directly borrows language from Joyce's Stephen Daedalus in explaining his own closeting, most notably the line "I am not a hero." Once again, Bruce is using the language of canonical modernist texts to 
fashion an identity, this time not the rugged masculinity of Hemingway or Fitzgerald but the intellectual antiheroism of Joyce. This identity, while less absurd, also represses the aspects of domination involved in both his relationship with his family and with the teenage boys he sleeps with. Bechdel also argues that in Bruce's attempt to adopt Joyce's language he either ignores or misconstrues the ethos behind Ulysses: "How could he admire Joyce's lengthy, libidinal 'yes' so fervently and end up saying 'no' to his own life?" (Bechdel 228). In adopting Joyce as a means of heterosexual wooing, Bruce tragically misses the text's queer erotic currents.

In her critique of standard academic techniques, Sedgwick sought to undermine what she saw as the restrictive affective register of symptomatic reading. She characterized her project as a turn away "from existing accounts of how 'one' should read," which necessarily entails a rejection of "how people should feel" and the "deontological project of 'ought" and "ethical gravity" of the hermeneutics of suspicion. Bruce Bechdel's approach to reading can hardly be described as paranoid - if anything, he is naive in his belief in canonical literary authority. But many of Sedgwick's critiques of paranoid reading are applicable to Bruce. Sedgwick describes paranoia as a theory of negative affect, in which one avoids "bad surprises" by maintaining a consistent presentation of cynicism and knowingness. Throughout the text Bruce always presents himself as having authoritative knowledge of any situation, and perhaps his ceaseless self-construction and self-suppression is a way of avoiding the "bad surprise" of his sexuality. In his love letters to Helen, as in other places, Bruce uses literature as a way of obeying the project of "ought," fashioning literature into an identity that obeys the affective demands of society. As demonstrated above, Bruce is also insistent in teaching Alison how one should read. As in Sedgwick, this is also implicitly instruction on how one should feel.

In developing their theories of reading, both Sedgwick and Felski present themselves as 
voices speaking against a stifling critical orthodoxy. In Touching Feeling, Sedgwick presents a list of "things that theory knows" as ironclad laws that stifle other critical approaches, which she aims to ultimately reveal as "less about the transcendental rightness of 'theory' than about the dynamics of consensus formation and cross-disciplinary transmission." She goes on to describe the common methodology of theory as an institutionally-mandated paranoid reading, which is a "privileged object" and "uniquely sanctioned methodology" (Sedgwick 126). Sedgwick goes so far as to suggest a psychological motivation for the dominant modes of academic reading, arguing that paranoid reading promises "no bad surprises" and exaggerates the importance of the critic's revelations (Sedgwick 130,138). The irate, ranting professor and dour closeted father of Bechdel's narrative would seem to be illustrations of the negative affect Sedgwick ascribes to conventional close reading. At one point in Fun Home Bruce rips up a library book in a fit of rage, in a literalization of the idea that negative approaches to literature can damage both text and reader (Chute 184).

It is worth noting, then, that all three authors who I am arguing here advocate queer reading dedicate a substantial amount of their texts to depicting and debunking an oppositional figure. For Sedgwick and Felski, this is a monolithic academic establishment whose dogmas are not as useful or explanatory as it believes. For Bechdel, it is the self-destructive reading practices of her father. This raises the question of whether queer reading must always exist in an oppositional relationship with restrictive, "straight" forms of reading. However, the difference in genre is critical here. While Sedgwick and Felski display a good deal of respect and even admiration to the critical traditions which they are rebuking, the genre of the academic monograph frames their writing as a correction to ignorant scholars of the past. Both critics express skepticism of the model of the heroic and singular critic whose writing exposes the truth, 
but the form they are working in inevitably presents themselves as that heroic critic. Bechdel's memoir about her father is much different. In the genre of memoir, the loving nature of the relationship between writer and subject is expected instead of discouraged. Bechdel firmly highlights her love for her father despite his flaws and secrets by beginning and ending the book with images of father and daughter engaged in childhood play. While Bechdel, Felski, and Sedgwick all rely on an oppositional figure with which to develop their own theory against, through Bechdel's use of the memoir form this opposition avoids the adversarial tone of academic rebuttal.

Fun Home links the tragedies of Bruce Bechdel's life with his literary misreadings, wilful and otherwise. Even if Bechdel wants to resist such a melodramatic criticism, she suggests that Bruce's act of reading of A Happy Death, leaving it around the house with underlined passages that act as an "epitaph" for his marriage, can be read as a suicide note. As in the classroom, Bruce's readings take on a public function, but inevitably say more about his private issues than they do the text. Through his acts of identification, Bruce aligns himself with canonical literary authority and heterosexual masculinity, allegiances that are mostly aspirational but nevertheless give him some degree of power. It is this authority that allows Bruce to insult his students' reading practices or lack thereof and impose his reading strategies and enthusiasms on Alison. This is the same dogmatic power that Sedgwick and Felski recognize in academic convention and which they define their own projects against. But the power recognition offers Bruce is ultimately a poisonous one, leading to self-repression and suicide. In response, Alison is forced to develop an alternative that allows the queer reader to survive. 


\section{Alison's Rebuke: The Queer Erotics of Reading}

By contrast, the project of Fun Home as a text is clearly reparative. The graphic novel uses textual document, both literary works and letters written by Bruce, to attempt to reconstruct his double life and come to terms with his death. Fun Home begins with several pages dedicated to Bruce's refurbishment of the old Victorian home in which Alison grew up. The early prominence of this event marks it as a symbol of both Bruce's carefully-maintained facade of propriety and Bechdel's own project of reconstructing her past and her father's life. As Bechdel said in an interview, she "had to dismantle [Bruce's] literary authority over me" before she could begin the book (Chute 158). Ultimately, however, this dismantling leaves space for a project of reparative reading which is, as Sedgwick suggests, inextricably linked to queerness.

The concept of reparative reading marks a return to reading and interpretation as a process of meaning-making. Both Sedgwick and Felski challenge politicized critique for presenting an unidirectional model of reading, in which texts' ideological assumptions simply impose themselves on the reader. In some ways their project hearkens back to reader response criticism, pioneered by scholars such as Wolfgang Iser and Stanley Fish. Iser positioned his work against canonical reading practices by arguing that, because interpretation causes an inevitable slide of meaning, "interpretation reveals the inherent problem of authority" (27). However, the text also holds its own and shapes the reader's interpretation, making the act of reading inherently dualistic (Iser 60). But where Iser and Fish posit an implied reader curated by the text, or (in Fish's later work) a multitude of interpretive communities, Sedgwick and Felski imagine a singular, even lonely reader. Their reader is implicitly suggested to be female and queer.

As Heather Love points out, Sedgwick does not aim to banish paranoia from academia - 
after all, she admits to being a paranoid reader par excellence - but rather aims to incorporate it into a more thorough and diverse critical approach. In describing "reparative reading," she is ultimately not describing a method but describing an effect which could be reached through multiple avenues of inquiry. Sedgwick continually describes this project as a queer one, opening the essay with an anecdote from her experience as an AIDS activist and stating that queerness has "a distinctive history of intimacy with the paranoid imperative" (126). Sedgwick draws on the example of intergenerational affective relationships between queer people as inspiration for a move away from this imperative into a more fluid and rebellious mode of analysis. She describes reparative reading as finding its objects not in hidden conspiracies but in hidden methods of survival such as the queer use of camp: "What we can best learn from such practices are, perhaps, the many ways selves and communities succeed in extracting sustenance from the objects of a culture -- even of a culture whose avowed desire has often been not to sustain them" (Sedgwick, 150-151). For Sedgwick, reparative reading is not just a corrective to academia, but also a way to save queer individuals from the domineering negative affect of paranoia to which it has become so accustomed. We can see this project running throughout Sedgwick's later work, most notably the articles collected in Touching Feeling, including "Paranoid and Reparative Reading." This collection is notable for its early advocacy of affect theory, but I wish to focus here on its more general ambitions. In her introduction to the collection Sedgwick focuses on the attempt to develop a "nondualistic" theory that avoids both the political binary of progressive/regressive and the poststructuralist binary of naïve realism and the supposedly subversive faith in groundlessness. By contrast, Sedgwick describes her own work as "slipslidey" and related to the "art of loosing," suggesting a desire to explore without the rigorous focus and orientation towards argument expected of academic prose (1-3). The physical process 
of touch is key to this approach, as it undermines dualistic conceptions of reality and creates a greater sense of the "texture" of texts and life (Sedgwick, 14). Sedgwick also writes that the most relevant proposition for her project is not "beneath," suggesting a paranoid excavation of hidden meaning, but "beside" (8) - a preposition that has resonance with Bechdel's memoir, where literary education and play take place next to both family members and lovers instead of in the hierarchical environment of the classroom. Through this shift in attitude, Sedgwick hopes to create a more playful and free-flowing criticism whose ultimate goal is not uncovering hidden truths but finding a way to relate to multivalent works within the "middle ranges of agency" (14). Queer reading, then, is that which takes place beside and between orthodoxies, aiming not for revelation (as in the religious exegesis that Iser uses as his chief examples) but recuperation.

Felski's approach is not one based explicitly on queer theory or experience, but the queer reader remains a privileged subject in the way Felski narrates various reading choices. She prominently uses Radclyffe Hall's novel The Well of Loneliness as an example of both the depiction of literary identification and the object of such identification by real readers. Felski later draws on D. A. Miller's depiction of the male reader of Jane Austen, who in the midst of shamefully transgressing gender norms experiences "a temporary severance from a personhood that is felt to be anomalous, queer, out of place" (Felski 64). For both Felski and Miller, the homosexual is a figure society associates with devalued forms of reading, with deviant reading practices analogous to deviant practices of gender. Felski also associates alternative modes of reading with feminist consciousness, citing anecdotes of women watching Ibsen plays and identifying with the female oppression depicted therein and arguing that Austen's attention to style presents a kind of quietly deviant pleasure (Felski 31, 64). Whereas Sedgwick intends to wrench queer experience away from the paranoid imperative, Felski argues that popular 
approaches to reading, maligned by cultural authorities, have always been used by women and queer people as a way to better experience and explain their own subjectivity. In her chapter on recognition, she deliberately stresses the double meaning of the term as both a synonym for identification and a political project (Felski 30). It would certainly be possible to frame the project of accepting and valuing different reading styles otherwise - for instance, as an appeal to neoliberal consumer choice or in the name of cultural populism -- but Felski implicitly presents an openness to different styles of reading as analogous with an openness to the diversity of sexual and gender identity and experience. Throughout her work, Felski emphasizes that reading practices, in particular any sort of "progressive" reading practice, must be communal and shaped by material functions. The queer reader, even if not an explicit focus of Felski's work on reading practices, is central to her arguments.

In exploring divergent modes of reading, Bechdel uses much of the same vocabulary as Sedgwick and Felski. Felski and Sedgwick both use a mythological allusion to the sirens' song in order to describe their attraction to deviant reading practices - and, in Bechdel's case, lesbian sex itself (Felski 71, Bechdel 207). The way in which Felski narrates the reader's sudden "flash of recognition" (23) echoes the way Bechdel depicts her own moment of sexual self-awareness while reading a book. Both scenes are similar to a passage in which Sedgwick describes her project through the narrative of a nascently queer child encountering literature:

Such a child - if she reads at all - is reading for important news about herself, without knowing what form the news will take; with only the patchiest familiarity with its codes; without, even, more than hungrily hypothesizing to what questions the news may proffer an answer. The model of such reading is hardly the state of complacent adequacy that Jonathan Culler calls "literary competency," but a much more speculative, superstitious, and methodologically adventurous state where recognitions, pleasures, and discoveries seep in only from the most stretched and ragged edges of one's competence. (2).

I quote this section at length because of the striking similarity between Sedgwick's rhetorical 
child and Alison, who gradually develops this speculative and adventurous method of reading as a way of "reading for important news about herself." Throughout Fun Home, Alison borrows magpie-like from assorted texts as a way of understanding her relationship with her father. Ariela Freedman describes this as a bildungsroman-like process of "self-invention" through reading (130). Hillary Chute notes that "On every page of Bechdel's text comics builds a certain kind of space that counters the methodology of her father and the modality of the family home he shaped" (180). Chute describes this distinction as an attention to loss and absence, a focus that echoes the priorities of queer theorists such as Sedgwick and Heather Love (Chute 181). Alison's reading practice can also be compared to the more positive version of recognition outlined by Felski, in which texts are used to understand interior desires and construct a self through the recognition of others. If Bruce offers us a case of what can happen when identification goes wrong, Bechdel's book-long attempt to recognize her life in literature, to hear "the news about herself," is a more positive portrayal, one in which recognition destabilizes instead of upholds the strict and direct relationships between author, text, and reader that Bruce's readings rely on. But there is also a physical and sensual aspect of Alison's literary approach that is more difficult to capture through theoretical comparisons. Alison's literary play has pleasures far more immediate than deconstructive jouissance. Fun Home draws a direct connection between the joys of literary disobedience and queer sexual pleasure, both practices that Bruce attempts to disavow and Alison ultimately accepts.

Alison's encounters with literature, canonical or otherwise, allow her to develop a reading strategy that drastically differs from her father's reverence for literary authority. One early signal is a weekend Alison spends with her parents' friends the Gryglewiczs. Alison and her friend Beth break up a game of "authors," apparently a literature-themed card trading game (Bechdel 
160). The parodic character of the game ("Give me $A$ Child's Garden of Verses!") suggests an awareness of the complicated ways in which literary and authorial identities circulate as well as a refusal of the rules of literary practice. This scene occurs in an air of sexual strangeness and uncertainty, from the nude picture of Dr. Gryglewicz on the wall to Alison and Beth's drag play as male gangsters to the opposing page depicting Bruce's attempt to pick up another teenage boy (Bechdel 160). This weekend, which Bechdel narrates as "a veritable Saturnalia, a two-day binge of nonstop play," implies a strong connection between literary play and sexual deviance (161).

This call to textual play informs the way in which Bechdel incorporates canonical literature and its creators into her graphic memoir. Critics such as Chute and Friedman have discussed at length Bechdel's intertextuality and its radical potential. Bechdel's narration makes many comparisons between her own life and canonical literature, especially modernist texts, but her identification with these texts is much more considered and complicated than Bruce's unidirectional and totalizing method of identification with an author through his or her work. For instance, at one point Bechdel makes a comparison between her father's ersatz Victorian home and Jay Gatsby's fake bookcase, writing that "Like Gatsby, my father fuelled this transformation with 'the colossal vitality of his illusion'. Unlike Gatsby, he did it on a schoolteacher's salary" (64). Already, we have a formal difference from Bruce's reading, acknowledging both the like and the unlike. Beneath this panel, Alison depicts her family watching the 1974 film version of Gatsby, and comparing her father's appearance to Robert Redford. This quick move between different versions of the text and different means of identification - thematic and physical - suggest an approach to reading that is more willing to take what it needs in terms of identification, stitching together a quilt of textual artifacts from 
different places and times in order to express one's history and inner feelings. This scene also places Fitzgerald's text in the presence of homoeroticism, with Bruce handing the novel to one of his teenage lovers. Predictably, Bruce's spoken rationale is caught up in canonical authority -"It's the great American novel" - but his sexual motives show through (Bechdel 60). The fact that both Bruce and Alison are depicted commenting on Fitzgerald texts (see Bruce's response to The Far Side of Paradise, discussed above) makes such a comparison easy to draw.

Fun Home's practice of playing with multiple textual elements and meanings in order to understand her queer reality is best displayed in its final chapter. Chute describes this chapter as the piece de resistance of Bechdel's technique, and in particular focuses on a page near the end in which the narrative and narration moves effortlessly between four different narrative strands and settings (207). The chapter as a whole functions as a four-way comparison between Alison's emerging lesbianism, Bruce's closeted life, Joyce's Ulysses, and Homer's Odyssey. Bechdel is queering Joyce and Homer in a straightforward way by using their texts to express queer sexual awakening, but she is also practising queer reading by freely skipping between several narratives at once and not allowing any one pride of place, as her father does. For Bechdel, Joyce and Fitzgerald are still sources of recognition, but it is a recognition that does not regard the text as a holistic authority but rather as a field of play.

Alison's encounter with an emerging body of queer literature, chronologically simultaneous with her reading of Ulysses, takes place along similarly unorthodox grounds. This reading is presented as a self-education, with Bechdel comparing it to an "independent study" (205). It is not, however, simply a matter of recognizing repressed desires in queer texts. Bechdel attributes these texts with not just reflecting her queerness but in some sense creating it. She describes her coming-out as "a revelation not of the flesh, but of the mind" (74). One aspect 
of this literary awakening is a free play between different texts and genres. Alison reads omnivorously, moving between fiction, autobiography, polemic, medical studies, and dictionaries as part of what Bechdel describes with the caption "One siren led to another in an intertextual progression" (207). This caption is part of two panels showing Alison tracing the influence of Colette, with quotes from May Sarton and Jill Johnston citing Colette as an influence (Bechdel 207). This is a fairly direct example of intertextuality, but it still complicates Bruce's simplistic model of the author speaking to the reader through the text. Instead, Alison traces the history of lesbian readership to see how texts speak to each other.

Nor is Alison's approach to see literature as either supporting or undermining gay liberation, the kind of political valuation that Felski criticizes in symptomatic reading. In a brief scene late in the chronological narrative, Alison mentions to her father that the gay advocacy group she belongs to is picketing Cruising for its homophobia, but she is unable to articulate the group's symptomatic critique (Bechdel 218). Bechdel then includes a very large panel of Bruce snorting (219). For Alison, looking for a way to have an open conversation with her father about his own cruising, reading-as-politics is a dead end, and this version of queer critique has little place in the critical methods of either Bechdel. By dominating the page, Bruce's dismissal of political critique formally stops the argument in its track and disrupts the rhythm of the conversation, in stark contrast to the more productive moment of mutual recognition in the car that follows it, which is represented by twenty-four small panels over a two-page grid (Bechdel 220-221). This is not to say that Bechdel's perspective is entirely apolitical. Prior to Fun Home, she was best known for coining "the Bechdel test," which became a cornerstone of feminist popculture criticism. ${ }^{47}$ However, Fun Home makes clear that Bechdel herself is not in favour of the

\footnotetext{
${ }^{47}$ In a 1985 Dykes to Watch Out For strip, a character explains that "I only go to a movie if it satisfies three basic requirements. One. It has to have at least two women in it who, two, talk to each other about, three, somehing
} 
cavalier dismissal of texts on political grounds. While this sort of argument could certainly be used for quietist ends, Fun Home is not criticizing queer activism or even politicized reading - it depicts Alison doing plenty of both - but it is rejecting a simplistic imposition of a political dichotomy onto literature that does not take into account the pleasures of reading and the variability of reading practices.

By contrast, Alison's reading is reparative because it searches for ways in which problematic texts can be re-read in useful ways instead of rejected and condemned. Among the books that form Alison's textual exploration of queerness is Homosexualities by Masters and Johnson, which has a prominent place in one panel (Bechdel 75). Masters and Johnson were noted for their involvement in anti-homosexuality treatments - a fact that is surely not lost on Bechdel, given her interest in authors' lives - and even at its most complementary their work treats queer people as strange laboratory specimens, but nevertheless they are as much a part of Alison's intertextual odyssey as any of the queer feminist texts she reads. Similarly, Bechdel forgives Joyce his betrayal of his lesbian publishers, quoting Sylvia Beach as saying "A baby belongs to its mother, not to its midwife, doesn't it?" (Bechdel 230). This reading, so close to the end of the book, suggests that Alison's ability to imaginatively repair her relationship with her father lies in a refusal to consign him to a totalizing moral or political category. The Beach quotation also suggests the importance of queerness to reparation - only by making Joyce a "mother" can Beach overcome his betrayal. Bechdel calls into question her own willingness to label Bruce as gay and her ability to be nonplussed about his predatory affairs (Bechdel 230, 100). Bechdel's imaginative reparation of her relationship with her father is directly linked to a practice of reparative reading.

besides a man." This was taken up as a more widespread way of critiquing the sexist nature of Hollywood, such as on the still-updated bechdeltest.com. 
The comparison between the interpretation of a text and the interpretation of a life would be more tenuous if Alison's relationship with her father was not so frequently mediated by texts. This is evident in their bonding and eventual disenchantment over shared literary reading, as detailed above, but it is also true for more everyday texts. Fun Home reconstructs a number of purely functional texts - letters, court documents, passports - which Chute describes as an archive of Bruce's life (Chute 199). Most critically, Alison declares her own homosexuality and learns of her father's through an exchange of letters between her and her mother. This scene is repeated three times throughout Fun Home, each with different detail and framing, suggesting its centrality to the narrative (Chute 183). If Alison's reading of this exchange that sets the framework for Fun Home as an autobiographical project. Alison has to uncover her father's homosexuality through a difficult exchange of letters with her mother, in which she has to demand clarification of unclear phrases like "another form that almost resulted in catastrophe" (Bechdel 78-79). Bruce also writes a cryptic letter that assumes that Alison is already aware of his sexuality. Alison's attempt to decipher this letter involve a complex calculus of perspectives: "He thought that I thought that he was a queer, whereas he knew that I knew that he knew that I was too" (Bechdel 211-212). While the truth ultimately emerges through a phone call, it requires an inquisitive reading practice that involves attempting to understand an unknown perspective. For both Alison and her parents, understanding queerness involves a form of reading. If reading is a way of discovering queer sexuality, queer sexuality is also a way of reading. Alison's growing interest in gay literature is described in captions that increasingly imply a sexual allusion. Bechdel describes herself as "ravish[ing]" the library's collection of books about homosexuality, and the next panel describes loaning out books in the terms of cruising: "soon I was trolling even the public library, heedless of the risks" (75). On the next 
page, the subtext is made explicit, with the top panel showing Alison reading Delta of Venus and masturbating (Bechdel 76). She is also depicted masturbating to Colette's autobiography, the book her father intended as a means of identification (Bechdel 207). The emergence and maturation of Alison's own reading style, diverging from her father's self-denial, involves a turn to autoerotic play. Admittedly, masturbating to erotica is not perhaps the best example of disorderly and disobedient reading processes. The clearest example of the role of the erotic in Alison's reading practice occurs during a sequence depicting her love affair with Joan, another lesbian student. Bechdel describes Joan's bed as "strewn with books, however, in what was for me a novel fusion of word and deed" (80). This caption is within a panel displaying said bed, with books by Adrienne Rich and Mary Daly prominent in the frame. What Alison and Joan develop, then, is a practice that allows the literary pleasures of reading, the physical pleasures of sex, and the political power of lesbian feminism to speak to each other and bleed into one another. In one panel, Alison and Joan use the children's book James and the Giant Peach in sexual play, playing off the double entendre of the word "peach" (Bechdel 80). The dictionary, formerly a source of prescriptive linguistic authority, becomes another source of eroticism: "Os-, mouth, oral, oscillate, osculate, orifice" (Bechdel 80). Bechdel writes that "In the harsh light of my dawning feminism, everything looked different" (81). The turn to play is not a turn away from critique: in between bouts of lovemaking, Joan takes time to read The World of Pooh and declares that "God, Christopher Robin's a total imperialist!" (Bechdel 81). Literary erotics is a way to recognize the sensuous pleasures of the text and the way its elements can be played with and used in ways that go beyond identification and even the neat performances of deconstruction and analysis that are rejected by Bechdel as well as critics such as Sedgwick. Instead of a text expressing, substituting for, or being symptomatic of erotic desire, it becomes an active part of 
sensory play - Bechdel's "fusion of word and deed."

This appreciation of the erotics of textuality leads Alison to a new appreciation of authors like Colette. Rather than simply recognizing her own sexuality in Colette, Alison uses her own queerness as a starting point to identify aspects of strange sensuality in Colette that go beyond same-sex attraction. Bechdel notes one moment in which Colette moves quickly from a sensuous description of a butcher boy to a description of his suicide in "voluptuous detail" (Bechdel 208). The captions which describe the text lie directly above quotes which illustrate Bechdel's point, a formal device which resembles nothing so much as an English term paper and mark this as a moment of critical analysis (Bechdel 208). While Bechdel does not fully draw the argument out, and doing so would perhaps be against the ethos of her reading practice, it is clear that an attention to the erotic sensuality of Colette's text, including its involvement in her sexual practice, allows Bechdel to observe aspects of Colette's technique and influence that escaped her father, who saw only the author's lesbian literary milieu. For Alison, literature and sex are coextensive worlds that have the capacity to illuminate one another.

It is fitting that the dictionary plays an unlikely part in Alison and Joan's sexual play, as dictionary definitions are a recurring device in Fun Home. In some cases, the definitions are simply used to mark Alison's growing knowledge of the world, as when she is "86ed" for the first time (Bechdel 106). Other uses of the dictionary reinforce Bechdel's practice of playing with and ultimately refusing meanings. For instance, one large panel shows the many definitions of "queer" in the Bechdels' dictionary, with the caption noting that "every sense of that multivalent word" could apply to Bruce's death (Bechdel 57). Bechdel also notes that the dictionary's definition of "queer" excludes the connotation of homosexuality. This neatly encapsulates Alison's response to the definitive power of male and heteronormative literary tradition: taking as 
many aspects from that tradition as she can, even contradictory ones, but also attempting to correct its conspicuous and telling exclusions. The dictionary also functions as a way of isolating words from any meaning. A crucial part of Alison's reading practice is the word as a sound image and the sensory experience of speaking or hearing it. When Alison discovers the word "orgasm" in the dictionary, she is immediately alert to its meaning because of "the approximant liquid of that 'or', the plosive 'ga', the frictive 'z' or the labial, nasal sigh of the final 'um"' (Bechdel 171). In this sign of the fusion of text and sex, Bechdel describes the pronunciation of the word "orgasm" as comparable to the experience of an orgasm. A young Alison even omits the word from her diary, hoping that this will "cancel out" her physical masturbation (Bechdel 172). This eroticization of phonetics is not too far removed from Alison and Joan discovering the many possibilities of "os." Bechdel even attributes her first encounter with lesbianism to the dictionary: "I was thirteen when I first learned the word due to its alarming prominence in my dictionary" (74). This caption is spread unusually across two panels depicting first Alison's startled look and then the image of the dictionary definition, with "lesbian" standing out in bold curved letters. This pair of panels is reminiscent of the cinematic eye-line match, suggesting that this moment of reading is akin to a romantic encounter. Alison's erotics of reading involves a careful attention to the sensory aspects of words, including their appearance and their sound image. The sensation of sound is also another sensory experience that academic reading and Bruce's literary identification marginalize, and which Alison's queer reading draws out as a source of pleasure.

There are elements of contradiction in this celebration of queer reading, and moments where Bechdel engages in the same kind of selective interpretation that her father practised. Even as Bechdel rejects the definitive and compulsory modes of identification laid down by her 
father, she finds herself identifying with everyone from truckers to Ulysses. Even as they range across genre, Bechdel's reading could be said to conform to a kind of queer literary canon -- Nin, Colette, Wilde. And despite her rebuke of academic overanalysis, Bechdel ultimately performs a symptomatic reading of her father's life, reading every part of her life with her father as cannily concealing hidden truth, and using this interpretation to fill her emotional needs. Explaining why she and her mother believe that Bruce's death was a suicide and not an accident, Bechdel notes that "It's possible that we chose to believe this because it was less painful. If he'd intended to die, there was a certain consolation in the fact that he succeeded with such aplomb" (29). This is not strictly "reading," unless one uses a very broad definition of textuality, but it suggests a distinctive practice of interpretation, and a strong emotional investment in the result. Near the end of Fun Home, Bechdel belatedly acknowledges that "'Erotic truth' is a rather sweeping concept. I shouldn't pretend to know what my father's was. Perhaps my eagerness to claim him as 'gay' in the way I am 'gay', as opposed to bisexual or some other category, is just a way of keeping him to myself - a sort of inverted Oedipal complex" (230). In psychoanalyzing her father with a clear investment in identifying him as gay, Bechdel opens herself up to such psychoanalysis, in a potentially endless recursive spiral of symptomatic reading. In a way, the example of Fun Home leads us in the end back to paranoid and symptomatic reading.

But by the act of openly displaying the psychological desires and anxieties that lead to her interpretation of her father's life, Bechdel ultimately breaks the cycle of critique by not sublimating or hiding her own personal and ideological investment and acknowledging that her narrative is a partial and subjective interpretation which creates meaning as much as it interprets it. Rather than forcing a definitive meaning on her father's suicide, Alison acknowledges the event as being a field of many meanings which she can act on. While Bruce presents his reading 
as definitive, Alison admits that hers are always partial and biased. As Chute suggests, there is an "elasticity" to Alison's perspective that is missing in that Bruce's obsessive neatness (186188). Part of this elasticity is the willingness to depict the struggle between paranoid and reparative impulses within the book, and ultimately end up use both approaches. Fun Home's contradictions are ultimately productive instead of disabling because the text embraces them. Fun Home represents not so much a model of queer reading to be followed as an example of the difficulty and the promise of reading differently.

The difficult hybridity of Alison's reading experience, mirrored by the hybridity of the comics form, is an essential aspect to Bechdel's approach. Numerous critics have suggested that comics naturally lend themselves to narratives that resist straightforward ideas of authorship and plot. Adrielle Mitchell describes comics as consisting of networked image fragments that resists any easy distinction between words and images as well as character and background. Gillian Whitlock has coined the term "autographics" to describe what she describes as a unique interaction between the visual and the verbal and the complicated relationship to memory it creates in autobiographical comics. In his article “Autography's Biography, 1972-2007,” Jared Gardner argues that the comics memoir has a natural self-reflexivity determined by the hybridity of its form, with Fun Home a prime example of the genre. Gardner links this trend with a comment made by Bechdel in an interview with The Comics Journal that "comics demand autobiography." Furthermore, structural theorists of comics have argued that comics invite a kind of active readership that prose doesn't. In Scott McCloud's foundational work Understanding Comics, he argues that the presence of gutters between panels requires the reader to imagine whatever kind of movement or transition takes place between the panels (68). In Projections, Jared Gardner makes a similar argument along more historic lines, suggesting that 
the history of comics as a serial medium has created a back-and-forth relationship between reader and creator. If Bechdel is interested in promoting a more active and skeptical mode of readership, comics would seem to be a natural fit. I am skeptical of statements about the inherent nature a the medium, but in Fun Home comics have exactly the qualities attributed to them by critics such as Whitlock, McCloud and Gardner, and are a vital element of the queer reading that Alison develops.

Throughout the memoir Bechdel suggests that the interplay of words and images is an essential part of her response to her father's legacy. In the scene involving Bruce's false identification with Fitzgerald's heterosexual sentiment, another soldier is seen reading a horror comic in the background, suggesting comics as an alternative to Bruce's reverence for canonical literature (Bechdel 62). Early examples of Alison's art also point to the tangle of creation, memory, domination and sexuality that Bechdel ascribes to comics. A young Alison writes a poem and illustrates it, combining image and words. Tellingly, her father supplies the last line, suggesting that at this stage Alison's artistic voice is still largely controlled by her father's literary practices (Bechdel 129-130). This scene is immediately followed by one in which Bruce chastises Alison for miscolouring the canary-coloured caravan from The Wind in the Willows. By the end of the scene, Bruce has taken over for Alison and does his best to correct the image, saying that "your blue side will be in shadow" (Bechdel 131). This segment demonstrates that Alison's artistic practice as well as her attempts to queer the texts she reads (she colours the caravan midnight blue, a shade associated with masculinity) are under threat from her father's literal readings and obedience to the authorial persona.

The mixture of text and image plays a central role in Alison's self-awareness of her own sexuality, from her young obsession with men's fashion magazines to the Word is Out photo- 
essays, which she is reading at the moment of her lesbian self-realization (Gardner, “Autography's Biography" 4). Bechdel's artistic process is also one which involves queer recognition and empathy. As Chute details, Bechdel created a reference shot for each panel by posing in the posture and clothing of one of the characters (200). This is both a strikingly literal gesture of empathy and a form of physical transgression, inhabiting her father's clothes and posture and hence his masculine self-presentation. The queer and transgressive nature of this process is hinted at in a scene in the text itself, depicting an adolescent Alison trying on her father's own clothes. The caption reads: "Putting on the formal shirt with its studs and cufflinks was a nearly mystical pleasure, like finding myself fluent in a language I'd never been taught. It felt too good to actually be good" (Bechdel 182). In creating Fun Home, then, Bechdel finds a means of identification and empathy through the pleasurable transgression of drag. But rather than using this identification to bury her own identity, as Bruce does with the literature he reads, Bechdel uses sympathetic recognition to create a work that is both infused with her own voice and troubles stable notions of identity entirely. There is also a sensory dimension to this approach: Bechdel says in an interview "it seemed important not just to know what that looked like, but what it felt like" (Chute 200). Bechdel's creative process involves the same form of identification as self-recognition that Boone and Sedgwick describe. Without conflating reading and creation, I would like to argue that Bechdel sees the comic form as an essential part of her interpretive apparatus that shapes both her approach to literature and, ultimately, her understanding of her father.

Fun Home goes beyond combining word and image in the routine way familiar to comics readers. Its heavy use of text, sometimes replacing images altogether, calls attention to both the importance of reading to the text and the hybrid and patchwork nature of the comics form. Fun 
Home contains dozens of panels in which the "image" is simply a reproduction of a textual document, whether it be the pages of a published book, one of Bruce's old letters, or Alison's diary. These panels are text on text, with Alison's narration in the caption presenting an interpretation of the text in the panel. In these moments, Bechdel's concern with reading and interpretation overwhelms the visual nature of the genre she has chosen. The use of "text on text" panels also suggests a comic form which is conditional and can be altered by the addition of other mediums. Bechdel follows this form by incorporating numerous other media in a kind of collage-like atmosphere - most notably photographs, which introduce each chapter as well as making up the central spread of the book, but also maps and forms of writing ranging from love letters to police reports. If, as scholars such as Gardner and Bechdel herself have argued, comics lends itself to a particularly subversive and postmodern forms of autobiography, Bechdel heightens this effect by bringing even more genres into the generic collage that is the graphic memoir. This mixing of genres is tied to queer self-awareness through the narrative of Alison's "independent study" into homosexuality, which like Fun Home itself indiscriminately encompasses a variety of genres. If Sedgwick and Felski call for a multivalent mixture of reading strategies, this mixture is exactly what Bechdel practices.

However, all of these different media and genres are incorporated into a broader project aligned with Bechdel's emotional connections and subjectivity. Prose texts, photos, maps, and other primary documents are redrawn in Bechdel's art style. As Hilary Chute argues, this means that these texts become embodied - every word or image has been personally rendered by Bechdel's pen (Chute 183). The photograph of Bruce's teenage lover Roy, which Bechdel depicts in a two-page spread in the very centre of the book, ties together the physical process of constructing the graphic memoir and the queasy sensory appeal of queer sexuality. Bechdel's 
fingers, the instruments of Fun Home's creation, appear prominently in the spread, placing the physical body into the reparative process of research and mourning - the only appearance of the adult narrator's body in the art of the panels. Just as the Alison of the narrative incorporates bodily experience and sexual play into her reading practice, Bechdel the author incorporates physical labour into her interpretation of her father's life. The images are also incorporated into Bechdel's style and message through the use of the colour green, the only colour which appears throughout the text and which is present on every page. The presence of Bechdel's physical body in her creative practices, in distinction with the disembodied reader of both hierarchical and paranoid reading, is distinctly queer.

This does not mean that we have to use Fun Home as a prescriptive model of how to read queerly, which would of course be contrary to the point of queer reading. Nevertheless, Bechdel is not always the flagbearer of queer reading that I would like her to be. She relies, as Sedgwick and Felski do, on an implicit narrative confrontation between a liberated queer reader and a paternal authority figure, in which the authority's seemingly objective mode of reading is revealed to be a form of repressing self and others. This is certainly not non-dualistic thinking. In depicting her father's closeting as a trauma which ended his life and from which Alison must escape, Bechdel places the same faith in exposure of inner truth as Sedgwick's paranoid critics. But what is so valuable about Fun Home is that it offers a detailed and complex treatment of one person's queer reading practice. Perhaps because Bechdel is writing a graphic memoir instead of an academic article, she is able to more fully articulate a method of queer reading than any theorist I've encountered has, and possibly more than any theorist can. If we turn to queer reading strategies in a search for direct political effect, we are likely to be just as disappointed as we were in symptomatic reading. But Fun Home demonstrates that on a personal and affective 
scale, such approaches can be illuminating and liberating.

\section{The Graphic Memoir as Queer Literary Education}

For all of the salient criticisms of academic reading practices raised by scholars such as Sedgwick and Felski, a meaningful alternative seems difficult to realize in the contemporary academic environment. While we may like the ethical connotations of reparative reading or surface reading, they are often difficult to implement in the sentence-by-sentence construction of an academic journal article. The same could be said of the chapter you are reading, which seeks a way beyond the limitations of close reading through a very close reading of a criticallyacclaimed text. I have hoped to highlight the potential of a project that would carve out new ways of reading across both creative and academic nonfiction. This is a project far from completion, and one that will likely involve a reinvention of the language and format of criticism far beyond the capabilities of this article. The difficulty of fulfilling a new critical project in academic writing, however, is exactly why Fun Home is so valuable. The graphic novel positions itself as a kind of alternative literary education, demonstrating techniques of queer and divergent reading. Its narrative demonstrates the ways in which literary texts can be mined for objects of play which in turn can be used as objects of identification and recognition.

The memoir as literary theory has distinct limitations. By its generic nature, it offers a fundamentally individualistic view of reading and writing, one in which literary texts ultimately offer a route towards a new understanding of personal trauma. While Bechdel gestures towards the complicated publication histories and material circumstances of texts like Ulysses, there is little mention of the broader social conditions or aesthetic movements in which her texts were immersed. Instead these texts appear, as in Eliot, as a constellation of past great works shining 
out of the darkness of history. There is, likewise, little conception of reading as a social or communal activity - it is practised individually or in pairs, and speaks specifically to that individual's psyche or that pair's relationship. Alison's inability to articulate a political critique of Cruising marks a kind of blind spot towards the type of critique practiced within both academia and movements for social justice. Bechdel's approach is not more individualistic than that of her predecessors in alternative comics, in particular those described in previous chapters, but it also does not dispute the primacy of the individual as literary protagonist. Even if, like me, one does not see a focus on the individual as necessarily antithetical to progressive literary criticism, it is worth noting the limitations that come with using the memoir as critique.

With these caveats in mind, Fun Home remains an important text in the history of the relationship between comics and the literary. The author-focused approach I detailed in the first chapter and the iconic approach I described in the second both privilege the text as the origin of its meaning. The literary greatness and autonomy of a work or its mythical cultural resonances are both thought of as stemming from essential properties of the text. In other words, a text's reception is latent within itself. In Bechdel and Schrag, however, a text's reception is dependent primarily on the reader's history, psychology and chosen approach to the text. This is not to say that the details of Joyce and Fitzgerald are irrelevant to Bechdel, but rather that they are relevant to the extent that they resonate with her own life. Neither approach enables a social understanding of textual production and reception, but the difference is notable. This psychologized understanding of reading is also very compatible with contemporary literary texts and intertexts. Bechdel's understanding of the literary is of a piece not just with thinkers like Felski and Sedgwick, but also paraliterary phenomena such as the memoir boom and Oprah's 
Book Club. ${ }^{48}$ Fun Home marks a point where comics began to engage in contemporary literary debates and movements instead of rehashing decades-old positions.

After two decades of her father's literary instruction, Alison finally begins to reverse or at least equalize the process, accidentally leaving Kate Millet's autobiography Flying for her father to read (Bechdel 224). Bruce likes the book, but ultimately finds himself unable to practice Millet's open and radical queer politics. Alison's moment of instruction may have come too late. Bechdel resists any attempt to fit her father's death into a grand philosophical narrative, which would include using it as a cautionary tale about the perils of literary authority. I am inclined to agree, but I would also note that Fun Home demonstrates the way in which, if queer reading cannot save a life, it can at least create a reparative encounter with the memory of that life. The lesson for scholarship is less clear - I doubt many of Alison's practices would pass peer review. No wonder, then, that Bechdel rejected academia in favour of the graphic memoir as a way to discover and retell the "important news about herself."

${ }^{48}$ See Eva Illouz's Oprah Winfrey and the Glamour of Misery for a fuller treatment of this trend. 


\section{Conclusion}

In 2013, Eddie Campbell (British cartoonist and illustrator of, among other things, Alan Moore's From Hell) wrote an editorial in The Comics Journal (now a predominantly web-based publication) denouncing a group of fans, creators and critics he dubbed "the literaries."

Campbell begins by defending EC Comics from criticism that he feels focuses overly on plot and neglects attention to the comic art. Campbell goes on to argue that these "literaries" obsess over authorship in a way unsuited to the comics medium, and in doing so undervalue the history of comics. A year later, longtime critic R. C. Harvey struck a similar theme in a Journal column entitled "The Perversion of the Graphic Novel and its Refinement," ostensibly reviewing a graphic biography of Zelda Fitzgerald. Harvey writes that, thanks to the graphic novel boom, “the shelves of the nation's bookstores have been increasingly polluted with the works of ambitious well-meaning comics enthusiasts who don't understand the medium and whose perversions of it not only threaten the form but indoctrinate an audience with false perceptions." SuperZelda's sin is that it has "abandoned, violated" the "vital function" of images. The form is familiar to readers of the Journal in its earlier decades: the jeremiad that uses metaphors of perversion and corruption to denounce a misuse of the comics art. But here, the subject and object of the Grothian narrative is reversed: it is comics as literature that is betraying the tradition created by popular comics such as MAD Magazine and Captain America, both cited by Campbell as an example of good form. The literary sphere represents not salvation for the autonomy of comics but corruption.

These two articles do not represent a universal feeling among creators and readers of the increasingly anachronistically-named alternative comics, but they do have an increasing number of echoes. We can also see this line of argument in recent comics scholarship by Bart Beaty and 
Christopher Pizzino, who have called into question the narrative of comics reaching literary maturity.

What to make of this recent development? In some sense, the entry of graphic novels into the bookstore as not just an occasional novelty but a full-fledged genre is the successful culmination of the comics-as-literature strategy promoted by The Comics Journal and artists such as Pekar and Sim. And yet this success has come to seem increasingly hollow to many of those responsible for it. Perhaps this reaction is, as Pizzino suggests, a product of artists chafing under the limitations of a respectability-driven discourse that grants literary status only to select few comics. Yet the figures complaining about the shift towards literary values have not been particularly disadvantaged by it. Despite the clear genre influence in their work Hernandez, Miller and to a lesser extent Campbell are all firmly parts of the "canon" promoted by the comicas-literature project. ${ }^{49}$ A more likely explanation is that in a cultural field where expressing faith in conventional cultural hierarchies is seen as elitist and conservative, expressing disdain for these hierarchies and the literary in general can be a canny gesture of autonomy. Of course, it only became possible to disdain literary status once comics had achieved some measure of it.

This is not to say that Campbell and Harvey are being hypocritical poseurs, or at least not any more than Groth and Thompson were when advocating for comics as literature in the same publication decades earlier. The shape of the cultural field allowed these writers to vent longheld inner feelings with hope of a positive reception, and likely discouraged them from dwelling upon other inner feelings. Bourdieu's model allows us to glimpse both the complicated and often contradictory aesthetic philosophies of individual creators as well as the broader intellectual and material shape of a movement, which can even be simplified down to a line on a

\footnotetext{
${ }^{49}$ For instance, all three placed highly in TCJ's 1999 list of the century's top comics.
} 
two-dimensional chart. Thus, while alternative comics creators and critics did not share a common image of the literary, much less a common idea of how to relate to it, collectively their works and actions oriented the genre towards a literary horizon. Perhaps a new movement is beginning, one which positions comics as sophisticated pulp objects that can be accused of neither snobbery nor idiocy. If so, its story is not yet written.

The story I have written is of a largely one-sided relationship. If we stretch the romantic metaphor, the generation of Groth, Pekar and Sim saw literature as an unattainable crush. Literary status appeared as a way of solving all their problems and of soothing their deep inner rage. Literature would help restore comics' reputation after its scandalous dalliance with mass culture in the 1950s. This crush was, by its nature, a form of misrecognition and idealization. These authors saw only an outdated, conservative version of literature, ignoring its more freewheeling contemporary presentation. That this older version had often expressed categorical disdain for comics was simply another element of its attraction: capturing literary affection would allow the likes of Pekar and Sim to prove that they were different from their peers. As Felski suggests, identifying misrecognition is not an ending but a starting point. This misidentified version of literature proved to be a powerful impetus for Groth, Sim and Pekar to develop their own aesthetic philosophies and construct improvisatory canons of both comics and literature. In arguing about literature, they were also implicitly (and sometimes explicitly) arguing about the burgeoning genre of alternative comics: how it should be created, how it should represent the world, and what attitude it should take towards mainstream comics. Ultimately, Groth's vision more or less won out, although traces of Pekar can continue to be found in contemporary autobiographical or journalistic comics.

Alan Moore was, along with Art Spiegelman, the initiator of a less one-sided relationship 
between comics and the literary sphere. This shift did not necessarily lead to a less idealized image of the literary. In Moore, as in his contemporaries Neil Gaiman and Grant Morrison, literature is valued for its ability to create resonant and popular cultural symbols. But while Gaiman and Morrison presented highly canonized authors such as Shakespeare and Byron as the apex of this myth-making, Moore focused on popular genres, presenting a vision of the literary in which Arthur Canon Doyle takes pride of place over James Joyce. Moore also highlighted that this was a version of the literary in which comics could compete with prose, having produced its own share of enduring images and characters. Moore focused less on the differences between comics and literature and more on the continuity between them. This involved directly confronting and subverting cultural hierarchies between genres, an act that Moore presented as commensurate with an anarchist overturning of the social order. At the same time, this conception of the literary preserved a role for the author as a re-mixer of previous texts. Though Moore's work in the late 1990s and 2000s was less well-read than his pioneering superhero texts of the 1980s, it worked to develop a model for a relationship between comics and the literary on even terms.

Alison Bechdel's graphic novel Fun Home represents perhaps a more mature stage of the comics-literature relationship. The love for the literary, and the desire to incorporate it into comics, is still very much present, as demonstrated by Bechdel's constant use of literary intertexts. However, Bechdel suggests that her feelings towards certain literary works are due not to their inherent greatness but rather her own personality and history. This is a more personalized and psychological understanding of the literary, one that builds upon earlier work by Ariel Schrag. Fun Home hinges on the question of how to relate to texts, and draws a complex but clear distinction between the kind of identification practiced by Bruce and the 
multiplicitous, embodied queer reading that Alison develops over the course of the graphic novel. Bechdel argues that this distinction, rather than being academic, is in fact a matter of life and death, with her father's suicide as ultimate proof. To extend the romantic metaphor, by the time of Fun Home's intervention the relationship is not old but no longer in the honeymoon period, and raw infatuation has faded to a more introspective mood about what drew them to literature in the first place. Bechdel sketches both an explanation of her love for literature and a road to a more workable relationship to the literary that does not do away with misrecognition but rather recognizes it and accounts for its worst qualities.

All of these authors reckon in their own way with the image of comics and their creators as deviant and perverse, a legacy of the 1950s comics scare and the industry's subsequent selfcensorship. Early alternative cartoonists aimed to deflect these accusations, establishing that it was only other comics which were unhealthy and disturbing, and that they themselves were respectable artists. By contrast, Moore and Bechdel both admit to this deviancy and aim to reclaim it in their own ways. The censorship drama of the Comics Code is a scene that comics feels compelled to continually revisit and re-enact. Even Fun Home, a text seemingly disconnected from the comics industry and fandom, stages an opposition between repressed postwar morality and the opportunity for sexual exploration represented by the 1970s that has clear resonances in comics history. Claiming the identity of deviancy does not dispel it, nor does it stop Moore and Bechdel from making their own ideologically-informed assumptions about literature. What this maneuver does is present an opening, one not fully seized by either of the above-mentioned authors, to challenge cultural hierarchies without conceiving of art as a capitalist panoply of equally-valid consumer choices. For this reason, the ways in which comics grapple and continue to grapple with the problems of literature have significance beyond comics 
scholarship.

My romance metaphor is fanciful, but it is not original. The creators of alternative comics who most explicitly focused on the process of literary creation and the problem of literary status typically did so by placing it in relation to love and sex. Harvey Pekar expressed his anxiety about his cultural status as the inability to get an "intellectual" wife. Dave Sim used the central romance of Cerebus to argue that the feminine "void" stifled masculine creativity. Alan Moore's embrace of polyamorous perversity has a clear parallel with his proliferate use of literary intertexts. Ariel Schrag and Alison Bechdel both draw comparisons between discovering their queer sexuality and discovering literary creativity. This metaphor occurs across alternative works diverse in genre, period, and aesthetic. Its roots lie in the language of perversion and maladjustment long used to stigmatize comics. However, in Moore, Schrag, and Bechdel, the influence of comics leads instead to happy and non-heteronormative relationships.

In my (admittedly small) selection of texts, the literary remains important throughout different genres and periods of alternative comics, but where the literary is located shifts. In the early period, literariness comes entirely from the author, who chooses to pursue their own genius and must be enabled to do so by critics, publishers and fans. Thus Groth, Pekar, and Sim hold contempt towards both creators who choose to produce commercially-friendly and mediocre work and the fans who prefer it to autonomous art. To the "groundlevel" writers of the 1990s, who were on much friendlier relations with commercial comics, the most pertinent property of literature was located in its relation to culture. Gaiman, Morrison, and especially Moore focused on literary fictions that had influenced readers as a whole and created enduring cultural tropes. The author's role was that of re-mixer of existing material rather than that of originary genius. Finally, in Bechdel and Schrag we can find an emphasis on the experience of the individual 
reader as the central factor in understanding literature. Literary greatness still exists to these authors, but it is marked by a kind of personal and psychological resonance, one which requires an adept and versatile reader to fully access. Thus, over the thirty-year span surveyed here, we can see a shift between a vision of the literary with the author at its centre to one with the reader at its centre. Whether this is a reflection of broader cultural trends, and whether it is best to describe this shift as marker of literary democratization or a more consumerist idea of art, is beyond the scope of this project, but is an important concern that deserves further investigation.

Consider also the recent IDW Publishing series Kill Shakespeare, created by Anthony del Cor and Conor McCreery. Promoted as “an epic adventure that pits Shakespeare's greatest heroes against his most frightening villains," Kill Shakespeare places its canonical characters into a fairly rote fantasy adventure plot. Hamlet becomes an action hero, Juliet his love interest, and Richard III the scheming villain they must defeat. While this approach has its similarities with the icon-centric approach taken by the likes of Gaiman and Moore, the series ultimately seems entirely of a piece with other IDW titles such as Transformers vs. G. I. Joe. Dealing with literary topics, it would seem, no longer requires comics to adapt an elevated register or strive towards being literary art. If graphic novels have become a product of the mainstream bookstore like any other, perhaps literature has become just another source of intellectual property that the comics mainstream can put through its ringer of crossovers and re-boots. Kill Shakespeare is not the first instance of this approach - comics have mined the public domain for material since the days of Classics Illustrated in the 1940s, and Frankenstein and Dracula have exited for decades in both the Marvel and DC universes. If anything, the success of del Cor and McCreery's series 
demonstrates that the changes brought about to mainstream ${ }^{50}$ comics by the emergence of alternative, "literary" comics may be superficial at best.

How, then, can we account for the anti-literary reactions documented above? Is this simply a lover's quarrel? Does it stem from comics, no longer having to admire the literary from afar, now beginning to see its flaws and resent the restrictions their relationship imposes? It is here that my fanciful metaphor fully breaks down, for of course comics and literature were never singular minds but rather rough and sometimes overlapping spheres consisting of thousands of actors who are each in turn influenced by material circumstances as well as the ghosts of past authors. There were comics artists who looked askance at the literary mainstream in the 1970s, such as the willfully obscene underground cartoonists, and those who still fixate on it today, such as the artists Campbell criticizes. But alternative comics have always had to exist in some kind of relation to the literary. Reactions like Campbell's and Harvey's are both an angry acknowledgement of this fact and the latest in a long line of attempts to establish a new way of relating to the literary.

This new wrinkle also suggests that the long, torrid relationship between comics and literature has not come to the conclusion of a happy marriage, but rather remains an ongoing and uncertain affair. As cultural ideas of aesthetic value shift, so will the ways in which creators attempt to align themselves with those values. Creators will act in ways shaped by their own individual tastes, aesthetics, and personalities, but will as a whole move (or attempt to move) towards a spot in the cultural field that allows for both material and cultural rewards. In this quest, they will have the guidance of an experienced older lover in literature, which has been

\footnotetext{
${ }^{50}$ While IDW's sales are typically lower than those of Marvel and DC, they are chiefly known for comics liscenced from popular genre properties, and thus I consider them "mainstream" in form if not popularity. See the Introduction for more on the somewhat contradictory mainstream/alternative divide.
} 
Hutton 203

going through this constantly-changing dance for millennia, and doesn't look to stop anytime soon. 


\section{Works Cited}

Adelman, Bob (ed). Tijuana Bibles: Art and Wit in America's Forbidden Funnies, 1930s-1950s. Simon \& Schuster, 1997.

Ayres, Jackson. “The Integrity of the Work.” Journal of Modern Literature Vol. 39, No. 2016, p. 144.

Beaty, Bart. Fredric Wertham and the Critique of Mass Culture. Jackson, UP Mississippi, 2005.

Beaty, Bart and Woo, Benjamin. The Greatest Comic Book of All Time. Palgrave Macmillan, 2016.

Blythe, Hal and Sweet, Charlie. "Formula and the Superhero." The Comics Journal No. 73, 1982, pp. 82-90.

Bredehoft, Thomas A. "Comics Architecture, Multidimensionality, and Time. Chris Ware's Jimmy Corrigan: The Smartest Kid on Earth.” Modern Fiction Studies Vol. 52, No. 4, 2006, pp. 869890.

--- "Style, Voice, and Authorship in Harvey Pekar's (Auto)(Bio)Graphical Comics." College Literature, Vol. 38 No. 3, 2011, pp. 97-110.

Brigley-Thompson, Zoe. “Theorizing Sexual Domination in From Hell and Lost Girls.” Sexual Ideology in the Work of Alan Moore, ed. Todd A. Comer \& Joseph Michael Somers, McFarland, 2012.

Chute, Hillary. Graphic Women. New York: Columbia UP (2010).

Clifton, John. "De-Elfing Comics." The Comics Journal No. 71, 1982, pp. 64-78.

Cixious, Helen. Trans. Betsy Wing. The Book of Promethea. LUniversity of Nebraska Press, 1991.

---"The Laugh of the Medusa." Signs, Summer 1976.

Davis, Vincent et. al. "Still the Artist's Artist: An Interview with Alex Toth." The Comics Journal No. 98, 1985, pp. 59-79.

Decker, Dwight. "The Dilemma of the Adult Comic Fan." The Comics Journal No. 32, 1977, p. 11.

---"From Poughkeepsie to Elfland." The Comics Journal No. 63, 1981, 127-52. 
Dicecco, Nico. "Reflections on the Looking Glass." Sexual Ideology in the Work of Alan Moore, ed. Todd A. Comer \& Joseph Michael Somers, McFarland, 2012.

di Liddo, Annalisa. Alan Moore: Comics as Performance, Fiction as Scalpel. UP Mississippi, 2009.

Dreiser, Theodore. "True Art Speaks Plainly.” Norton Anthology of American Literature, Seventh Edition, ed. Nina Baym, Norton, 2007, Vol. C, p. 927.

Eklund, Christopher. “A Magic Realism of the Fuck.” ImageTexT, Vol 3, No. 3, 2007.

Eliot, T. S. "Tradition and the Individual Talent." Norton Anthology of English Literature Seventh Edition, W. W. Norton, Vol. D, 2007.

Fantagraphics. The Comics Journal advertisement. The Comics Journal No. 73, 1982, p. 4.

---The Comics Journal No. 114, 1987, p. 2.

---The Comics Journal No. 130, 1987, p. 61.

Felski, Rita. Uses of Literature. Malden, MA: Blackwell Publishing, 2008.

Fiore, R. "And Then Some Idiot Turned Out the Lights." The Comics Journal No. 60, 1981, p. 46-54.

---"Funnybook Roulette." The Comics Journal No. 116, 1987, p. 46-50.

---"Funnybook Roulette." The Comics Journal No. 123 (1988), pp. 35-40.

Freedman, Ariela. "Drawing on Modernism in Alison Bechdel's Fun Home." Journal of Modern Literature Vol. 32, No. 4, 2009, pp. 125-140.

Fujitake, Dennis. Editorial cartoon. The Comics Journal No. 40, 1978, p. 31.

Gabilliet, Jean-Paul. Of Comics and Men. Translated by Bart Beaty and Nick Nguyen, UP Mississippi, 2009.

Gaiman, Neil and Vess, Charles. "A Midsummer Night's Dream.” The Sandman No. 19, DC Comics, 1990.

---“The Tempest.” The Sandman No. 75, DC Comics,1996. 
Gardner, Jared. “Autography's Biography, 1972-2007.” Biography, Vol. 31, No. 1, 2008, pp. 1-26.

---Projections: Comics and the History of Twenty-First Century Storytelling. Stanford University Press, 2012.

Gilden, Mel. "Growing Up Weird." The Comics Journal No. 38, 1978, pp. 49-50.

Goldstone, Andrew. Fictions of Autonomy. Oxford UP, New York, 2013.

Green, Matthew J. A. “She Brings Apocalypse.” Literature Compass Vol. 8, No. 10, 2011.

Groth, Gary. "Another Call To Arms." The Comics Journal No. 100, 1985, pp. 9-12.

---"Art Spiegelman." The Comics Journal No. 180, 1994, pp. 55-106.

---Et. Al. "The Best and Worst of the Comics Journal." The Comics Journal No. 44, 1979, pp. 8-9.

---"Black and White and Dead All Over." The Comics Journal No. 116, 1987, pp. 9-10.

---Et. Al. "Blood and Thunder." The Comics Journal No. 63, 1981, pp. 33-86.

---Et. Al. "Blood and Thunder." The Comics Journal No. 123, 1988, pp. 30-31.

---Et. Al. "Blood and Thunder." The Comics Journal No. 132, 1989, pp. 29-40.

---"Criticism vs. Analysis." The Comics Journal No. 51, 1979, pp. 33-38.

---"Eclectic Banality." The Comics Journal No. 65, 1981, pp. 68-71.

---"Gutlessness and Greed." The Comics Journal No. 130, 1989, pp. 3-4.

---"Kenneth Smith." The Comics Journal No. 210, 1999, pp. 130-40.

---"A Life on the Fringe of Comics." The Comics Journal No. 58, 1980, pp. 56-83

---"A Paltry Matter of Principle." The Comics Journal No. 99, 1985, 5.

---"Recycling the Old, Searching for the New." The Comics Journal No. 71, 1982, pp. 40-50.

---"Steve Gerber." The Comics Journal No. 41, 1978, p. 28.

Guillory, John. “Canonical and Noncanonical.” ELH, Vol. 54, No. 3, 1987.

Hadju, David. Ten-Cent Plague. Farrar, Strauss and Giroux, 2008. 
Harvey, R. C. "DC Tries Again for the Best." The Comics Journal No. 63, 1981, p. 112

Hatfield, Charles. Alternative Comics. UP Mississippi, 2005.

---“A Review and a Response.” ImageTexT, Vol. 3 No. 3, 2007.

Hernandez, Gilbert. Heartbreak Soup. Fantagraphics, 2007.

Hopen, Stuart. "The Realism of Dreams." The Comics Journal No. 116, 1987, pp. 77-79.

Huyssen, Andreas. After the Great Divide. Indiana UP, 1986.

Iser, Wolfgang. The Range of Interpretation. Columbia UP, 2000.

Khoury, George. The Extraordinary Works of Alan Moore. TwoMorrows Publishing, 2009.

Kidder, Orion. "Self-Conscious Sexuality in Promethea." Sexual Ideology in the Work of Alan Moore, ed. Todd A. Comer \& Joseph Michael Somers, McFarland, 2012.

Kidd, Kenneth. "Down the Rabbit Hole." ImageTexT Vol. 3, No. 3, 2007.

Lopes, Paul. Demanding Respect. Temple UP (2009).

Luciano, Dale. "Trapped By Life." The Comics Journal No. 113, 1986, pp. 43-53.

Maguire, Emma. "Potential: Ariel Schrag Contests (Hetero-)Normative Girlhood." Prose Studies, Vol. 35, No. 1, 2013.

McCloud, Scott. Understanding Comics: The Invisible Art. Harper, 1993.

Moore, Alan. "Bog Venus Versus Nazi Cockring.” Arthur, Winter 2006, accessed via Internet Archive https://web.archive.org/web/20071221123418/http://www.arthurmag.com/magpie/?p=1685.

Moore, Alan and Gebbie, Melinda. Lost Girls. Marietta, GA: Top Shelf Productions (2006).

Moore, Alan \& O'Neill, Kevin. All Creatures Great and Small. The League of Extraordinary Gentlemen, Vol. 2, No. 4, Wildstorm, 2003.

---And the Dawn Comes Up Like Thunder. The League of Extraordinary Gentlemen, Vol. 2, No. 3 , Wildstorm, 2002. 
---Empire Dreams. The League of Extraordinary Gentlemen, Vol. 1, No. 1, Wildstorm, 1999.

---Gods of Annihlation. The League of Extraordinary Gentlemen, Vol. 1, No. 4, Wildstorm, 1999.

---The League of Extraordinary Gentlemen: The Black Dossier. Top Shelf, 2007.

---People of Other Lands. The League of Extraordinary Gentlemen, Vol. 2, no. 2, Wildstorm, 2002.

---Phases of Deimos. The League of Extraordinary Gentlemen, Vol. 2, No. 1, Wildstorm, 2002.

---Red in Tooth and Claw. The League of Extraordinary Gentlemen, Vol. 2, No. 5, Wildstorm, 2003.

---Some Deep, Organizing Power. The League of Extraordinary Gentlemen, Vol.1, No. 5, Wildstorm, 2000.

Moore, Alan and Williams, J. H. The Magic Theater: A Pop Art Happening. Promethea, No. 12, Wildstorm, 2001.

---Mercury Rising. Promethea, No. 15, Wildstorm, 2001.

---The Radiant Heavenly City. Promethea, No. 1, Wildstorm, 1999.

---Rocks and Hard Places. Promethea, No. 7, Wildstorm, 2000.

---Sex, Stars and Serpents. Promethea, No. 10, Wildstorm, 2000.

---A Warrior Princess of Hy Brasil. Promethea, No. 6, Wildstorm, 2000.

---Weapon for Liberty. Promethea, No. 5, Wildstorm, 2000.

---The Wine of Her Fornication. Promethea, No. 21, Wildstorm, 2002.

Morrison, Grant. Supergods. Spiegel \& Grau, 2011.

Morrison, Grant and Thompson, Jill. Arcadia. The Invisibles, Vol. 1 No. 5-8, DC Comics, 1995.

Nevins, Jess et al. "Notes on League of Extraordinary Gentlemen.” Web. http://www.enjolrasworld.com/Jess\%20Nevins/League\%20of\%20Extraordinary\%20Gentlemen/ LoEG\%20index.htm.

Nordau, Max. Degeneration. William Heinemann, 1898. 
Norris, Frank. “A Plea for Romantic Fiction.” Norton Anthology of American Literature, Seventh Edition, ed. Nina Baym, 2007, Vol. C, p. 925.

Nyberg, Amy Kiste. Seal of Approval. UP Mississippi, 1995.

Orkwins, Raymond. "You Get a Big Delight in Every Bite." The Comics Journal No. 40, 1978, p. 31. Pekar, Harvey Et. Al. "Alice Quinn." American Splendor No. 7, self-published, 1982.

---"An Argument at Work." American Splendor No. 3, self-published, 1978.

---"Christina Stead." American Splendor No. 9, self-published, 1984.

---"Comics and the Genre Literature." The Comics Journal No. 130, 1989, pp. 127-34.

---"A Dialogue." American Splendor No. 7, self-published, 1982.

---"The Garfield Monument." American Splendor No. 9, self-published, 1984.

---"The Harvey Pekar Name Story." American Splendor No. 2, self-published, 1977.

---Music Comics. American Splendor No. 23, Dark Horse, 1997.

---Odds \& Ends. American Splendor No. 24, Dark Horse, 1997.

Pizzino, Christopher. Arresting Development: Comics at the Boundaries of Literature. University of Texas Press, 2016.

Potts, Stu. Editorial cartoon. The Comics Journal No. 58, 1980, p. 54.

Prescott, Charles E. \& Giorgio, Grace A. "Vampiric Affinities." Victorian Literature Vol. 33, No. 2, 2005, pp. 487-515.

Richards, I. A. Principles of Literary Criticism. Allied Publishers,1924.

Round, Julia. “'Is This A Book?': DC, Vertigo and the Redefinition of Comics in the 1990s." The Rise of the American Comics Artist, ed. Paul Williams and James Lyons, UP Mississippi, 2010.

Royal, Derek Parker. “The Worlds of the Hernandez Brothers.” ImageTexT: Interdisciplinary Comics Studies, 7.1, 2013. 
Sabin, Roger. Adult Comics: An Introduction. Routledge, 1993.

Sanders, Joe Sutcliffe. "Theorizing Sexuality in Comics." The Rise of the American Comics Artist, ed. Paul Williams and James Lyons, UP Mississippi, 2010.

Scholz, Carter. "Post-Modernist Spacemen." The Comics Journal No. 98, 1985, pp. 41-45.

Sedgwick, Eve Kosofsky. Touching Feeling. Duke University Press, 2002.

Sim, Dave and Gerhard. Chasing YHWH. Cerebus the Aardvark No. 282-290. Aardvark-Vanaheim Press, 2002-03.

---Going Home. Cerebus the Aardvark No. 232-265, Aardvark-Vanaheim Press, 1998-2001.

---Jaka's Story. Cerebus the Aardvark No. 119-138, Aardvark-Vanaheim Press, 1988-90.

---Melmoth. Cerebus the Aardvark No. 139-150, Aardvark-Vanaheim Press, 1990-91.

---Mothers and Daughters. Cerebus the Aardvark No. 151-200, Aardvark-Vanaheim Press, 1991-95.

Smith, Barbara Hernstin. Contingencies of Value. Cambridge: Harvard UP (1991).

Smith, Kenneth. "Dramas of the Mind." The Comics Journal No. 120, 1988, pp. 125-28.

---"The Inferno of Fame." The Comics Journal No. 100, 1985, pp. 62-67.

---"Shaggy Shapes, Modern Motions." The Comics Journal, no. 86, 1983, pp. 39-50.

Tom Spurgeon et. al. "The Top 100 (English-Language) Comics of the Century" The Comics Journal, no. 210,1999 , pp. 34-124.

Squires, Claire. Marketing Literature. Palgrave, 2007.

Stallman, David. “The Cult of the Superhero." The Comics Journal No. 57, 1980, pp. 107-109.

Theisen, Nicholas A. "Is not Dave Sim: Writing life as parody in Cerebus." Studies in Comics, Vol. 1 No. 2, 2010, pp. 233-255.

Thompson, Kim. "Another Relentlessly Elitist Editorial." The Comics Journal, no. 55, 1980, pp. 6-9.

---"Death Warmed Over." The Comics Journal, no. 73, 1982, pp. 50-53. 
---"Waiting for the Fruit Salad." The Comics Journal, no. 71, 1982, pp. 36-39

Ware, Chris. Jimmy Corrigan, the Smartest Boy in the World. Pantheon, 2000.

Weiner, Stephen. "How the Graphic Novel Changed American Comics." The Rise of the American Comics Artist, edited by Paul Williams and James Lyons, UP Mississippi, 2010, pp. 3-13.

Wertham, Fredrick. Seduction of the Innocent. Rinehart \& Company, 1952.

Wilde, Oscar. The Picture of Dorian Gray. Project Gutenberg, 1890.

Wilson, Jim. "Gifted Young People and Average Space Opera." The Comics Journal, no. 32, 1977, p. 14. 